Portland State University

PDXScholar

$1-1-1986$

\title{
Determinants of the variations in the presence of the subfamily in U.S. metropolitan areas, 1980
}

John Ossaiedeme Umude

Portland State University

Follow this and additional works at: https://pdxscholar.library.pdx.edu/open_access_etds Let us know how access to this document benefits you.

\section{Recommended Citation}

Umude, John Ossaiedeme, "Determinants of the variations in the presence of the subfamily in U.S. metropolitan areas, 1980" (1986). Dissertations and Theses. Paper 55.

https://doi.org/10.15760/etd.55

This Dissertation is brought to you for free and open access. It has been accepted for inclusion in Dissertations and Theses by an authorized administrator of PDXScholar. Please contact us if we can make this document more accessible: pdxscholar@pdx.edu. 
DETERMINANIS OF THE VARIATIONS IN THE PRESFACE OR THE SUBFAMIIY IN O.S. MEIROPOUITAN AREAS: 1980

by

JOHN OSSAIEDEME UMUDE

A Dissertation submitted in partial fulfillment of the requirements for the degree of

\section{DOCTOR OF PHILOSOPHY \\ in \\ URBAN STUDIES}

Portland State University

1986 
TO THE OFFICE OF GRADUATE STUDIES AND REASEARCH:

The members of the committee approve the dissertation of John Ossaiedeme Umude presented December 9, 1985.

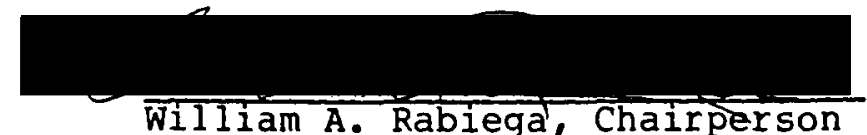

W̄illiam A. Rabiega, Chairperson
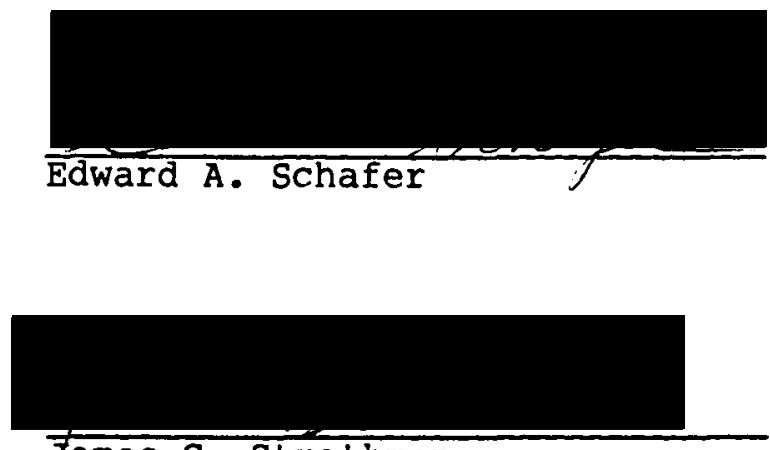

James G. Strathman

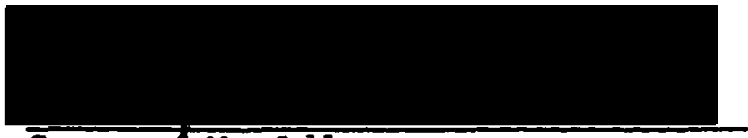

Seymouy M. Adler

APPROVED :

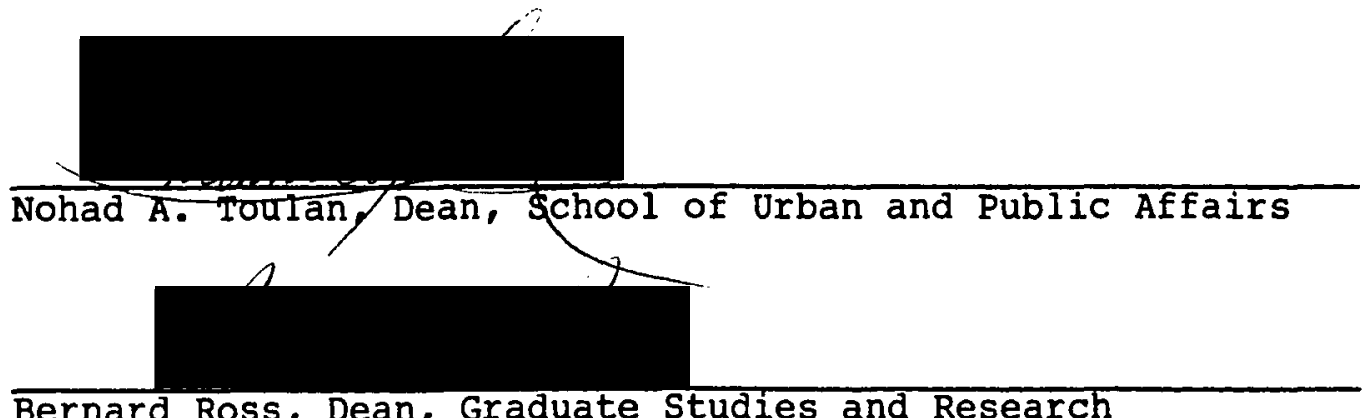

Bernard Ross, Dean, Graduate Studies and Research 
AN ABSTRACT OF THE DISSERTATION OF John Ossaiedeme Umude for the Doctor of Philosophy in Urban Studies presented December 9, 1985.

Title: Determinants of the Variations in the Presence of the Subfamily in U.S. Metropolitan Areas: 1980

APPROVED BY MEMBERS OF THE DISSERTATION COMMITTEE:

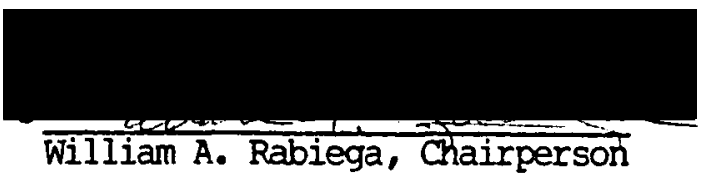

William A. Rabiega, Chairperson

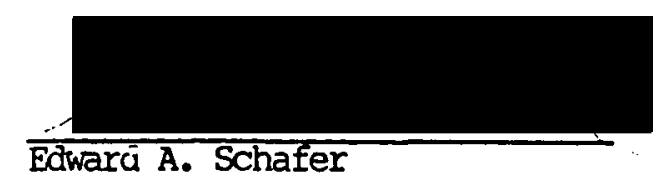

Edwarú A. Schafer

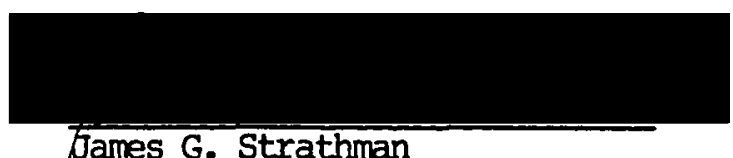

James G. Strathman

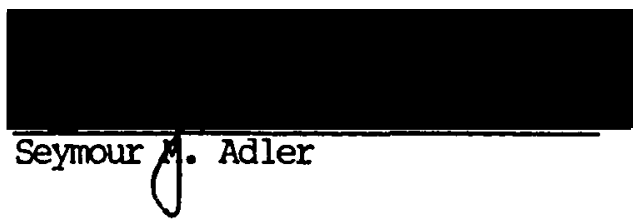

Over the years there has been interest in the living arrangements of Americans and the factors which influence those arrangements. Researchers have considered the growth of families headed by women, households consisting of single individuals, and those composed of 
unrelated individuals. One area, however, on which little attention has been focused is the presence of extended family living, characterized by the subfamily.

The aim of this dissertation is to establish if subfamilies are a random or systematic phenomenon, and to identify the factors responsible for the variations in its occurrences within and across U.S. metropolitan areas. A causal model which accounts for the systematic variations in the presence of the subfamily was developed and tested on the metropolitan and census tract levels. The technique of path analysis was employed and analysis was performed on two geographical levels (SMSA and census tract) using the 1980 census data to ascertain if conclusions were consistent at different levels of data aggregation. The variables employed in the analysis were grouped in four major categories-demographic, sociocultural, economic and housing characteristics.

A major finding of this study is that the subfamily is systematically predicted by demographic, sociocultural and economic characteristics and not by the housing variables. It suggests that subfamily will exist regardless of the housing conditions.

There were some differences and similarities in the results of the two geographical levels. Starting with the differences, it was found, for instance, that the unemployment rate was significantly associated with the subfamily when using Ios Angeles census tract data but not with the SMSA level data. This result can be attributed to data sensitivity to aggregation. The SMSA, based on a broader, aggregated referent set, has limited variability, which makes some relationships less definable. On the other hand Los Angeles (a lower 
aggregation level) has more variability and relationships at a given strength tend to be more statistically significant.

Despite the differences, there are a great many similarities between the results of the two geographical levels. Regression coefficients for causal variables are relatively equal. The means for the two geographical levels are about the same. These results indicate that variations of subfamilies is consistent between the two aggregate levels.

Overall, the model held fairly well as predicted except for the housing variables. The research findings suggest that subfamily may be both a voluntary and involuntary phenomenon. Given this, a number of questions were raised that must be addressed in determining whether subfamily living is a symptom of a major social problem or if it is an acceptable alternative family structure for some families in contemporary society. It might even represent both possibilities simultaneously. These questions cannot be addressed with the type of data used in this study. Future research should be directed toward addressing them. If subfamily living is determined to be a problem, future research should help planners and policy makers formulate and implement programs that will alleviate the negative consequences of subfamily life. 
ACKNOWLEDGEMENT

I would like to express my gratitudes to several people whose assistance has made the completion of this dissertation possible.

My special thanks go to Edward Schafer (Comittee Member), who kindled my interest in this dissertation topic, and who provided continual support, encouragement, methodological expertise and advice from its inception to its completion. Mr. Schafer's assistance was immeasurable. During the course of this study I have come to regard him as a friend and as a mentor.

My thanks also go to the other members of my comnittee: Dr. William A. Rabiega (Chairperson) for providing his expert guidance, painstakingly reading and editing the several drafts, and for offering valuable suggestions and methodological advice; Dr. James G. Strathman, Dr. Seymour M. Adler, and Dr. Grant Farr (Graduate Office representative), for their constructive criticisms and valuable comments.

I would like to thank Dr. Thomas Gihring and Dr. Sumner Sharpe for their advice and suggestions during the initial stages of this study.

My appreciation also goes to Nick Gattuccio who typed the drafts of the dissertation and to Lee Emmett for typing the final copy.

Finally my thanks go to my parents and the other members of my family--Lucy, Sunday, Theresa, Kelly, Bartholomew and Roseline--for their support and encouragement. 
TABLE OF CONTENTS

PAGE

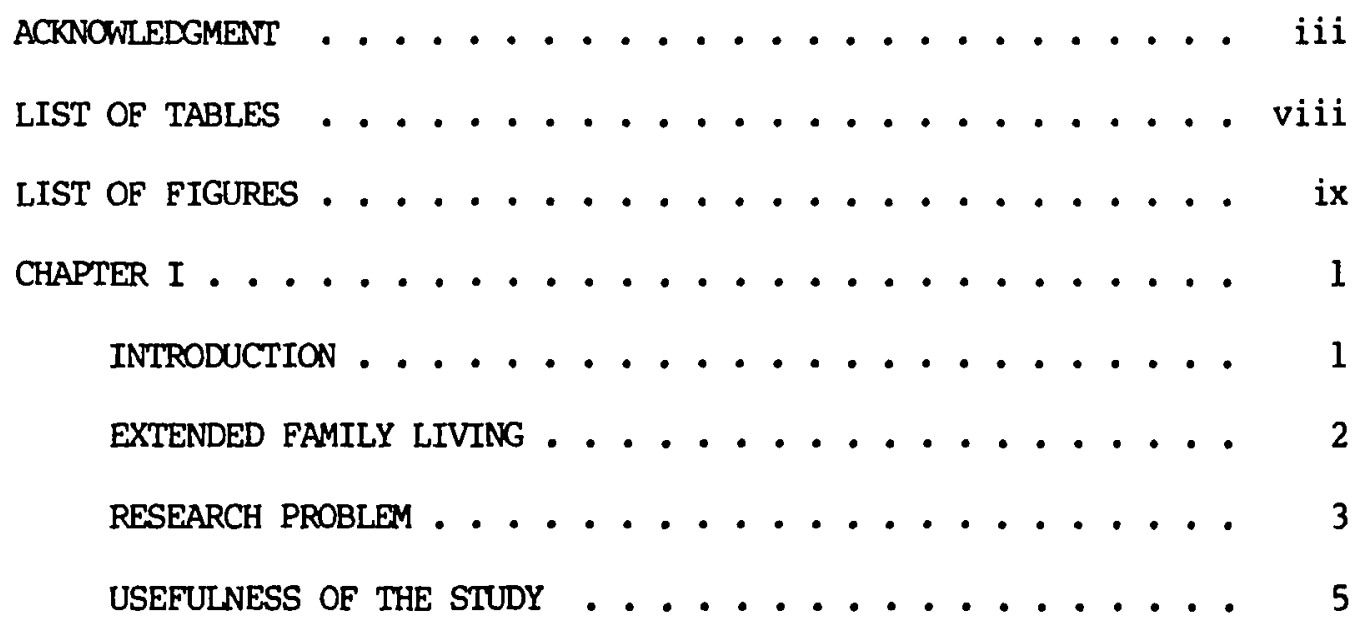

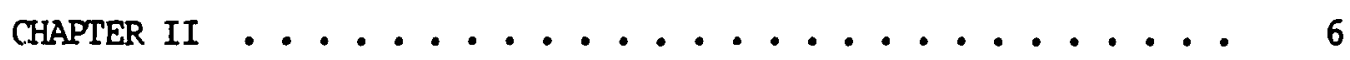

REVIEW OF LITERATURE .................... 6

INTRODUCTION ....................... 6

The Functionalist Perspective . . . . . . . 6

ALTERNATIVE PREMISES . . . . . . . . . . . . . 9

The Life Cycle Theory . . . . . . . . . 10

HISTORICAL AND CONTEMPORARY STUDIES OF FAMILY

STRUCTURES ............................ 10

The Medjuck Study . . . . . . . . . . . . 11

The Agresti study . . . . . . . . . . . 13

The Angel and Tienda Study .......... 15

The Monahan Study . . . . . . . . . . 19

Other Studies Concerned with Household Sharing and Housing supply Issues ........... 19 
THE EFFECTS OF DEMOGRAPHIC VARIABLES CN FAMILY AND HOUSEHOLD COMPOSITION . . . . . . . . . . . . 20

Fertility ..................... 21

Marriage and Divorce ............ 21

CLOSING COMMENTS .................. 22

CHAPTER III . . . . . . . . . . . . . . . . 24

THEORETICAL DISCUSSION AND PRELIMINARY OPERATIONALIZATION . . . . . . . . . . . . . . . . 24

CHAPTER IV ....................... 29

DATA AND VARIABLE SET . . . . . . . . . . . 29

INTRODUCTION . . . . . . . . . . . . . . 29

THE DEPENDENT VARIABLE ................ 29

INDEPENDENT VARIABLES ............. . . 30

Demographic Characteristics .......... 30

sociocultural characteristics ......... 33

Econamic Characteristics .......... 37

Housing Characteristics .......... 39

THE VARIABLE MODEL OF THE SUBFAMILY . . . . . . . . 41

DATA SOURCE ........................ 53

CHAPTER V . . . . . . . . . . . . . . 56

METHODOLOGY .................. 56

PROCEDURES OF PATH ANALYSIS . . . . . . . . . . 59

CALCULATING THE DIRECT AND INDIRECT EFFECTS IN PATH

ANALYSIS ........................... 60

Predetermined or Exogenous Variables ....... 64 
Endogenous variable ............. 64

Intervening Variables ... . . . . . . . 64

THEORY TRIMMING AND PATH ANALYSIS . . . . . . . . 64

THE PROGRAM USED ......................... 65

CHAPTER VI ........................... 66

DATA ANALYSIS AND RESULTS . . . . . . . . . . 66

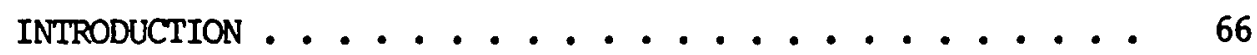

AN OVERVIEW OF THE GENERAL HYPOTHESIS USING SMSA DATA $\ldots . .67$

COMPARISON OF THE PREDICTED MODEL WITH THE FINAL TRIMMED ONE, CONTAINING SMSA CENSUS DATA RESULTS ........ 69

COMPARISON OF THE CONCEPTUALIZED MODEL WITH THE RESULTS USING SMSA CENSUS DATA ................ 79

AN OVERVIEW OF THE RESULTS OF THE LOS ANGELES CENSUS TRACT DATA ....................

COMPARISON OF THE PREDICTED MODEL WITH THE FINAL TRIMMED ONE CONTAINING LOS ANGELES COUNTY CENSUS TRACT DATA . . 84

COMPARISON OF THE CONCEPTUALIZED MODEL WITH THE RESULTS using LOS ANGELES CENSUS TRACT DATA . . . . . . . . 94

COMPARATIVE ANALYSIS OF THE GENERAL SMSA RESULTS WITH THOSE OF LOS ANGELES COUNTY . . . . . . . . . . . 98

CHAPTER VII . . . . . . . . . . . . . . . 104 SUMMARY AND CONCLUSIONS . . . . . . . . . . 104 THE DEMOGRAPHIC CHARACTERISTICS . . . . . . . . 104 THE SOCIOCULTURAL CHARACTERISTICS . . . . . . . 105 THE ECONOMIC CHARACTERISTICS . . . . . . . . . 106 IMPLICATIONS FOR FUTURE RESEARCH . . . . . . . . 107 
LIMITATIONS OF THE STUDY ............ 109

MERITS OF THE STUDY .................... 109

APPLICATION TO OTHER AREAS ............ 110

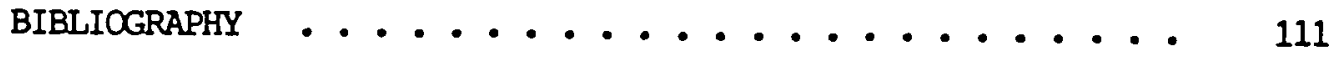

APPENDIX A

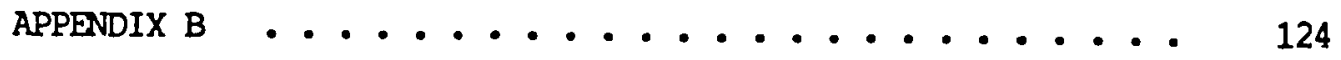

APPENDIX C . . . . . . . . . . . . . . . 133

APPENDIX D . . . . . . . . . . . . . . . 137 
LIST OF TABLES

TABLE

PAGE

I Endogenous and Corresponding Explanatory Variables of the Subfamily Variable Model . . . . . . 54

II Comparison of Predicted Relationships Between Endogenous Variables and Explanatory Variables with the Results Using SMSA Census Data . . . 68

III The Correlation Matrix of the Variables in the Subfamily Model Using SMSA Census Data . . . . 72

IV Decomposition of Effects of One Variable (SF) in a

Path Model of the Subfamily Using SMSA Census Data . . . . . . . . . . . 80

V Comparison of Predicted Relationships Between

Endogenous Variables and Explanatory Variables

with the Results Using LA County Census Data . .

VI The Correlation Matrix of the Variables in the Sub-

family Model Using LA County Census Tract Data . . 86

VII Decomposition of Effects of one Variable in a Path

Model of the Subfamily using Los Angeles County Tract Data .............. 95

VIII Comparison of the Unstandardized Beta (B) of SMSA

Census Level Data with the Unstandardized Beta (B)

of LA County Census Tract Data . . . . . . 99

IX Comparison of the Mean and Standard Deviation of SMSA

Census Data with IA County Census Tract Data . . 100 
LIST OF FICURES

FIGURE

PAGE

1. Effects of Demographic, Sociocultural, Economic

and Housing Characteristics on the Extended

Family Household ............. 26

2. The Conceptual Path Model of the Influences of

Demographic, Sociocultural, Econamic and Housing

Characteristics on the Extended Family Household . . . 27

3. The Effects of Demographic Variables on the Subfamily . . 32

4. Path Diagram Showing Hypothesized Relationships of

Selected Sociocultural Variables on the Subfamily . . 36

5. Path Diagram Showing Hypothesized Relationships of

Selected Economic Variables on the Subfamily . . . . 38

6. Path Diagram Showing Hypothesized Relationships of

Selected Housing Variables on the Subfamily ..... 41

7. Schematic Path Diagram of Effects of Selected

Variables on the Prevalence of the Subfamily . . . . 42

8. A graphic Illustration of a Saturated Model of Path

Analysis Showing Each Endogenous Variable

Regressed with all Causally Prior Variables ... . . 61

9. An Example of Direct and Indirect Effects in Path

Analysis ................. 62 
10. Path diagram of the effects on the Subfamily of Race and Ethnicity (RAE), Proportion of Foreign Born (PFB), Proportion of the Population Divorced and Not Remarried (POD), Educational Level of Head of Household (ELOH), Female Head (FH), Proportion of the Household Population Under the Age of 18 and Living with Only One Parent (PUNAG), Unemployment Rate (UNEMP), Median Family Income (MFI), Proportion of Household Income Below 1979 Poverty Level (PHIBP), Housing cost as Percent of Incame (HCAPI), and Vacancy Rate (VR), using SMSA census data (the Saturated Model) . . . . . . 70

11. Path diagram of the effects on the Subfamily of Race and Ethnicity (RAE), Proportion of Foreign Born (PFB), Proportion of the Population Divorced and Not Remarried (POD), Educational Level of Head of Household (ELOH), Female Head (FH), Proportion of the Household Population Under the Age of 18 and Living with only one Parent (PUNAG), Unemployment Rate (UNEMP), Median Family Income (MFI), Proportion of Household Income Below 1979 Poverty Level (PHIBP) using SMSA census data (the trimmed

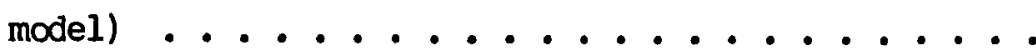


12. Path diagram of the effects on the Subfamily of Race and Ethnicity (RAE), Proportion of Foreign Born (PFB), Proportion of the Population Divorced and Not Remarried (POD), Educational Level of Head of Household (ELOH), Female Head (FH), Proportion of the Household Population Under the Age of 18 and Living with Only one Parent (PUNAG), Unemployment Rate (UNEMP), Median Family Income (MFI), Proportion of Household Income Below 1979 Poverty Level (PHIBP), Housing Cost as Percent of Income (HCAPI), and Vacancy Rate (VR), using LA County Tract Data (the saturated model) ........

13. Path diagram of the effects on the subfamily of Race and Ethnicity (RAE), Proportion of Foreign Born (PFB), Proportion of the Population Divorced and Not Remarried (POD), Educational Level of Head of Household (ELOH), Female Head (FH), Proportion of the Household Population Under the Age of 18 and Living with only one Parent (PUNAG), Unemployment Rate (UNEMP), Median Family Incame (MFI), Proportion of Household Incame Below 1979 Poverty Level (PHIBP) using LA County Tract Data (the trimed

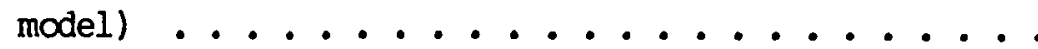




\section{CHAPTER I}

INTRODUCTION

In recent years, researchers have paid increasing attention to the living arrangements of Americans and to the factors which influence those arrangements. Such considerations as the growth of families in which females are the head of the household, the increase in households composed of unrelated individuals, and the economic theories of household formation behavior have been analyzed. A number of studies have also focused on the decline in average household size and on households consisting of single individuals (see, for example, Troll, 1971; Carliner, 1975; Kobrin, 1976; and Kuznets, 1978).

One area, however, which has received relatively little formal attention is that of the extended family form of living arrangement, among which is the subfamily unit. The U.S. Bureau of Census describes the subfamily households as those which consist of:

a married couple with or without children, or one parent with one or more single children under 18 years old, living in a household and related to, but not including, the head of the household or his wife. The most common example of a subfamily is a young married couple sharing the home of the husband's or wife's parents $(1980: 15)$. 
The subfamily, according to the definition on the preceeding page, shares a home with a primary family.

"Sub́amily" is used here as a particular operationalization of the concept of the extended family. The extended family is generally defined as a living arrangement consisting of husband, wife, dependent and adult unmarried offspring, and married sons with their spouses and offspring. While "extended family" may also include the interaction patterns among related individuals, it will be confined here to the actual living arrangement of the family members. The subfamily was chosen because it is the only unique, self-contained measure of extended family life represented by the U.S. Department of the Census. This study focuses on the subfamily because it is a reasonable index and a useful measure of the extended family.

\section{EXTENDED FAMILY LIVING}

The extended family form of living arrangement in contemporary America is an area in which little research has been done. In view of some accepted social theories (e.g., those of the functionalists) the household structure in present day U.S. society should be nuclear. The functionalist theorists argue that industrialization was responsible for the nuclearization of the family. While it is clear that the nuclear family is predominant in modern U.S. society, these theorists gave no explanation for the existence of extended family living in industrial and post industrial 
urban society. Yet, the extended family form of living arrangement exists for a small proportion (2.5\%) of U.S. households.

The U.S. Bureau of the Census recognizes this, and therefore, they categorized and defined it as a subfamily in the 1980 census. The phenomenon is general enough that it was reported in the public press. Newsweek (April 7, 1980) noted that many young couples across the U.S. have returned to their parents' homes. Economic difficulties, inflation, the housing shortage, and rising divorce rates were said to be among the factors that have forced young adults back to their parents' homes in extended family living situations. some social theories and studies also indicate that contemporary U.S. cities may have other family structures besides the nuclear type that may be more appropriate to their sociocultural and economic circumstances. Berkner's (1972) life cycle theory, for example, is one which provides that household structure is not static, that families go through both extended and nuclear phases.

RESEARCH PROBLEM

Given that the extended family living arrangement exists and is represented by subfamilies, the question arises:

- Does this occur randomly or systematically in U.S. cities? 
If it occurs randomly, this means an inherent but relatively small error in the structural functionalist viewpoint and therefore, it is not theoretically significant. However, if it occurs systematically, then it is associated with certain variables and is theoretically significant.

- Assuming that it is systematic, can the differences in their presence across geographical levels be accounted for by a reasonable set of predictors in a causal model?

- And if so, can this be done at national and/or local levels of data aggregation?

This study seeks to answer the above questions. Currently, no study of this type has been undertaken. The subfamily may represent only a small percentage of all households, and it appears to be a limited arrangement; however, it affects hundreds of thousands of families nationally and tens of thousands in a given SMSA. This phenomenon may also affect Americans in ways that may not be obvious, but which nonetheless challenge very fundamental attitudes Americans have about family life. For example, the subfamily can lead to situations wherein grandparents are forced to play the role of principle parents, and a generation gap can be exacerbated by this.

The aim of this dissertation is to establish if subfamilies are a random or systematic phenomenon, and to identify the factors responsible for the variations in its occurrences within and across U.S. metropolitan areas. It 
employs 1980 data for the 318 U.S. SMSAS (Standard Metropolitan Statistical Areas).

USEFULNESS OF THE STUDY

The results from this study should be useful to housing planners and policy makers in addressing the housing, zoning, and related problems associated with the subfamily. current housing is designed for nuclear families, which poses problems in that subfamily life increases density, which, in turn, may affect zoning in many areas. If it is determined that subfamily living is linked to poverty or ethnicity, the information gained from this research may also be useful in the development of public housing programs optimized to subfamily life. This study overall will provide a clearer understanding of the factors responsible for the extended family form of living arrangement in contemporary urban America. 
CHAPTER II

REVIEW OF LITERATURE

INTRODUCTION

There is currently no significant literature on the subfamily. This living situation was only distinguished as a household type by the U.S. Bureau of the census in 1980. However there is literature on the extended family of which the subfamily is a subgrouping. The theories and studies that will be reviewed are those available and are most appropriate in establishing the general background for this dissertation. These research tracts are currently more or less independent. This section strives to integrate them into a concise, logically cohesive conceptual model that will be developed and analyzed in the subsequent chapters. The Functionalist Perspective

Functionalist theory holds that industrialization, i.e., the factory system of production, its concommitant technology and its associated forms of urbanism, was responsible for the nuclearization of the family. This argument is strongest among the functional theorists (Burgess and Locke, 1945; Parsons and Bales, 1965; and Ogburn, 1968).

They argue that prior to modern times, the family performed seven functions: (1) it was the basic economic 
unit of society; (2) it was the center of prestige and conferred status to its members; (3) it was the center for education; (4) it protected its members; (5) it exercised religious functions; (6) it provided recreational outlets; and (7) it provided affection for its members logburn, 1968) .

The industrial revolution brought with it new technologies which required a structural differentiation of the family to meet the needs of the new industrial system. Thus, the family became more differentiated and more specialized with the emergence of the factory system of production. The head of the household frequently left the home during the day to work in offices, stores, factories, and the like, thereby destroying the home-based economy. His absence meant that his authority could no longer be exercised to the same degree over family members, nor was he any longer the family's primary social and economic trainer.

The factory system also brought with it increased child labor, which removed the child from the realm of total family control. The educational and recreational training of the child also began to take place to a large extent outside the home. Teachers assumed the role of part-time or substitute parent (Ogburn, 1968). Parks, clubs, cinemas, and ultimately television provided much of the recreational outlet for children. Similarly, the economic performance of adults and children was segregated (Smelser, 1959). 
The result of these changes was that the family no longer served as the axis around which everything else revolved. Functionalists argue that this transformation of the family functions brought about the transformation of family structure as well. They concluded therefore that the extended family disintegrated because it was no longer functional.

The functionalists have constructed a strong internal logic to explain the predominance of the nuclear family. By that logic, urban families are nuclear families. There are, however, some underlying assumptions in their theory which, if violated, may lead to other family structures. They assume that a society is homogeneous, with all its members socialized to positively value nuclear family structure. However, this is not the case in the contemporary united States. It has been shown that ethnic minorities, especial$1 y$ blacks and Hispanics have a tradition of extended family living. Given that a great proportion of residents in many cities are members of those minorities, extended families are also likely to be present.

Another assumption is that the market will provide adequate supply of housing for many nuclear families. Again, this is not always so. Economic crises, localized housing shortages, and increased housing costs are cited as major factors which cause families to extend. The functionalists also assumed that family structure is static--i.e., once nuclear, always nuclear. This again is not true, for 
today's United States. Social forces, e.g., marriage dissolutions, can lead to single-parent household, extended family structure, or other non-nuclear living arrangements, for people in their lifetimes. Finally, the functionalists assumed that the nuclear family will occur at the same rate and in the same process everywhere in a supposedly homogeneous society. Thus, their theory may not work in a heterogeneous society with people dispersed over a large geographical area, even if it is industrializing. The forces that operate in one area may differ from those of others, or stage of development reached may differ. Thus, there are social and economic forces which can cause the functionalist theory to work inefficiently. Studies which take into account these forces will be reviewed below. Some of them offer alternative premises for the emergence of nuclear families, some detail historical processes, and others are directed at the relationship of household structures and variables of the social and economic system.

\section{ALTERNATIVE PREMISES}

One reason extended families might be present in industrial cities is because the theoretical premises underlying the functionalist model are wrong. The major alternative to it is the life cycle theory. 
The Life Cycle Theory

Berkner employed the concept of life cycle in his study of Austrian peasants (1972). He noted that in a rural society an eldest son, his wife and his children might for a time live in the parents' household. During this period, usually in the children's early marriage years, the family will be extended, but the structure reverts to nuclear later on when the parents die or the young couple moves out. The implication of this study as was earlier noted is that families go through both extended and nuclear phases.

The lifecycle concept might operate in contemporary U.S. society, with even more than two phases described by Berkner. In today's society there are periods of nuclearfamily households, and periods of multiple-person households. The theory, unlike the functionalist theory, offers systematic explanation of the occurrence of extended family living by noting that at a certain point in life the family would be extended. On the average, some proportion of families will be extended at any time in a large city. It recognizes social forces, such as divorce, which affects family formation.

\section{HISTORIC AND CONTEMPORARY STUDIES OF FAMILY STRUCTURES}

There are two sets of theoretical conditions under which the presence of subfamilies might systematically Exist in urban places. One would see them as an inevitable and continuing outcome of temporary dislocation in advanced 
urban systems. The other would see them as one of the usual and inevitable structures a family takes over its life cycle. Historical and contemporary studies of family structure in various developmental and economic contexts detail the situations in which other than nuclear families are present in cities. Some of these studies will now be reviewed.

The Medjuck Study

One empirical study was undertaken by Medjuck (1979). Her work examined the validity of various hypotheses regarding the effect of industrialization on household structure. Focusing on the period between 1851 and 1871, she examined the transformations which occurred in the structure of families and households in Moncton, New Brunswick, as a result of rapid economic changes. Using census statistics, she found that household size was large and unstable in Moncton near the beginning of the industrial revolution. The mean household size was 8.49 in 1851 ; it shrank to 5.95 in 1861 , and grew slightly again to a mean of 6.07 in 1871 .

These results are in sharp contrast to the Laslett (1965) findings that household size was relatively small and stable (about 4.75 average member/household) in England during the mid-nineteenth century. The Medjuck research points out that mean household size was so large in 1851 Moncton because almost 408 of the population lived in multiple-family households. Heads of many of these multiple 
family households were young immigrants where quarters were shared because they had little money. The aged also lived in multiple-family households. Her study concludes that essentially only relatively affluent, native-born households were likely to be in single-family units.

The Medjuck study found Laslett's conclusions, that children moved out of their parents' homes to start their own families, to be true; however, she indicates that this led to the erroneous conclusion that nuclear family structures consistently prevailed. What the Laslett study (and others like it) failed to envision was a situation such as Moncton, in which young men and families from outside the colony immigrated to share in the economic boom precipitated by the industrial revolution and consequently shared a household with other families, unrelated to them by birth or marriage.

In 1851, for example, 648 of all households were simple, nuclear configurations, while $24 \%$ were multiple; in 1861, however, when industry declined, 828 were once again nuclear. Thus, rapid economic growth appears to have had a dramatic effect on household structure, and consequently on household size.

In the nineteenth-century Moncton, it [shared housing] served as an institutional interface between economic conditions and individual well being, providing many new immigrants, as well as the community at large, a mechanism for adapting to the rapidly changing economic conditions of the nineteenth century (Medjuck, 1979: 285). 
It would seem then, that household structure is, among other things, extremely malleable, and in periods of economic boom and consequent housing shortages will extend.

Medjuck's study of Moncton, produced no evidence of a strengthening of family ties with the growth of industry. Total strangers, not kin, came to dwell with native-born families. This represents the "doubling up" phenomenon. She notes, however, that as the surge of impact of the industrial revolution and concomitant migration declined, relatives began to replace boarders in multiple-family households. These findings are basically similar to those of empirically based research projects focusing on the United states during the eighteenth and nineteenth centuries (e.g., Demos, 1970; Pryor, 1972; and Modell \& Hareven, 1973). Here, then, an extended family situation is associated with later stages of industrialization.

The Agresti Study

Another study of the same general type as Medjuck's was conducted by Agresti in 1979. This work examined the impact of changing economic conditions on household composition in Walton County, Florida, during the period between 1870 and 1885. Using data from census manuscripts, she compared kinship structure and lodger presence within households. Comparisons were made over time between rural and village residents and by stage of primary family life cycle. 
Her results indicated a relatively important percentage of extended family households. The percentages were higher for families in later stages of the life cycle. Agresti also noted that within all stages of the life cycle, the percentage increased in response to increasing economic difficulties which occurred during the 1870-1885 period. Young married men had difficulty in establishing and maintaining a household in Walton County during this interval. This difficulty was reflected in the statistics which showed that the percentages of young married men heading their own households declined from 988 in 1870 to about 808 in 1885 .

Agresti also found that the presence of extended kin in households increased as economic problems increased. Her findings, like those of Medjuck, suggest that the early American family structure was neither as stable nor as simple as had previously been assumed. Her conclusion is that "norms defining family residence should be seen as influenced by economic and social contexts" (p. 257).

The general conclusions reached by Medjuck and Agresti are that extension is a response to severe social and economic crisis. Their findings point to conditions under which other than nuclear families will be present in urban settings, however where hard evidence is available, the nuclear household still predominates. 
The Angel and Tienda Study

Angel and Tienda's research (1982) examines the relationship between household composition and sources of household income among Hispanics, Blacks, and non-Hispanic Whites. Specifically, they investigated the extent to which extended living arrangements help buffer the effects of labor market disadvantages faced by minority household heads. Their analysis was based on the 1976 survey of Income and Education.

They began with a decomposition of total household income into five categories: (1) earnings of the head of household; (2) earnings of nonnuclear members; (3) earnings of the spouse and adult children; (4) welfare income; and (5) other nonwork income. The study had two objectives: (1) to document differences in the income contributions of nonnuclear members among the various racial and ethnic groups; and (2) to determine whether the formation of extended family households might be instrumental in the alleviation of poverty, or whether other cultural and demographic factors might be more important explanatory variables. This second objective is similar to the principal question posed in the current research project.

With regard to the first objective, Angel and Tienda found that variations in the relative income contributions of nonnuclear members reflect differences in the labor market success of the various racial and ethnic groups, as well as group differences in the motivation to form and 
maintain extended family households. They noted that the income contributions of nonnuclear members are more substantial among female-headed households than among households where both spouses are present.

Additionaliy, their data reveal that the earnings of nonnuclear members are found to be significantly and positively related to total household income in minority households. This finding is consistent with Sweet's 1973 study, which noted that a relatively greater share of income is contributed by secondary workers among Black households. The analysis reveals that

\begin{abstract}
extended family structure is more prevalent among minority households and those headed by single women than among nonminority and husband/wife households and that the economic roles of nonnuclear members differ according to the race, ethnicity, and sex of the head (1982: $1379)$.
\end{abstract}

They also determined that non-Hispanic Whites and Central/ South American households contain the fewest members, averaging 4.3 persons in husband/wife households and 3.0 persons in female-headed households. Mexicans and Blacks were determined to have the largest median family size, averaging between four and five persons per household. Other, earlier studies, have noted that for these groups, large family size is due in part to the persistence of higher fertility rates and to norms which favor large families (see, for example, Bradshaw \& Bean, 1972; Edington \& Hays, 1978). 
To achieve their second objective--a determination of the extent to which extended family household formation may be related to the alleviation of poverty--they employed multivariate analysis. Logistic regression was first used to examine the propensity of various ethnic and racial groups to form extended households. Following that determination, the researchers employed regression analysis to determine the extent to which the earnings of nonnuclear members contribute to total household income.

The logistic regression employed by Angel and Tienda used a dichotomous dependent variable--extended versus nonextended family structures. The logarithm of the probability of extension was then expressed as a linear function of a constant set of terms--ethnicity, the educational level, female headship, the ratio of household income to poverty, full-time employment status of the head of household, and nativity. Their data indicates that in every case, nonWhite or Hispanic origin increases the likelihood of an extended family structure presence.

They found that the education of the household head has an impressively strong negative impact on the odds of extension. For each year of school completed by the head of household, the likelihood of extension decreases 1.68 . Female headship was associated with a large increase in the likelihood of extension. They noted that the ratio of household income to poverty has a significant but small positive impact on the likelihood of extension. For each 
1008 increment in the ratio of household income to poverty, the odds, of extension increase by 1.18 .

Their data show that full-time employment of the household head is associated with a decrease in the odds of extension. Surprisingly, foreign birth of the head of household has a negative impact on extension, suggesting that foreign-born heads of household may be in a process of adjustment to a new society and thus are less able to incorporate nonnuclear members than are households with nativeborn heads of household (Angel \& Tienda, 1982: 1371).

Overall, the results of the Angel and Tienda study lend considerable support to the claim that extension is related to the desire to alleviate the temporarily or chronically low earnings of the primary wage earner. This study seems, as they suggest, to have provided

an empirical basis for the claim that families rely on immediate relatives or nonnuclear members within the same household for support when social and economic demands are great (1982: 1380).

While the Angel and Tienda study concerns itself to some extent with the economic aspects of extended family structuring, they are adamant that such explanations must also look beyond economic considerations if the subject of extended family and structures is to be fully explained. Montiel (1970) and Mirande (1977), for example, have suggested in their respective studies that intrafamilial non- 
monetary contributions are particularly important among households containing families of Spanish origin.

The Monahan Study

The Monahan's study (1956) was one of the earliest to note that the shortage of sufficient housing units is a major reason for families "doubling up." Using census statistics, he found that "doubling up" increased from 1910 to 1940 and peaked in 1947, with a level of one in ten families sharing a household with another family. He cites three primary reasons for this occurrence: (1) the depression created an economic need for it; (2) the war perpetuated it in the form of housing materials shortages, and the propensity of war-wives to live in the parental homes of either spouse; (3) the postwar boom in marriages, but not in the available housing accommodations.

Other Studies Concerned with Household Sharing and Housing Supply Issues

It was not only in the United States that housing shortages led to doubling up, but also in other countries. A study by Prince (1942) detailed the same phenomenon in Canada. His study predicted that the severe housing shortages of wartime Canada would worsen after the war was over and would consequently lead to more sharing of accommodations. Several other writers have also noted that in addition to influences of housing shortages, doubling-up is a response to personal economic difficulties. In addition to 
the Monahan study (1956) cited earlier, Glick (1949) also studied this aspect of extended family living. He found that doubling up is most significant among older low-income couples and among newlyweds. Prince's Canadian study indicated that shared housing afforded families the opportunity to "pool resources" by doubling up.

It should be noted that subfamily living, the subject of the current study, is only one aspect of doubling up. Doubling up can also involve unrelated persons or single adult children; however, these aspects will not be dealt with here in that they are beyond the parameters of this study.

Other, less predictable reasons for shared housing (such as a personal choice) have been suggested by several writers. Rose (1947), for instance, has pointed out that low income immigrants and migrants to the cities often share households with their peers because it gives them the security of their own cultural environment as well as the benefits of living with peers who are acquainted with the new environment. This element would seem to be still relevant today among refugee immigrants and also ethnic migrants from the rural areas of the country.

THE EFFECTS OF DEMOGRAPHIC VARIABLES ON FAMILY AND HOUSEHOLD COMPOSITION

This section will focus on the effects of recent changes in demographic factors upon family and household composition. Demographics will be discussed in terms of the 
life events which affect family composition. While effects on family structure are associated with these events, there is no necessary linkage between them and industrialization/ urbanization. Thus, a separate social trends literature is considered here in the search for possible systematic causes of family extension.

\section{Fertility}

Most literature in this area focuses on the decline of fertility and a decrease in household size. However, a change which may have the impact of increasing household size and emphasizing extended structure is the increased proportion of births to unwed mothers. Since many of these women are now keeping their children, an increasingly larger percentage of families are beginning with one fewer member-the father (Rabiega and Schafer, 1980: 28). Female heads of households with children are the most likely group to be with their parents in a subfamily. Thus, this trend can be expected to lead to extension.

\section{Marriage and Divorce}

The recent change in attitudes about marriage and the increase in marriage dissolutions have effects on both household size and composition. The decade of the seventies witnessed a major shift in marriage and divorce rates. Rabiega and Schafer's proposal (1980: 29) show that "between 1972 and 1975, the first marriage rate-first marriage per 
1,000 single men/women over 14 years old--declined from 70 to 56, a 3-year decline of 20 percent." The remarriage rate has also declined. All this has resulted in a large number of divorced men and women who have not remarried.

Michael et al. (1980) have also noted that the propensity among divorced men and women to live alone has increased since 1950. Their data reveal that among divorced men, 18-24, their propensity to live alone increased from 4.08 in 1950 to 23.98 in 1976. For divorced women in the same age group, the increase was from 3.1 in 1950 to 19.1 in 1976. For divorced men in the age category 25-34, the increase was from 10.7 in 1950 to 36.7 in 1976 ; for women in the same age group, the increase was from 8.7 in 1950 to 12.5 in 1976 . While all of this points to smaller nuclear families as a trend, the divorced female group, especially with children, are likely candidates for subfamily structures.

\section{CLOSING COMMENTS}

It should be noted that even if one accepts the basic functionalist model, there are conditions of housing shortage, housing expense, poverty, ethnic diversity, fertility, marriage customs, and developmental diversity under which urban places may exhibit different proportions of extended families. Insofar as these conditions are perpetuated, the extended family structure can be expected to persist in urbanized society. 
The theoretical and empirical literature reviewed in this chapter is disparate, and has some limitations. While the studies presented here have identified factors that influence the formation of the extended family households, none have looked at the causal structure of these variables in a holistic model. Examining the causal relationship of these variables and their effect on the subfamily is central to this research, and this effort is detailed in subsequent chapters. 


\author{
THEORETICAL DISCUSSION AND \\ PRELIMINARY OPERATIONALIZATION
}

The literature reviewed in Chapter II suggest that the existence of subfamilies are particularly affected by four generic conditions. The four conditions or conceptual variables are: (1) demographic characteristics, (2) sociocultural characteristics, (3) economic characteristics, and (4) housing characteristics. These characteristics are closely associated with the major theoretical and empirical studies detailed earlier. In the literature, the term demographic characteristics was used. The other three conditions, however, are not named as above. But the variables used such as female headed households, educational level of the head of household, median family income, unemployment rate, seem appropriate to be classified under sociocultural, economic, and housing characteristics.

Three variables--fertility, marriage rate, and divorce rate--were used as indicators of demographic characteristics in the literature. One or more of these variables are incorporated in the arguments underlying life cycle theory. The life cycle theory uses the variable marriage and death to illustrate that families go through both extended and 
nuclear phases. Bogue (1969) and Kobrin (1976), in their respective studies, employed the variable fertility. Michael et al. (1980) used the variable divorce in their own study.

Sociocultural characteristics used in past studies include the educational level of the head of household and female headed households (Angel and Tienda, 1982). Implicit in Agresti's study (1979) are some sociocultural discussion. The variables used in the literature that can be classified here as economic characteristics are unemployment rate and the ratio of household income to poverty level. Angel and Tienda (1982) employed these two variables in their study. Agresti's study (1979) is basically an economic argument. Personal economic difficulties were identified as major causes for not being able to establish and maintain a household.

Housing characteristics mentioned previously include rent and mortgages. Discussions were also focused on housing shortages, supply and demand. Implicit in the life cycle theory are also discusions about housing, and this can also be seen in Berkner's (1972) argument. Housing shortages, and the depression which created economic need were addressed by Monahan in his study (1956). The Prince study (1942) was focused on forecasting housing shortages.

From the preceding discussion it can be inferred that each of the four conceptual variables independently affects 
the extended family household. A set of simple models can be developed to show this (see Figure 1).

$\begin{array}{lc}\text { Demographic Characteristics } & \text { Extended } \\ & \text { Family } \\ \text { Household } \\ \text { Sociocultural Characteristics } & \text { Extended } \\ & \text { Family } \\ \text { Economic Characteristics } & \text { Extended } \\ & \text { Family } \\ \text { Housing Characteristics } & \text { Household } \\ & \text { Extended } \\ & \text { Family } \\ & \text { Household }\end{array}$

Figure 1. Effects of demographic, sociocultural, economic and housing characteristics on the extended family household.

Following the argument of life cycle theory, Kobrin (1976) and $A r_{1} \%$ and Tienda (1982), it can be inferred that demographic characteristics affect the extended family and the model developed in Figure 1 illustrates this. Following Agresti's (1979) and Angel and Tienda's (1982) studies, it can be inferred that sociocultural characteristics influence the extended family household. The model developed in Figure 1 also shows this. Following Medjuck's study (1979) and also that of Angel and Tienda, it can be conceptualized that economic characteristics influence the extended family household (see Figure 1). Following the life cycle theory and the study by Monahan (1956) and that of Prince (1942) it 
can be inferred that housing characteristics affect the extended family household (see Figure 1).

in Figure 1 each of the four conceptual variables are seen to have a direct and independent effect on the extended family household. Those models, however, can be further developed and synthesized to show how each of the four variables are causally related to affect the extended family household. The synthesized model is the more general model of the causal effects on the extended family and it is depicted in Figure 2 .

In Figure 2 demographic characteristics have direct effect on sociocultural characteristics, economic characteristics, and the extended family household. It indirectly affects the extended family household through sociocultural and economic characteristics. Sociocultural characteristics have direct effect on the extended family, housing, and economic characteristics.

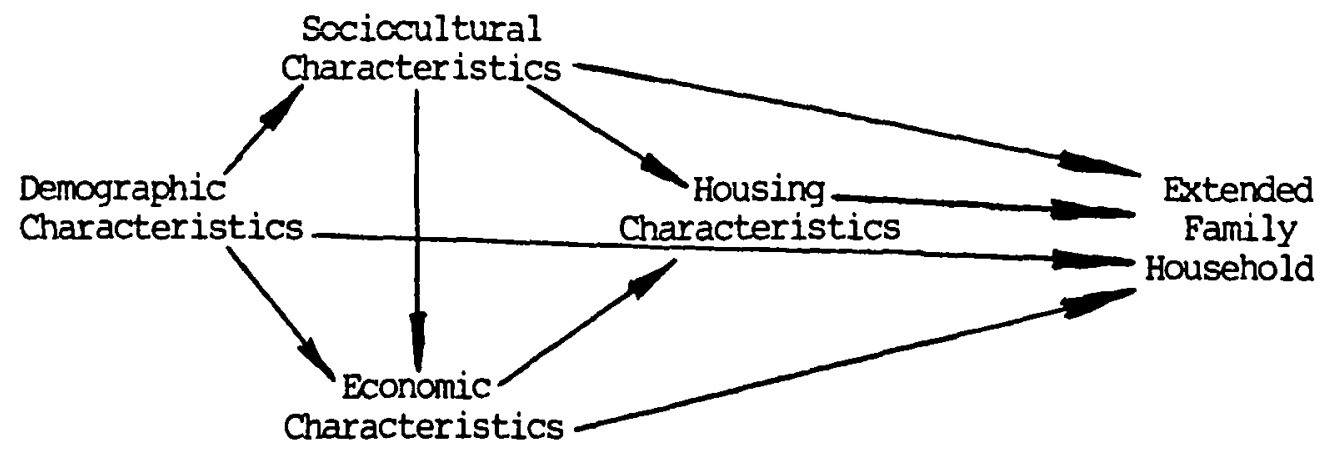

Figure 2. The conceptual path model of the influences of demographic, sociocultural, economic and housing characteristics on the extended family household. 
Economic characteristics have a direct effect on the extended family and also on housing characteristics, while housing characteristics have a direct effect on the extended family. Both sociocultural and economic characteristics affect the extended family indirectly through housing characteristics. The operationalization of the four conceptual variables identified here and how they are to be used in this study is the focus of the next chapter. In that chapter (IV) a detailed discussion of why the variables are ordered the way they are in Figure 2 will be given. 
CHAPTER IV

DATA AND VARIABLE SET

INTRODUCTION

In chapter III, the theoretical model of the influences of extended family was developed. However, that model (Figure 2) cannot be tested in its present form because it describes associations among a set of constructs. By definition, theoretical constructs are abstract and cannot be directly measured. One purpose of this chapter, then, is to operationalize the constructs in order to posit from the conceptual model a model or models having directly measurable construct indicators. These models will then be tested.

Five models will be developed from the conceptual model: one for each of the four major constructs, identified earlier in Figure 2, and their indicators, and a fifth which will include all four constructs and their specific indicators.

\section{THE DEPENDENT VARIABLE}

The dependent variable in this study is the percent of family households with subfamilies. The Bureau of the Census has defined four types of subfamilies, as discussed 
in chapter I: (1) a married couple with children; (2) a married couple without children; (3) a father with children; and (4) a mother with children living with another nuclear family to whom they are related by primary kinship.

\section{INDEPENDENT VARIABLES}

The four factors identified in Chapter III as the major causes of extended family encompass the independent variables used in this study. To reiterate, these factors are demographic, sociocultural, economic, and housing characteristics. The specific indicators for each of the four conceptual variables and how they affect one another and the subfamily will now be discussed.

\section{Demographic Characteristics}

The three indicators of demographic characteristics selected in this analysis are race and ethnicity (RAE), proportion of foreign born (PFB), and proportion of the population divorced and not remarried (POD). As noted earlier, race and ethnicity increased the likelihood of extension: Mexican and Black populations, particularly, have shown a long history of preference for extended family life. Mexican Americans are depicted as having established patterns of support and mutual aid among family members so strong and cohesive that collective needs take precedence over individual needs (Mirande, 1977; Keefe 1980). Other studies note that the large family size of Mexicans and Blacks is due in part to the persistence of higher fertility 
rates and to norms which favor large families (Bradshaw \& Bean, 1972; Edington \& Hays 1978). Data collected by Angel and Tienda (1982: 1373) indicate also that "Black households are 148 more likely than non-Hispanic white ones to be extended. Mexican, Puerto Rican, and other Spanish households are approximately 58 more likely to extend than nonHispanic white ones."

The second demographic variable mentioned here is the proportion of foreign born. This variable refers to all persons not classified as native. Foreign born frequently experience problems in acclimating themselves to a new country, both economically and culturally. Jobs are often scarce for this segment of the population, and social contacts are few--both problems which often cause them to extend. As Medjuck (1979: 281) noted: "Native-born family heads were far more likely to be in single family household than foreign-born family heads."

The third demographic variable used in the analysis is the proportion of the population divorced and not remarried. The seventies witnessed a major shift in marriage and divorce rates. Glick and Norton (1977) point out that there has been a downward shift in the remarriage rate, resulting in an accumulation of divorced (and not remarried) persons. Marriage dissolutions frequently are accompanied by a loss of property and finances by those involved. The assumption here is that the higher the proportion of those divorced and 
not remarried the righer the chances of extension.

The preceding discussion has established that the three demographic variables--race and ethnicity, proportion of foreign born and the proportion of the population divorced and not remarried--are directly related to the proportion of extended families in an area. A model was developed to investigate this premise on the subfamily proportions. The model depicted in Figure 3 reflects this premise. Subfamilies are predicted to be positively influenced by race and ethnicity, proportion of foreign born and proportion of population divorced and not remarried. There are three two headed arrows. One connects RAE and PFB. Another Connects PFB and POD and yet another connects RAE and POD. Two headed arrows are generally used in path diagrams to show unanalyzed correlations between variables not dependent upon others in the system (Duncan, 1966: 3).

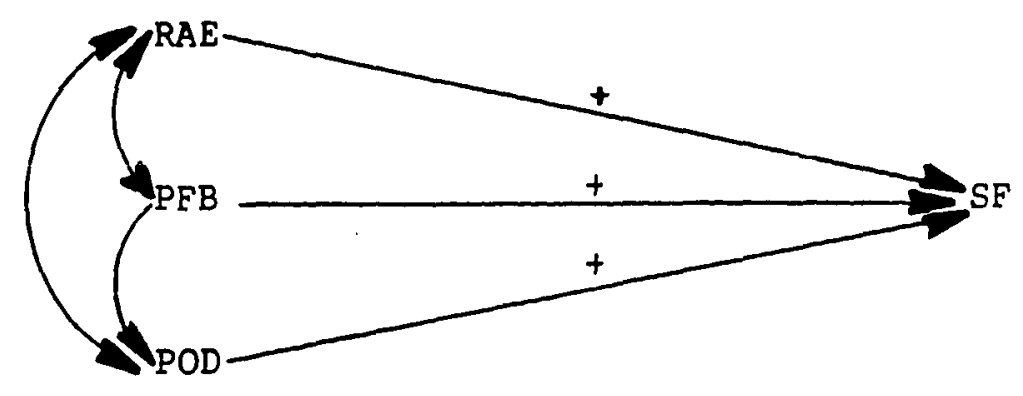

KEY: $\quad$ RAE = race and ethnicity

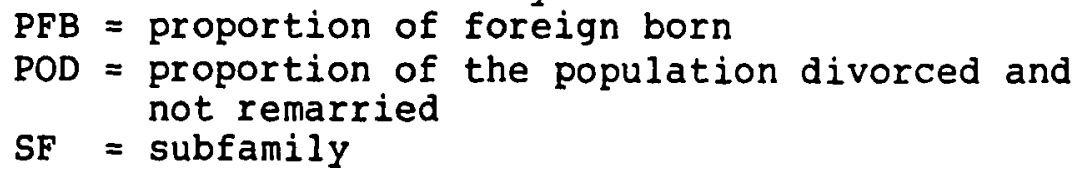

Figure 3 . The effects of demographic variables on the subfamily. 
Sociocultural Characteristics

Three indicators of sociocultural characteristics are included in our analysis. They are female head (FH), the educational level of head of household (ELOH), and the proportion of the household population under the age of 18 and living with only one parent (PUNAG). Female head is the proportion of family households headed by females. This condition, while nontraditional, is occurring with increasing frequency due largely to the increasing divorce rate. "The number of annual legal divorces per 1,000 existing marriages was 1.2 in $1860,9.4$ in 1960 , and 15.2 in 1970" (Heather et al., 1975, quoted in Gonder and Gordon, 1980). As the literature shows, units headed by single women are more likely to extend owing to the economic deprivation often associated with female headship. Angel and Tienda (1982) show that "the prevalence of poverty among femaleheaded units is three to four times higher than for husband and wife households." Gonder and Gordon (1980: 6) also state that "in all age groups, female headed families have significantly lower income than either two parent or father only families." Conditions such as the ones just discussed often lead to extension.

The educational level of head of household is the second indicator of sociocultural characteristics used in this analysis. As Angel and Tienda (1982) noted, the education of the head of household has strong negative impact on 
the likelihood of extension. Generally, the higher the educational level, the higher the income, and the higher the income, the less the chance that extension will occur. Conversely, when the head of household has a low educational level, extension is more likely to occur.

The third and final variable used as an indicator of sociocultural characteristics is the proportion of the household population under the age of 18 and living with only one parent. The under-18 age group is normally dependent on parents for financial support, thus their presence is likely to create a financial burden on the single parent, especially when the established system of assistance, such as alimony and child support, does not adequately meet the needs of this household type. Gonder and Bordon (1980: 7), using statistics from Abrahamse, Deferranti, Fleischauer and Lipson (1977), state that "of all divorced and separated women in the United States, about 148 are awarded alimony and only 468 of these women collect it regularly. Approximately 448 of all divorced mothers are awarded child support and only 458 of these collect it regularly." The assumption here is that the nigher the proportion of the household population containing members under 18 years of age, the higher the chances are that a subfamily living arrangement will exist.

The above literature review has indicated that the three sociocultural variables--female head, educational level of head of household, and the proportion of the house- 
hold population under the age of 18 and living with only one parent--increase the chances of extension. Figure 4 shows the affect of these variables on the subfamily. In the model, female head is shown to have a direct effect on the proportion of the household population under the age of 18 and living with only one parent and on the subfamily. It is predicted, however, to have an indirect effect on the subfamily through the proportion of the household population under the age of 18 and living with only one parent. The proportion of the household population under the age of 18 and living with only one parent has a direct effect on the subfamily, while the educational level of head of household affects female head and the subfamily directly. In the model a positive relationship is predicted between female head and the proportion of the household population under the age of 18 and living with only one parent. In general, females elect to keep their children. The Gonder and Gordon study (1980: 5), for example, indicates that over 908 of the heads of one-parent families are women. The assumption here is that as female-headed households increase, the proportion of the household population under the age of 18 and living with one parent is also likely to increase. As earlier discussions indicate, the proportion of the household population under the age of 18 and living with one parent and the female head is expected to have a positive relationship with the subfamily. 


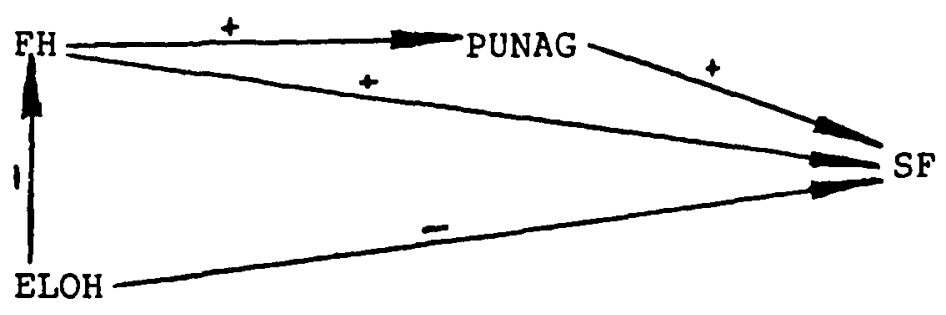

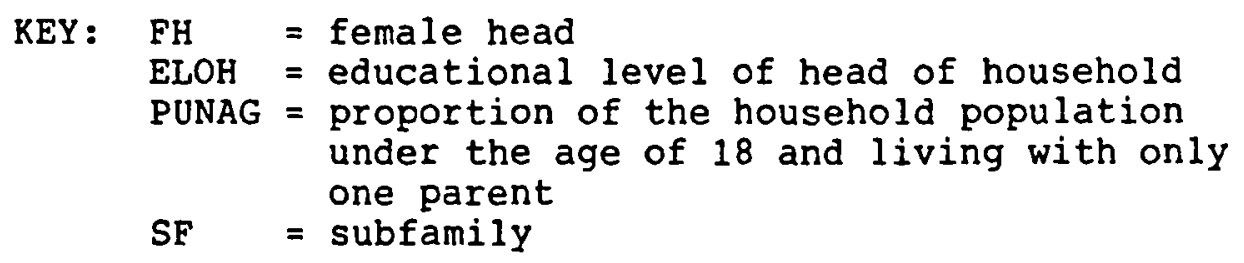

Figure 4. Path diagram showing hypothesized relationships of selected sociocultural

variables on the subfamily.

The relationship that exists between the educational level of head of household and the subfamily was also discussed earlier, and as shown in Figure 4, a low educational level of head of household is predicted to increase the chances of subfamily living. A low educational level of head of household also increases the chances of a mother being a single parent. A qualification must be made here however, because generally low educational level is associated with women with lots of children. The reasoning behind that association is that some women may have opted for children instead of education at a younger age and so when divorce occurs they are more likely to become single 
parent and head their own households. In this study a similar assumption is implied between educational level of Head of Household and female head and a negative relationship is expected. The National Academy of Sciences 11976: 43) points out that the less schooling a mother has, the more likely she is to be a single parent. Economic Characteristics

The economic variables employed in this analysis are the unemployment rate (UNEMP), median family income (MFI), and proportion of household income below 1979 poverty level (PHIBP). Unemployment increases the likelihood of extension. Angel and Tienda (1982) concludes, for example, that full-time employment of the household head is associated with a decrease in the odds of extension. The assumption here is that adverse economic conditions will force people into an extended family situation. The reasoning behind is that unemployment affects income which in turn affects housing affordability which directly affects the subfamily. Median family income is the second economic variable used in this study. Median income measures a family's income from salaries and wages. Median income is included on the assumption that the lower the median family income, the higher the prevalence of subfamilies. A negative relationship, therefore, is expected.

The final economic indicator used is the proportion of household income below 1979 poverty level. The assumption 
here is that families with income below poverty are more likely to extend due to their economic difficulties. Angel and Tienda (1982) noted an increase in the ratio of household income to poverty has a positive.impact on the likelihood of extension.

Based on the preceding discussions, the model in Figure 5 was developed to determine how the three economic variables affect the subfamily.

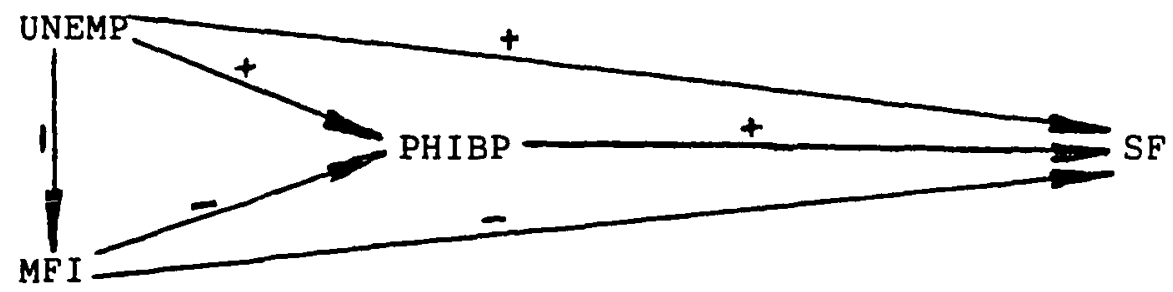

KEY: UNEMP = unemployment rate

$$
\begin{aligned}
\text { MFI } & =\text { median family income } \\
\text { PHIBP } & =\text { proportion of household income below } \\
& 1979 \text { poverty level } \\
\text { SF } & =\text { subfamily }
\end{aligned}
$$

Figure 5. Path diagram showing hypothesized relationships of selected economic variables on the subfamily.

In the model, the subfamily is predicted to be positively affected by the unemployment rate, and the proportion of household income below 1979 poverty level, and negatively influenced by median family income. The relationships between these variables and the subfamily has earlier been discussed. The unemployment rate, the first variable in the model, is seen to have a negative influence 
on the median family income, and the assumption here is that as the unemployment rate increases, the median family income decreases. Other studies have arrived at similar conclusions. Corcoran's study (1979), for example, revealed how drastic the income losses from unemployment can be. Her statistics show that male family heads who lost their jobs in 1976 lost on the average about a fourth of their normal disposable income. The unemployment rate undeniably is associated with the proportion of households with income below the 1979 poverty level, and a positive relationship is expected between the two variables. Median family income is predicted by the model to have a negative effect on the proportion of households with income below the 1979 poverty level, and the assumption here is that as median family income decreases, the proportion of household income below the 1979 poverty level increases.

\section{Housing Characteristics}

The two indicators of housing used in our analysis are Housing Costs as a Percent of Income (HCAPI) and vacancy rate (VR). The first variable (HCAPI) isolates the share of a family's or person's income which is spent on housing costs such as mortgages, rent, utilities, property taxes, and insurance. One may expect that a high rent figure, or a high proportion of income to mortgage payment, will increase 
the likelihood of subfamily presence, especially during bad economic times.

The second economic variable, vacancy rate, is a measure of the availability of housing. The notion here is that as vacancy rate decreases (i.e., fewer housing units are available) the likelihood of a rise in subfamilies increases; a tight housing supply will force some people to extend. Monahan (1956) for instance has noted in his study that housing shortage led to household sharing.

As previously, a model was also developed to depict the affect of housing cost as percent of income and vacancy rate on the subfamily. That model is depicted in Figure 6 and, as can be seen, subfamily is predicted to be positively affected by housing cost as percent of income and negatively influenced by vacancy rate. The relationship between these two variables and the subfamily was discussed above. Vacancy rate is predicted by the model to be positively affected by housing cost as percent of income. The reasoning here is that an increase in housing cost as percent of income is also likely to result in an increase in vacancy rate because, for instance, a high rent or mortgage payment could force some people out of their homes and increase the vacancy rate until a new match of houses and people occurs. The assumption is that the displaced people will likely share accommodations with others. A positive relationship is thus predicted between these two variables. 
As vacancy rates increase (i.e., housing becomes more available) the likelihood of the existence of the subfamily decreases. Conversely, as vacancy rates decrease the chances of living in a subfamily household will increase. A negative relationship is expected between vacancy rate and the subfamily.

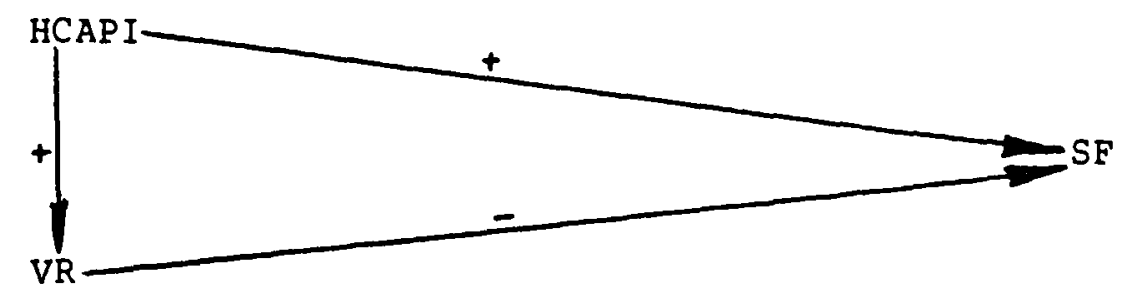
KEY: HCAPI = housing cost as percent of income VR = vacancy rate
SF $\quad$ subfamily

Figure 6. Path diagram showing hypothesized relationship of selected housing variables on the subfamily.

THE VARIABLE MODEL OF THE SUBFAMILY

Four models have thus far been developed from the conceptual model depicted in Figure 2 to illustrate the effect of each of the four major independent dimensions on the subfamily. Figure 7 is the fifth model and it represents the operationalized model of Figure 2; it consists of all the indicators of the four major independent variables discussed earlier. This model is the result of the sequential development of the four operationalized models depicted in Figures 3 through 6. 

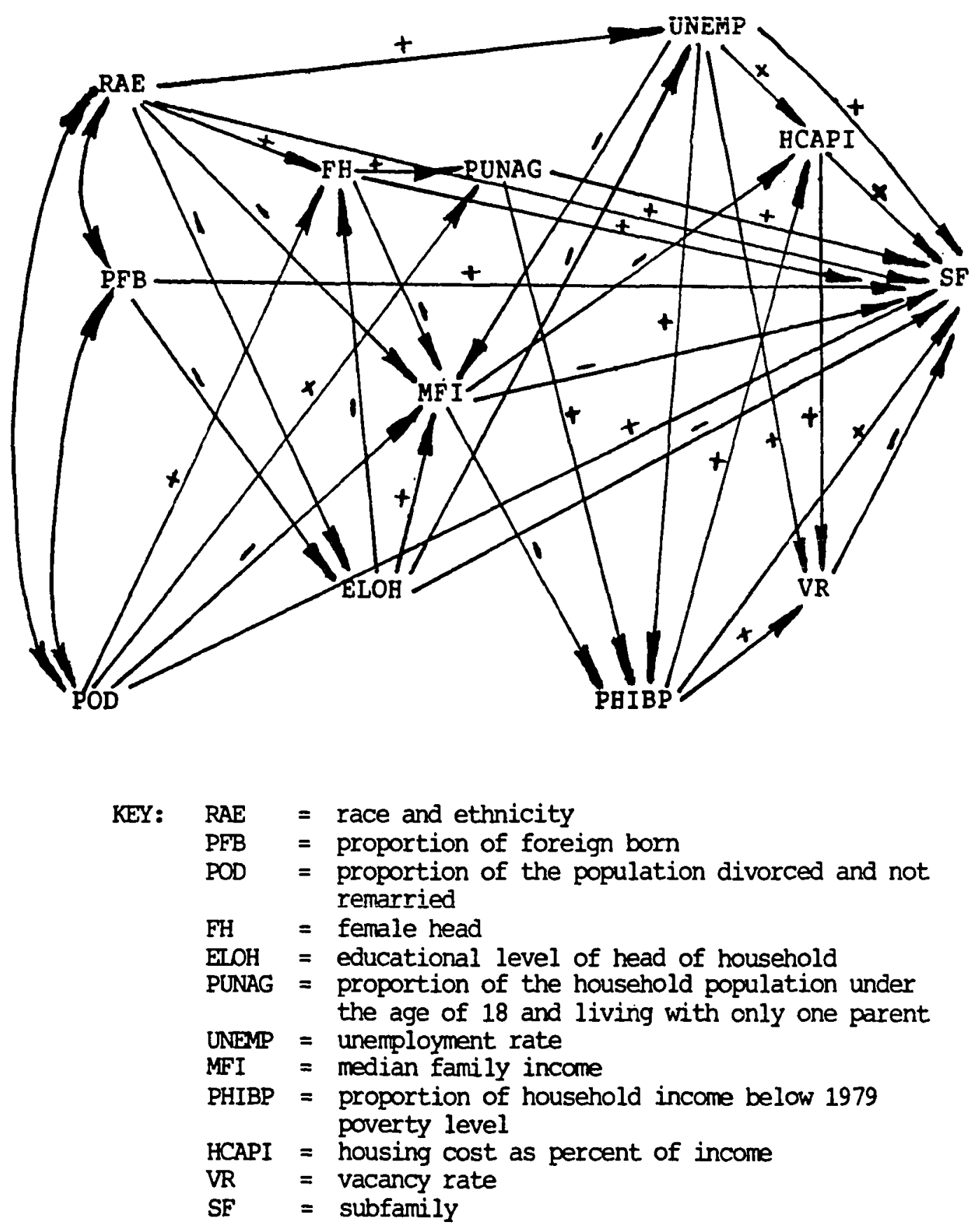

Figure 7. Schematic path diagram of effects of selected variables on the prevalence of subfamily (the predicted modell. 
The work of others and the relative importance of individual models developed in Figures 1 through 6 are synthesized into one holistic model (Figure 7). The model has indirect and direct paths that have not been recognized before. In the model, demographic characteristics are seen to influence the subfamily directly and indirectly through sociocultural, economic and housing variables. Sociocultural variables are predicted to influence the subfamily directly and indirectly through economic and housing variables. Economic variables are assumed to affect the subfamily directly and indirectly through the housing variables, while the housing variables are predicted to directly influence the subfamily.

The structuring of the model is largely based on what was covered in the literature, which indicated the direction of influence of the individual paths and also some of the authors assumptions. Demographic variables, for instance, appeared first because they are fixed variables, taken as given. In terms of the time ordering of events, one would also expect them to come first. For example, before making the argument that the proportion of female-headed households are higher among non-white than white households, the first thing to be taken into account to enable that distinction is the race and ethnicity of the females involved. Two examples can be given to show the rationale used in structuring the synthesized model. 


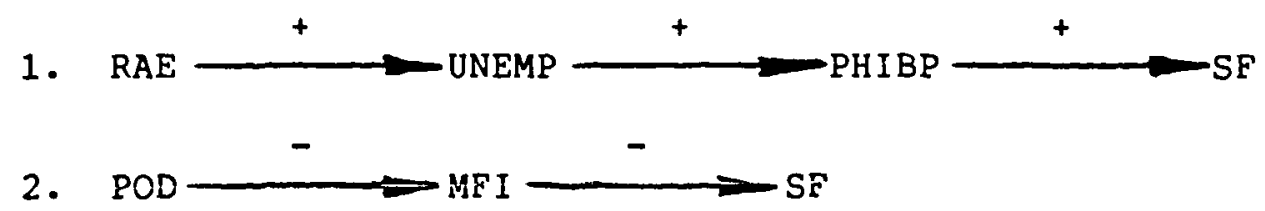

In the first example, race and ethnicity (RAE) is seen to have a positive effect on the unemployment rate (UNEMP), which in turn has a positive influence on the proportion of household income below poverty (PHIBP). PHIBP was posited to affect the subfamily positively. The reasoning behind that structuring is that generally the higher the proportion of ethnic minorities the higher the unemployment rate. A high unemployment rate is reasoned to pose severe financial difficulties on those involved, which in turn will force some families to extend.

In the example number 2, above, it was hypothesized that the higher the proportion of the population divorced and not remarried (POD), the lower the median family income (MFI), and the lower the median family income, the higher the chances that those involved will extend. Thus, the path was ordered and signed as it was in the model. Similar integration of literature was used for all the paths within the predicted model. In general the predicted model follows the simple conceptual models and the integrated one. There are some points however, at which they seem to depart. One of the major differences between the predicted model (Figure 7) and the conceptual one illustrated in Figure 2 is that the former one contains curved, two-headed arrows between 
demographic variables. One of the arrows connects race and ethnicity with the population divorced and not remarried, another connects race and ethnicity and the proportion of foreign born, and yet another connects the proportion of foreign born and the population divorced and not remarried. These arrows represent unanalyzed relationships. In the model, the three demographic variables are taken as given, and are referred to as predetermined.

The rest of the relationships that exist between the variables are depicted in the model by single-headed arrows and these can be explained. It should be pointed out that in this study the word positive refers to direct relationships while the word negative denotes inverse relationships. This terminology is used to avoid confusion between variable relationships and "direct" and "indirect" paths in the model. In the model, the subfamily is predicted to be positively influenced by all the variables except the educational level of head of household, median family income and vacancy rate which has a negative effect. The relationship of each of these variables with the subfamily was discussed in Figures 3 through 6 .

The first variable in the model is race and ethnicity. It is predicted to influence the unemployment rate, female head, median family income, and educational level of head of household. Earlier studies have noted that there is a relationship between these variables and race and ethnicity. 
It is evident that great disparities in joblessness still exist among the races. Bianchi (1981: 72) noted that by the late 1970 s about twice as many black men as white men had no work at all. Thus, race and ethnicity have a direct path to unemployment. The second variable that is predicted by the model to be directly influenced by race and ethnicity is female head. Some of the studies reviewed showed a very rapid growth of female-headed families among the minority groups. Currie and Skolnick statistics (1984: 159) show that "by the beginning of the 1980s more than two out of five black families were maintained by a woman, as compared to less than one in eight white families." Bianchi (1981: 31) also noted that since 1960 the growth in non-white families headed by a woman has been twice as fast as that among whites. Gonder and Gordon (1980: 5) pointed out that while over $90 \%$ of the heads of one-parent families are women and come from all ethnic groups, non-whites are over represented. Their data reveal that, between 1960 and 1974 , Anglo-headed families increased $83 \%$ while non-Anglo headed families increased by 155.58 .

The third variable shown to be influenced by race and ethnicity is median family income. The inequality of income among races and ethnic groups is very apparent in U.S. society. Statistics from the U.S. Bureau of Census, Current Population Reports, Series P.60, No. 146 (1984: 1) show, for example, that the 1982 median income was $\$ 21,120$ for white households, $\$ 11,970$ for black households, and $\$ 15,180$ for 
Spanish-origin households. Race and ethnicity influence median family income and the predicted direction of influence is regative.

The educational level of head of household is the fourth variable and it is predicted by the model to be influenced by race and ethnicity. Generally racial and ethnic minorities have the greatest disadvantages, and as a result are likely to have lower educational attainment. Currie and Skolnick (1984: 170) noted that, while differences in school attainment are narrowing among the races, they still exist, particularly between Hispanics and Whites. A negative relationship is predicted between race and ethnicity and the educational level of head of household.

The proportion of foreign born is the second demographic variable shown in Figure 7 and it is predicted to have a negative influence on the educational level of head of household. The particular problems of the foreign born discussed earlier will undeniably affect their educational attainment.

The population divorced and not remarried is the next variable and it is predicted by the model to influence female head, the proportion of the household population under the age of 18 and living with only one parent, and median family income. As noted earlier, female head is occurring with increasing frequency and this has been due largely to increasing divorce rate. A positive relationship 
is predicted between the two variables because as divorce rate increases, female head is also expected to increase. The proportion of the household population under the age of 18 and living with only one parent is expected to be positively affected by the population divorced and not remarried for similar reasons. The population divorced and not remarried is predicted to have a negative influence on median family income because, as was noted earlier, marriage dissolutions frequently are accompanied by a loss of property and finances by those involved. An increase in the population divorced and not remarried, therefore, is likely to result in a decrease in median family income.

Female head is the first sociocultural variable to be discussed in Figure 7 and it is predicted to influence the proportion of the household population under the age of 18 and living with only one parent and median family income. The influence of female head on the proportion of the household population under the age of 18 and living with only one parent has been discussed in Figure 4, and as is shown, a positive relationship is predicted between the two variables. A negative relationship is predicted between female head and median family income, the assumption being that an increase in female head will likely lead to a decrease in median family income. Households headed by females have been shown to have very low median income. Gonder and Gordon (1980: 8) cite statistics (gleaned from the National 
Academy of Sciences Report of 1976) which indicate that

the median income for a two parent family with at least one child under age six was $\$ 12,886$ for

1974. The average income for a father-only family with children under six in the same year was $\$ 9,226$. The total available income for a single mother with children under six in the same year was only $\$ 3,891$.

The educational level of head of household is the second sociocultural variable and it is predicted to affect female head, the unemployment rate, and median family income. The relationship that exists between the educational level of head of household and female head was discussed under Figure 4 , and the predicted direction of influence of educational level of head of household on female head is negative. The educational level of head of household is also predicted to have a negative relationship with the unemployment rate. As noted earlier in the discussion of the relationship between the female head and the educational level of head of household in Figure 4, low education was associated with low paying jobs. The negative relationship between the two variables is also evident in the discussion of the influence of the educational level of head of household on median family income. Several studies have shown that there is a strong positive relationship between the educational attainment of the householder and family income. Statistics from the U.S. Bureau of the Census, Current Population Reports, Series P-60, No. 129, (1981: 5), for instance indicate that 
In 1979, the median income for families maintained by householders 25 years old and over with 8 or less years of school was $\$ 11,500$. For families with householders who were high school graduates, the median income was $\$ 20,680$, compared with $\$ 28,070$ for families with householders who had completed 4 years of college and $\$ 32,420$ for families with householders who had completed 5 or more years of college.

The assumption here is that the higher the educational level, the higher the income; thus, a positive relationship is expected between educational level of head of household and median family income.

The proportion of the household population under the age of 18 and living with only one parent is the third sociocultural variable and it is predicted by the model to influence the proportion of household income below 1979 poverty level. As was noted earlier, the proportion of the household population under the age of 18 and living with only one parent households experience severe economic difficulties. An increase in their number therefore is also likely to increase the proportion of household income below 1979 poverty level. A positive relationship is anticipated between these two variable.

The unemployment rate is the first economic variable in the model. It is predicted from race and ethnicity and the educational level of the head of household and, in turn determines median family income, the proportion of household income below 1979 poverty level, vacancy rate, and housing cost as percent of income. The influence of the unemployment rate on the median family income was discussed earlier 
and a negative relationship is predicted between these two variables. The unemployment rate is highly associated with poverty and it is expected to have a positive relationship with the proportion of household income below 1979 poverty level. The unemployment rate is also anticipated to have a positive relationship with vacancy rate, and the assumption is that a high unemployment rate will likely lead to an increase in vacancy rate as some people will be forced to leave their homes.

A positive relationship is predicted between the unemployment rate and housing cost as percent of income. Generally the Population unemployed are known to experience severe economic difficulties, a condition which often limits their ability to pay for rent and mortgages. Data from the Bureau of Labor Statistics (in Rosenfield, 1977: 42-43) for example, reveal that 7 out of 10 unemployed workers were meeting living costs by cutting back on funding for food, transportation, and clothes, and over 1 in 10 had been forced to move to cheaper housing.

Median family income is the second economic variable in the model. It is predicted from race and ethnicity, the proportion of the population divorced and not remarried, educational level of head of household, female head and the unemployment rate. It influences housing cost as percent of income and the proportion of household income below poverty. Median family income is expected to bear a negative 
relationship with housing cost as percent of income, the assumption being that a low median family income will increase the difficulty of those involved to pay rent and mortgages. The influence of median family income on the proportion of holisehold income below poverty was discussed earlier in Figure 5 and a negative relationship is predicted between the two variables. Following the median family income in the model is the proportion of household income below 1979 poverty level. It is predicted to influence housing cost as percent of income and vacancy rate. A positive relationship is expected between the proportion of household income below poverty and housing cost as percent of income. The argument is that a high proportion of household income below poverty is likely to increase the difficulty by those involved to pay rent or mortgages. The proportion of household income below poverty is also anticipated to have a positive relationship with vacancy rate. The reasons for this are similar to those earlier cited between the unemployment rate and vacancy rate.

Housing cost as percent of income is the first housing variable in the model. Its immediate determinants are the unemployment rate, median family income and the proportion of household income below the poverty level. It influences vacancy rate and that relationship was discussed earlier, under the housing characteristics subtitle. Vacancy rate is the second housing variable and it influences only one variable--the subfamily. The relationship that exists 
between the two variables was discussed under Figure 6 . Table I is a summary of the preceding discussions. It contains a list of all variables explained in the model and the variables predicted by the model to be the influence of each of these variables. The expected direction of influence between variables, based on the literature reviewed and the author's argument, is shown in parentheses. The table represents the general hypotheses that. were postulated in this dissertation. In view of the preceding discussion, race and ethnicity, the proportion of the population divorced and not remarried, female head, the unemployment rate and housing cost as percent of income are expected to emerge as key variables to the overall model. They should emerge as more important in explaining the subfamily than are the other six variables (PFB, ELOH, PUNAG, MFI, PHIBP and VR). Overall, the validity of the variables will also lend support to the validity of the theoretical model.

DATA SOURCE

The major source of data for this study is the 1980 Census of Population and Housing, Summary Tape File 3-C (known familiarly as The National File). This file contains sample data adjusted to represent the total population. These data are summarized for various geographical levels, including SMSA, census regions, and areas containing 100,000 or more population. 
TABTE I

ENDOGENOUS AND CORRESPONDING EXPLANATORY

VARIABLES OF THE SUBFAMILY

VARIABLE MODEL

\begin{tabular}{|c|c|}
\hline Endogenous variables & Explanatory Variables \\
\hline ELOH & $\operatorname{RAE}(+), \operatorname{PEB}(-)$ \\
\hline FH & $\operatorname{RAE}(+), \operatorname{POD}(+)$, ELOH $(-)$ \\
\hline PUNAG & $\mathrm{FH}(+), \mathrm{POD}(+)$ \\
\hline UNEMP & $\operatorname{RAE}(+)$, ELOH (-) \\
\hline MFI & $\begin{array}{l}\text { UNEMP }(-) \text {, FH }(-), \text { RAE }(-), \\
\text { EIOH }(+), \text { POD }(-)\end{array}$ \\
\hline PHIBP & $\operatorname{UNEMP}(+), \operatorname{MFI}(-)$, PUNAG $(+)$ \\
\hline HCAPI & $\operatorname{UNEMP}(+), \operatorname{MFI}(-), \operatorname{PHIBP}(+)$ \\
\hline VR & HCAPI $(+), \operatorname{UNEMP}(+)$, PHIBP $(+)$ \\
\hline $\mathrm{SF}$ & $\begin{array}{l}\operatorname{RAE}(+), \operatorname{PFB}(+), \text { POD }(+), \text { ELOH }(-) \\
\text { FH }(+), \text { PUNAG }(+), \text { UNEMP }(+) \\
\text { MFI }(-), \operatorname{PHIBP}(+), \operatorname{HCAPI}(+), \operatorname{VR}(-)\end{array}$ \\
\hline
\end{tabular}


The SMSA level data were obtained from this file. This data base also generated the dependent and independent variables of the study.

The other source of data is the 1980 Census of Population and Housing, Summary Tape File 3-A. This file is identical in form to the Summary Tape File 3-C described above and it is known as the state File. It provides summaries for the state, counties, minor civil divisions, census tracts, and Congressional districts. Data from this source on the same variables will be used for analysis at the census tract level. 
CHAPTER V

METHODOLOGY

This chapter discusses the techniques used to determine the adequacy of the model postulated in Chapter IV. The basic technique employed is path analysis which uses Multiple Linear Regression (MLR) to decompose and estimate the structural coefficients causally linking a system of variables. Path analysis was originally introduced by Sewall Wright (1921) as a means of measuring the direct and indirect effects of exogenous variables on endogenous ones through various paths. The method according to wright (p. 557)

depends on the combination of knowledge of the
degree of correlation among the variables in a
system with such knowledge as may be possessed
of the causal relations. In cases in which the
causal relations are uncertain, the method can
be used to find the logical consequences of any
particular hypothesis in regard to them.

In subsequent papers, Wright elaborated the proper use of the method by noting that it is not intended to accomplish the impossible task of deducing causal relations from the values of the correlation coefficients (1334: 193) but rather the purpose "is to determine whether a proposed set of interpretations is consistent throughout: (1960: 444). 
Wright's original works were developed and disseminated in the social sciences by Duncan in his landmark article (1966). Others who have elaborated and refined the path analysis technique include Land (1969), Houser (1969), and Finney (1972). Two basic requirements of path analysis have emerged from these additional writings. These are (1) a complete theoretical model, and (2) data enabling the estimation of unbiased structural coefficients for the model (Schafer, 1985).

The first requirement is basic to all social surveytype data; that is, causality cannot be inferred from the statistical manipulation of a data set, but that a lack of association disproves causality. It is not possible to differentiate direction of the influence between the variables from the coefficients when an association between variables is demonstrated. The theory must provide the direction of influence (Heise, 1969: 61-65, as cited in Schafer, 1985).

The second requirement pertains to the assumptions of Multiple Linear Regression (MLR). These are interval-level and theoretically continuous variables, linear relationships between the dependent and independent variables, normal distribution of error terms, and no auto-correlation of the independent variables used in the mode (Duncan, 1975: 1-8). Multiple Linear Regression technique is the most predominant and most statistically powerful method available for examining the relationship between a dependent variable and a set 
of independent variables. The dependent variable is seen as a linear function of multiple independent variables. The general MLR equation is:

$$
\mathrm{Y}=\mathrm{a}+\mathrm{b}_{1} \mathrm{x}_{1}+\mathrm{b}_{2} \mathrm{x}_{2}+\cdot \cdot \cdot \mathrm{b}_{\mathrm{k}} \mathrm{x}_{\mathrm{k}}
$$

Where $Y$ is the dependent variable, $x_{1}, x_{2} . . x_{k}$ are the independent variables, $a$ is the regression constant, and $b$ is the regression coefficient.

Path analysis, a specialized application of multiple linear regression, is the technique selected for this study. It facilitates the decomposition and evaluation of causal relationships into constituent direct and indirect effects. The direct effect is that which is mediated by one variable on another, and the indirect effect is that caused by intervening variables. One important advantage to using path analysis is that it permits one to visualize relationships. The diagrammatic representation of relationships is of great value to the researcher in working out the empirical logical consequences of a model.

The basic theorem of path analysis, according to Duncan (1366:5), may be written in the general form as:

$$
r_{j k}=\sum_{i} p_{j i} r_{i k}
$$

where $r_{j k}$ is the correlation between variables $j$ and $k \cdot P_{j i}$ is the direct effect of variable $i$ on the variable $j$, and the correlation between variables $i$ and $k$ is represented by 
$r_{i k}$. The subscript $i$ is an indexing notation which refers to each variable directly causing $j$ (Finney, 1972: 177).

As was earlier stated, in order to use path analysis technique, two requirements must be met. 1) A model must be developed; and 2) data set must lend itself to MLR assumptions. This study meets the two basic requirements. The data used are consistent with MLR assumptions and a causal model (Figure 7) was also developed. In that model, as is consistent with path diagrams, one-way arrows lead from each determining variable to those dependent on it. The variables not dependent upon others have gone unanalyzed and are shown by two-headed arrows, and their connecting line is curved rather than straight. A full description of the path model shown in Figure 7 was given in Chapter IV.

\section{PROCEDURES OF PATH ANALYSIS}

In path analysis each endogenous variable is regressed with all causally prior variables and the regression coefficients of the regressions become the path coefficient of the model. The path coefficients, which are the standardized or unstandardized regression coefficients, are then mathematically manipulated to determine the direct and indirect effects. Standardized coefficients are used if one is interested in the relative amount of variance explained in the dependent variable for a given sample or population by various independent variables, while the unstandardized coefficients are preferred if one is interested in finding 
the causal processes and/or comparing parameters of one population to those of another (Nie, et.al., 1975, p. 397).

An example of the procedure of path analysis technique is illustrated graphically in Figure 8. The example, however, does not represent the general hypothesis in this study, which is shown in Table I. In Figure 8 each endogenous variable has a path from all causally prior variables; it is commonly called the saturated model, which is later trimmed. The saturated model is estimated for the purpose of testing both the implicit and explicit hypotheses. The explicit hypotheses are those already stated and are denoted with one-headed causal arrows. The implicit hypotheses does not have causal arrows and the relationship between the variables concerned are generally assumed to be zero, or insignificant. In reality there cannot be a zero relationship, so the saturated model is estimated to recover any significant path, even unanticipated ones.

\section{CALCULATING THE DIRECT AND INDIRECT}

EFFECTS IN PATH ANALYSIS

The direct effect, which is the standardized regression coefficient between $X$ and $Y$, can be correctly estimated by the magnitude of the path coefficient.

The indirect effect is the product of the standardized regression coefficient between $X$ and $Y$ that passes through one or more intervening variables. This is illustrated in Figure 9, where the direct effect is .382, while the indirect effect is $.621 \times .700=0.435$. 


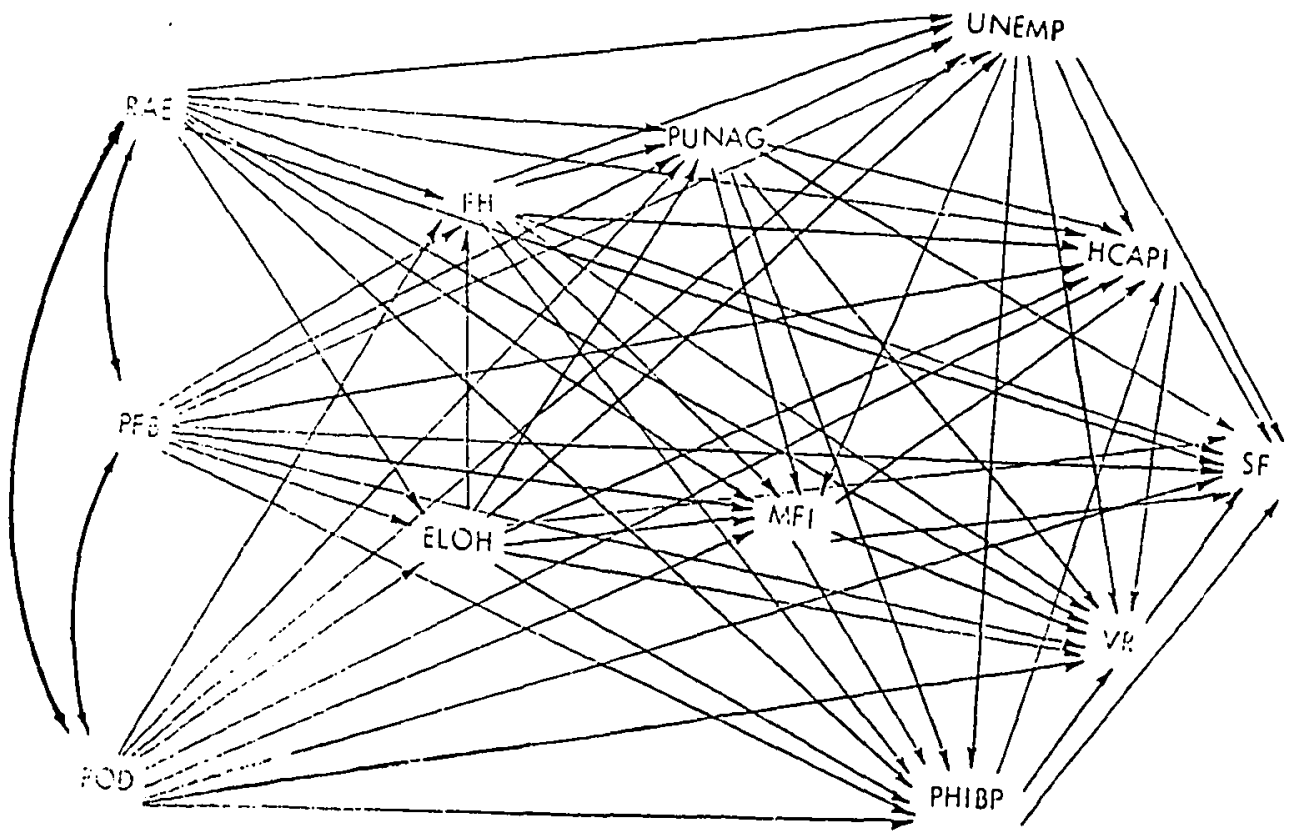

Figure 8. A graphic illustration of a saturated model of path analysis showing each endogenous variable regressed with all causally prior variables.

The functional equations implied by the saturated model depicted in Figure 8:

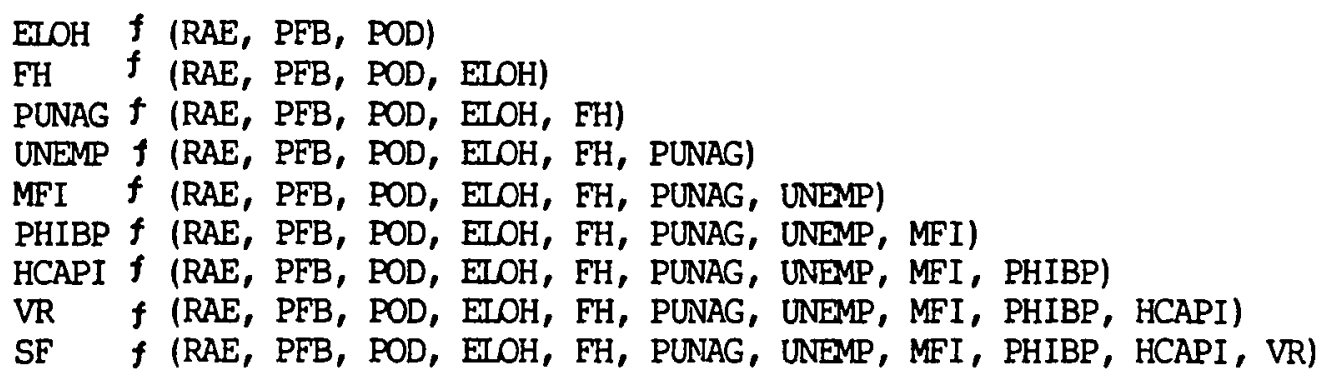




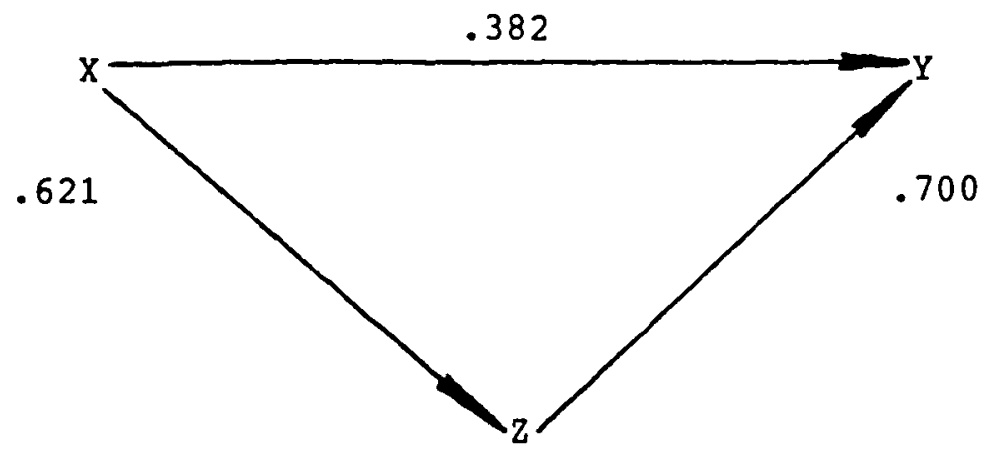

Figure 9. An example of direct and indirect effects in path analysis.

Using a variable from this study as an example, the direct and indirect effects can also be shown. In Figure 7 MFI, for instance, is seen to have a direct and indirect effect on the subfamily. Its indirect effect on the subfamily is through housing cost as a percent of income.

The earlier formula for decomposing effect is:

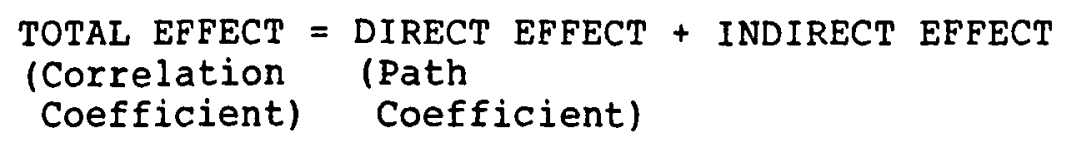

From the above formula the indirect effect was easily calculated by subtracting the value of the path coefficient from the value of the correlation coefficient (Finney, 1972: 176). Finney, however, has found fault with such calculations. According to him (1972: 176),

if we as path analysts wish the "indirect effect" component of the total association between two variables to in fact denote indirect causal effect, then the [above formula] yields estimates of indirect effects which are inconsistent with respect to this criterion across various applications. 
The three general guides to be used in romputing indirect effects from recursive path models recommended by Finney (1972: 183) are:

1. If the model contains only one predetermined variable, then its indirect effect on any endogenous variable is equal to the difference between the correlation coefficient and the path coefficient.

2. If the model contains more than one predetermined variable, then the indirect effect of one of them on any endogenous variable can be computed by stating the correlation in terms of path coefficients according to the fundamental theorem, and then summing those components which contain only path coefficients, and which do not contain a correlation coefficient. The summing procedure should be performed after the direct effect has been subtracted out of the value of the correlation. In complex path models, this procedure is tedious. A simpler approach is to trace effects through intervening variables, since only these can transmit indirect effects.

3. In computing the indirect effect of one variable not predetermined on another variable, one must trace through intervening variables. There is, in this case, no automatic procedure.

The computing of indirect effects in this study follows the "simpler approach" to guideline \#2 recommended by Finney, and it was chosen because more than one predetermined variable is involved. An example of how the computation was done, was in fact, illustrated with Figure 9. As was shown, $X$ has a direct effect of .621 on $Z$, and a direct effect of .382 on $Y$. $Z$ has a direct effect of .700 on $Y$. To obtain an indirect effect of $X$ on $Y$ through $Z$, the direct effect of $x$ on $z(.621)$ is multiplied by the direct effect of $\mathrm{Z}$ on $\mathrm{Y}(.700)$ to get 0.435 . 
Some of the technical language used in Finney's general guides is elaborated below.

Predetermined or Exogenous Variables. These are variables that are not explained in the model. They are taken as given and are generally assumed to affect the remaining variables in the set. In path diagrams the correlations between them are shown with curved two-headed arrows which denote unanalyzed relationships. According to Land (1969: 6) "the exogenous variables in a particular set may be correlated among themselves; however, the explanation of their intercorrelation is not a problem for the system under consideration."

Endogenous Variables. These are variables within the set that the model attempts to explain. In path diagrams each endogenous variable is shown with one-headed arrows leading into it from each determining variable.

Intervening Variables. Intervening variables are endogenous variables that are causally between the predetermined variables and the main dependent variable.

\section{THEORY TRIMMING AND PATH ANALYSIS}

Trimming of the theoretical model has been the generally accepted approach with path analysis; among the researchers who have used it are Merrick (1978), Guest (1981), and Blake (1982). The specific strategy that was used to trim and evaluate the theoretical path model developed in this study (Figure 7) is the one proposed by Heise (1969). 
This strategy consists of estimating the fully saturated model, then trimming from that model those paths found to be insignificant relative to some stated criteria (for example, accepting $b$ with an f-test at a given alpha level). The criteria for including or not including a path in the model used in this study was a significance test where alpha was set at $P<.05$.

Once the trimmed model is produced, it is compared to the original theoretical model to discern similarities and differences, and is used as a guide in reformulating the original model. According to Heise, "the potential for refining or trimming a theory, and thus making the theory more parsimonious, clearly is of considerable significance and could be listed among the issues of explanation and simulation as a basic gain to be acquired from the construction of linear models (1969: 59-60)."

THE PROGRAM USED

All statistical techniques were performed using the statistical Package for the social sciences (SPSS), as presented in SPSS, second edition, by Nie, et al., 1975. SPSS was run on a Honeywell $66 / 40$ computer at the facilities of Portland State University, Portland, Oregon. 


\section{CHAPTER VI}

DATA ANALYSIS AND RESULTS

\section{INTRODUCTION}

Analysis was performed on two geographical levels (Standard Metropolitan Statistical Area and census tracts) to ascertain if conclusions were consistent at different levels of geographical aggregation. This was done because this dissertation is a cross-sectional study. The data is limited to one point in time, 1980, and temporal stability could not be tested.

The first phase of the analysis used SMSAs as the units of analysis to examine variations in the presence of subfamilies in U.S. metropolitan areas. The results of this phase of the analysis provides us with a nationwide perspective on the relationship between demographic, sociocultural, economic and housing variables and variations in the presence of subfamilies. The second phase of the analysis used census tract data, and Los Angeles county was chosen. It was chosen because its characteristics are unusually useful to this study. Los Angeles county is a major metropolitan county with one of the tightest and more expensive housing markets in 1980 , the census year of the study. It was very 
expensive to purchase housing in that year because interest rates were very high. Renters faced the same problems because prices increased rapidly and vacancy rates were low. In addition, the county has a high proportion of ethnic minorities and a high percentage of foreign born. It clearly does not conform to the inherent assumptions of the functionalist model. Thus, it is an ideal county in which to test the model.

AN OVERVIEW OF THE GENERAL HYPOTHESIS USING SMSA CENSUS DATA

Table II contains the predicted and the actual results of relationships among the variables and highlights three major observations. First the results in the table show a greater number of relationships between variables than was originally predicted. This indicates the existence of a more complex model.

Second, it can be seen in the table that the direction of associations is different in a number of paths than was originally posited. For instance, subfamily was predicted to be positively influenced by all of the variables except the educational level of head of household and vacancy rate. In the results the unemployment rate is found to be negatively related to subfamily. A detailed analysis of the results of these variables will be given in succeeding sections.

Third, the two housing variables--housing cost as percent of income and vacancy rate were dropped from the 
TABLE I I

COMPARISON OF PREDICTED RELATIONSHIPS BETWEEN

ENDOGENOUS VARIABLES AND EXPLANATORY

VARIABLES WITH THE RESULTS USING

SMSA CENSUS DATA

\begin{tabular}{|c|c|c|}
\hline $\begin{array}{l}\text { ENDOGENOUS } \\
\text { VARIABLES }\end{array}$ & EXPLAKATORY VARIABIES (PREDICTED) & ELPLARTORY VARTABLES (RESULTS) \\
\hline ELOH & RAE (-), PFB (-) & $\operatorname{RAE}(-), \operatorname{PFB}(t)$, POD $(t)$ \\
\hline FH & RAE $(+)$, POD $(+)$, ELOH (-) & RAE $(+)$, PFB (-), \\
\hline PUNAG & FH $(+), P O D(+)$ & $\begin{array}{l}\operatorname{RAE}(-) \text {, PFB }(+), \text { POD }(+), \text { ELOH }(-) \text {, } \\
\text { FH }(+)\end{array}$ \\
\hline UNEMP & $\operatorname{RAE}(+)$, ELOH (-) & ELOH, $(-)$, FH $(-0$, PUNAG $(+)$ \\
\hline MFI & $\begin{array}{l}\text { UNEMP }(-), \text { FH }(-), \text { RAE }(-), \\
\text { ELOH }(+), \text { POD }(-)\end{array}$ & $\begin{array}{l}\operatorname{RAE}(-), \text { PFB }(+), \text { POD }(+), \text { ELOH }(+), \\
\text { FH }(+) \text {, PUNAG }(-),\end{array}$ \\
\hline PHIBP & UNEMP $(+)$, MFI $(-)$, PUNAG $(+)$ & $\begin{array}{l}\text { RAE }(+), \text { PFB }(-), \text { POD }(-), \text { ELOH }(+) \text {, } \\
\text { FH }(+) \text {, UNEMP }(+), \operatorname{MFI}(-)\end{array}$ \\
\hline HCAPI & ENEMP $(+), \operatorname{MFI}(-)$, PHIBP $(+)$ & PFB $(+)$, ELOH $(+)$, PUNAG $(+)$, PHIBP $(-)$ \\
\hline VR & HCAPI $(+)$, UNEMP $(+)$, PHIBP $(t)$ & $\begin{array}{l}\text { POD }(+), \text { ELOH }(+), \text { MFI }(-) \text {, PHIBP }(-) \text {, } \\
\text { HCAPI }(-)\end{array}$ \\
\hline SF & $\begin{array}{l}\text { RAE }(+), \text { PFB }(+), \text { POD }(+), \\
\text { ELOH }(-), \text { FH }(+), \text { PUNAG }(+), \\
\text { UNEMP }(+), \text { MFI }(-), \text { PHIBP }(+) \text {, } \\
\text { HCAPI, }(+) \text {, VR }(-)\end{array}$ & $\begin{array}{l}\text { RAE }(+), \text { ELOH }(-), \text { FH }(+), \operatorname{UNEMP}(-), \\
\operatorname{MFI}(+), \text { PHIBP }(+)\end{array}$ \\
\hline
\end{tabular}

- Significant at $p<.05$ 
table because they did not significantly impact the subfami1y. The saturated model with the path coefficients using SMSA data is presented in Figure 10. The criteria for including or not including a path in Table II and the trimmed model (Figure 11) was a significance test where alpha was set at $P<.05$. Table III shows the correlation matrix using SMSA data. The decomposition of effects in the overall path analysis is reported in Appendix $A$ and the regression output using SMSA data is shown in Appendix B.

\section{COMPARISON OF THE PREDICTED MODEL WITH \\ THE FINAL TRIMMED ONE, CONTAINING \\ SMSA CENSUS DATA RESULTS}

The analysis is divided into two parts. The first part will discuss the direct effects of the individual variables on one another and on the subfamily, and will indicate which paths are validated in terms of their direct effects, as was originally predicted.

The second part of the analysis follows and it will focus on the indirect and total effects of the variables on the subfamily. As will be seen, some paths may not be validated in their direct effects but they are as conceptualized in their indirect effects. The analysis here will proceed in the order in which the variables appear in the trimmed model.

First is the educational level of the head of household, predicted to be negatively influenced by both race and 


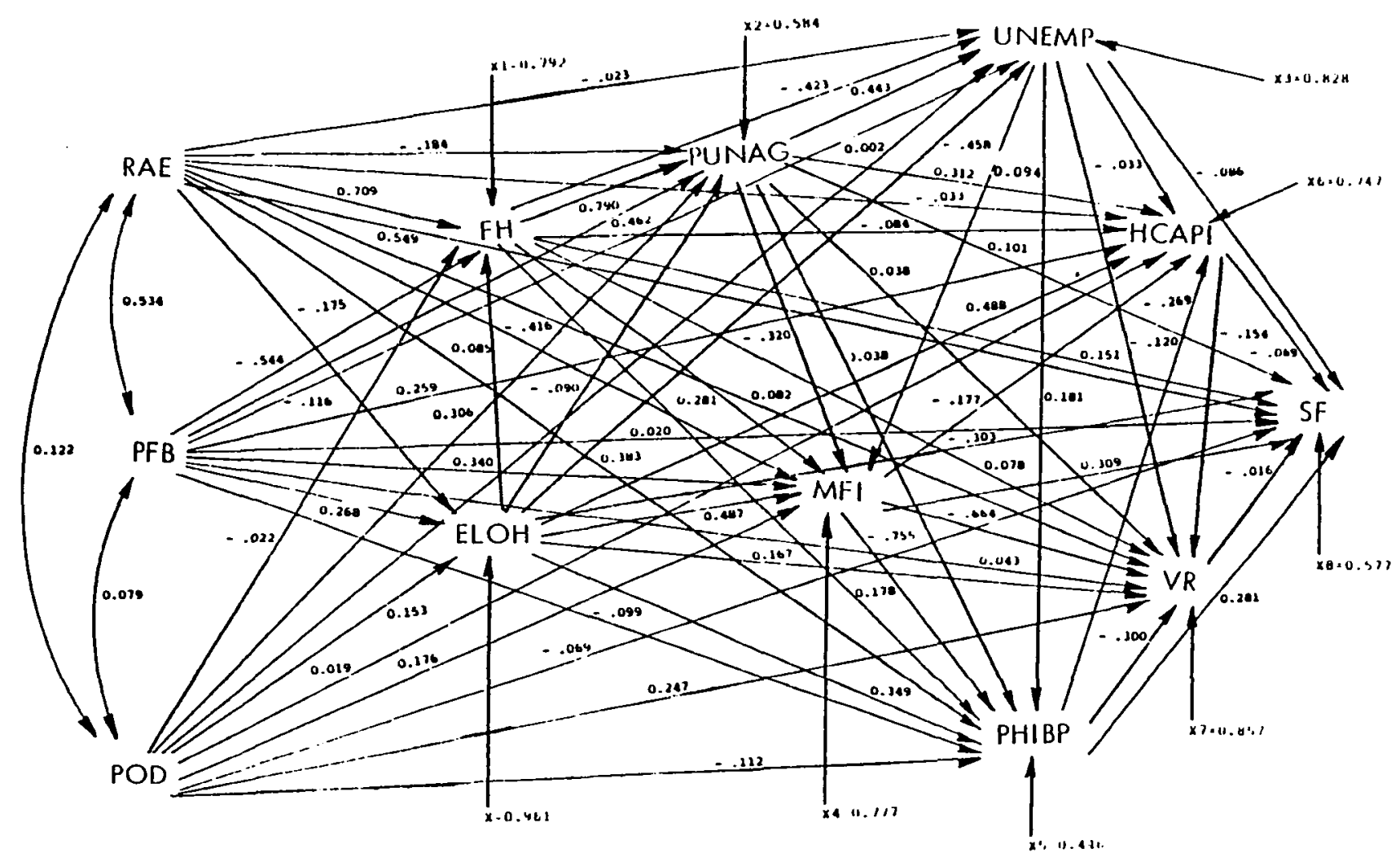

Plgure 10. Path diagram of the effects on the Subfamily of Race and Ethnicity (RAE), Proportion of Forelgn Born (PFB), Proportlon of the Population Divorced and Not Remarrled (POD). Educational Level of Head of Household (ELOH), Pemale Head (PH), Proportion of the Household Population Under the Age of 18 and Living with Only Below 1979 poverty Level (PHIBP), Housing COBt as Peran Family Income (MPI), Proportion of Household Income Below 1979 poverty Level (PHIBP), Housing Cost as percent of Income (HCAPI), and Vacancy Rate (UR), using SMSA 


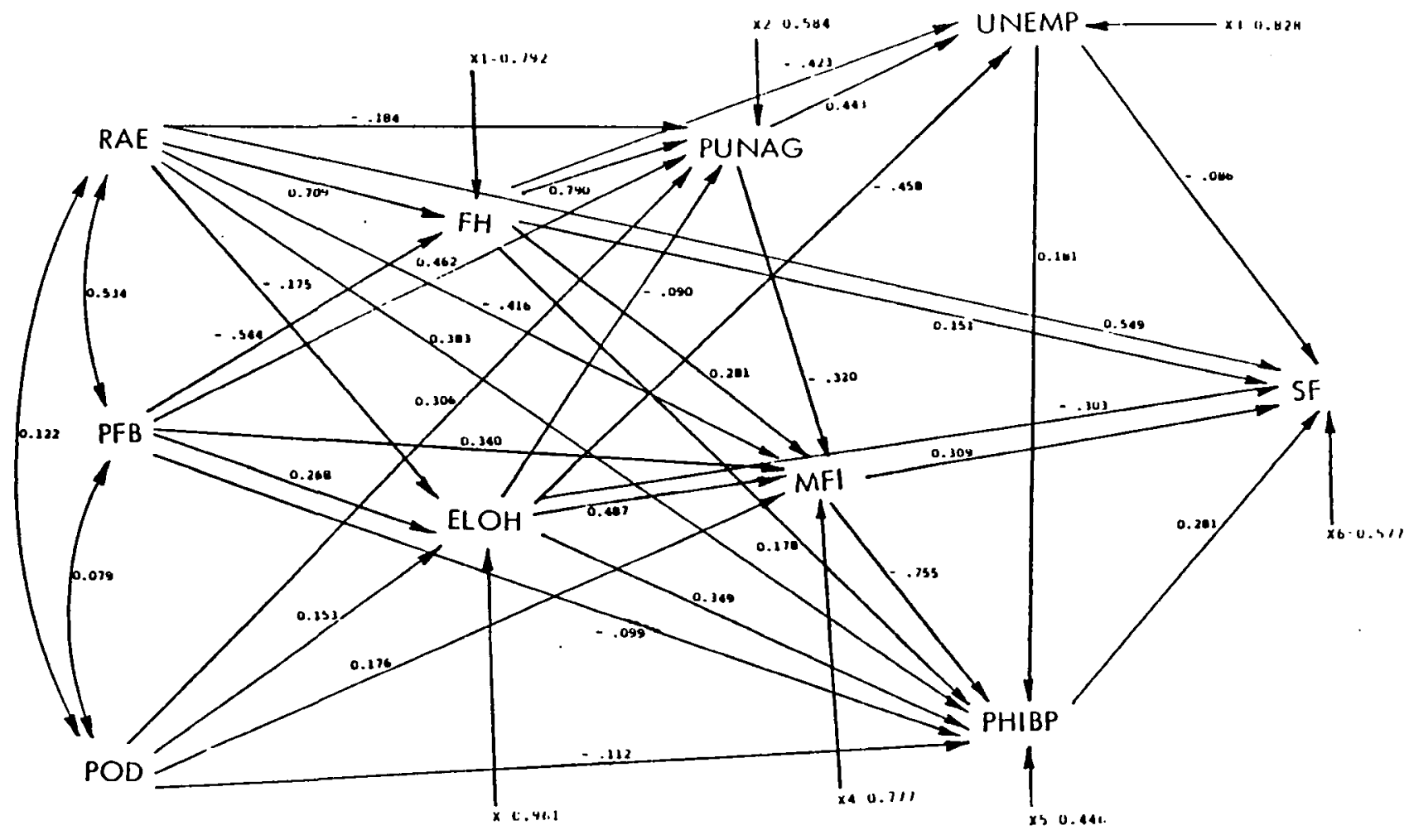

Fiqure 11. Path diagram of the effects on the Subfamily of Race and Ethniclty (RAR). Proportion of Forelgn Born (PFB). Proportion of the Population Divorced and Not Remarried (POD), Educational Level of Head of Household (ELH). Female Head (FH), Proportion of the Household Population Undar the Age of 18 and Living with Only One Parent (PUNAG). Unemployaent Rate (UNEMP), Median Family Income (MPI), Proportion of Household Income Below 1979 poverty Level (PHIBP) uning SMSA censue data (tha trimmed model). 
TMBLE III

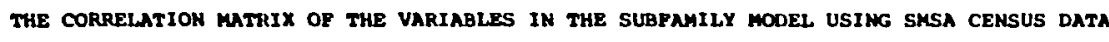

\begin{tabular}{|c|c|c|c|c|c|c|c|c|c|c|c|c|}
\hline & SP & RAE & PPB & $P O O$ & ELOH & $\mathbf{P H}$ & PUNAG & UNEMP & MFI & PHIQP & HCAPI & VR \\
\hline sP & 1.00000 & 0.73450 & 0.27333 & -0.02248 & -0.20192 & 0.52352 & 0.42605 & -0.00096 & -0.24286 & 0.50748 & -0.09450 & 0.10147 \\
\hline RAE & 0.73450 & 1.00000 & 0.53477 & 0.12220 & -0.01285 & 0.41413 & 0.42885 & -0.06476 & -0.24583 & 0.54384 & 0.09969 & 0.17359 \\
\hline PPB & 0.27333 & 0.53477 & 1.00000 & 0.07914 & 0.18687 & -0.15062 & 0.25150 & -0.03914 & 0.09605 & 0.04658 & 0.39664 & 0.00066 \\
\hline POD & -0.02248 & 0.12220 & 0.07914 & 1.00000 & 0.15339 & 0.03440 & 0.33365 & 0.05310 & 0.13482 & -0.11774 & 0.21795 & 0.20760 \\
\hline ELOH & -0.20192 & -0.01285 & 0.18687 & 0.15339 & 1.00000 & -0.02922 & 0.02210 & -0.45740 & 0.52485 & -0.17696 & 0.51897 & -0.10964 \\
\hline $\mathbf{F H}$ & 0.52352 & 0.01413 & -0.15062 & 0.03440 & -0.02922 & 1.00000 & 0.65823 & -0.21045 & -0.17145 & 0.42265 & -0.02471 & 0.13840 \\
\hline PUNAG & 0.42605 & 0.42885 & 0.25150 & 0.33365 & 0.02210 & 0.65823 & 1.00000 & 0.11559 & -0.14738 & 0.32213 & 0.26033 & 0.16861 \\
\hline UNEAP & -0.00096 & -0.06476 & -0.03914 & 0.05310 & -0.45740 & -0.11045 & 0.11559 & 1.00000 & -0.17404 & 0.10236 & -0.21479 & -0.07700 \\
\hline$M P I$ & -0.24286 & -0.24583 & 0.09605 & 0.13482 & 0.52485 & -0.27145 & -0.14738 & -0.27404 & 1.00000 & -0.74729 & 0.28986 & -0.37733 \\
\hline PHIBP & 0.50748 & 0.54384 & 0.04658 & -0.11774 & -0.17696 & 0.42265 & 0.32213 & 0.10236 & -0.74729 & 2.00000 & -0.16966 & 0.24286 \\
\hline HCAPI & -0.09450 & 0.09969 & 0.39664 & 0.21795 & 0.51897 & -0.02471 & 0.26033 & -0.21479 & 0.28986 & -0.16966 & 1.00000 & -0.09616 \\
\hline VR & 0.10147 & 0.17359 & 0.00066 & 0.20760 & -0.10964 & 0.13840 & 0.16861 & -0.07700 & -0.37733 & 0.24286 & -0.09616 & 1.00000 \\
\hline
\end{tabular}


ethnicity and the proportion of foreign born (Figure 7). In Figure 11, which may be regarded as a direct test of Figure 7, race and ethnicity shows a negative path of -.175 , and the proportion of foreign born had a positive path of 0.268 . Race and ethnicity support the predicted model while the proportion of foreign born did not. The reason for this is not clear, because generally foreign born are associated with low income, a condition which will limit their ability to obtain education. The proportion of the population divorced and not remarried was not hypothesized to influence the educational level of head of household, and yet it reveals a small positive path $(0.153)$. This path and others like it, which came out to be significant even though there was no prior prediction of any relationship, does not appear to affect the overall model. The significance of these paths suggest, however, that they are important as causal links in explaining the subfamily, and future research should take them into account.

Next is female head, predicted to be positively related to race and ethnicity and the proportion of the population divorced and not remarried and negatively related to the educational level of head of household. Race and ethnicity is the only variable validated in Figure 11 and it shows a fairly strong positive path of 0.709 . The paths from the proportion of the population divorced and not remarried and the educational level of head of household were dropped at the significance level of $P<.05$. The 
proportion of foreign born was not predicted to influence female head and it shows a negative path of -.544 .

Third is the proportion of the household population under the age of 18 and living with only one parent, originally predicted to be positively influenced by race and ethnicity and the educational level of head of household. The two variables support the predicted model. Female head shows a high positive path of 0.790 , and the proportion of the population divorced and not remarried a positive path of 0.306. Three other variables, race and ethnicity, the proportion of foreign born and the educational level of head of household, were not predicted to influence the proportion of the household population under the age of 18 and living with only one parent; however, they are seen in Figure 11 to do so.

Fourth is the unemployment rate, assumed to be positively influenced by race and ethnicity and negatively affected by the educational level of head of household. Figure 11, however, shows only educational level of head of household, with a negative path of -.458 , to support the predicted model. The path from race and ethnicity was dropped, but two other variables not originally predicted to influence the unemployment rate are seen in Figure 11 to do so. These two are female head and the proportion of the household population under the age of 18 and living with only one parent. 
Median family income, the fifth variable, was originally posited to be negatively influenced by the unemployment rate, female head, race and ethnicity, and the proportion of the population divorced and not remarried, and positively affected by the educational level of head of household. As can be seen in Figure 11, only race and ethnicity $(-.416)$ and the educational level of head of household (0.487) were validated. Both female head and the proportion of the population divorced and not remarried have positive paths $(0.281$ and 0.176 respectively). The path from the unemployment rate was dropped because it was not significant. The proportion of foreign born and the proportion of the household population under the age of 18 and living with only one parent were not hypothesized to affect median family income, but each has a path that leads to it in the final model.

The sixth variable is the proportion of household income below poverty, originally predicted to be influenced positively by both the unemployment rate and the proportion of the household population under the age of 18 and living with only one parent, and negatively by median family income. The unemployment rate $(0.181)$ and the median family income $(-.755)$ support the predicted model, but the path from the proportion of the household population under the age of 18 and living with only one parent was dropped. Five other variables not assumed to affect the proportion of household income below 1979 poverty level are seen to do so 
in Figure 11. These variables are race and ethnicity, the proportion of foreign born, the proportion of the population divorced and not remarried, the educational level of head of household, and female head.

The seventh and final variable, the subfamily, was posited to be positively influenced by all the variables in the model except for the educational level of head of household, median family income and vacancy rate, which were assumed to have a negative effect. As can be seen in Figure 11, only four variables, race and ethnicity (0.549), female head (0.151), the educational level of head of household $(-.303)$, and the proportion of household income below poverty level $(0.281)$, support the predicted model. The unemployment rate, with a small negative path of -.086 , and median family income with a positive path of 0.309 do not support the model. The two paths from the housing variables (housing cost as percent of income and vacancy rate) were dropped because they do not have an effect on the subfamily, based on the significance level of $P<.05$. The paths from the proportion of foreign born, the proportion of the population divorced and not remarried and the proportion of the household population under the age of 18 and living with only one parent were also dropped.

The proportion of foreign born did not affect the subfamily. This is surprising, because generally foreign born experience economic problems which incline them toward 
extended family living situations. This finding, however, agrees with Angel and Tienda's (1982) study which showed that foreign birth of the head of household had a negative impact on extension.

The proportion of the population divorced and not remarried was not validated and the theoretical reason for holding it may be faulty. The results suggest, however, that it is not an important variable in explaining the subfamily. The proportion of the household population under the age of 18 and living with only one parent also did not support the predicted model. The reason for this may be due to multicolonearity. Since this variable is directly related to female head of household, which was validated, its impact may have been reduced. The correlation coefficient between the two variables, as is seen in Table III, is high (0.658). The unemployment rate was not validated when SMSA data was used, but it was validated with the LA data as will be seen shortly. This result may be due to data sensitivity to aggregation. The SMSA data based on summary information, has limited variability, which makes relationship less significant. A more detailed discussion of data sensitivity to aggregation will be presented later in the chapter. The result of the unemployment rate, using SMSA data, is contrary to the literature reviewed.

Median family income did not support the predicted model. This might be attributed to the problems of timing 
in measuring the variable. The data used in this study measures household income after extension, not before, so that what is seen is the effect of extension on median family income and not vice versa as was originally predicted. Extension, then, increases family income. This explanation is consistent with Angel and Tienda's study (1982) which showed that the earnings of nonnuclear members is significantly and positively related to total household income in minority households.

The two housing variables were not statistically significant. Vacancy rate has been an important variable in assessing the need for housing. Housing cost as a percentage of income was predicted to be a key variable in the overall model. The dropping out of the housing variables is surprising and it suggests that they are not important in explaining the subfamily. Perhaps they only function during a severe housing shortage.

While other conclusions will be reached as more data is reviewed, it can be said now, based on the preceding discussion, that the subfamily, using SMSA data, is a function of race and ethnicity, female head, the educational level of head of household, and the proportion of household income below poverty level. This can be represented as:

$$
S F=f(R A E, F H, E L O H, P H I B P) \text {. }
$$

The paths that were not supported do not render the conceptual model invalid. However, the final model is more parsi- 
monious than was originally conceptualized and it holds fairly well except for the housing variables.

COMPARISON OF THE CONCEPTUALIZED

MODEL WITH THE RESULTS USING SMSA CENSUS DATA

This is the second part of the analysis and it will focus on Table IV, which shows the decomposition of effects for only one variable--the subfamily. The discussion will follow in the order in which the variables appear in Table IV. First is race and ethnicity which has its most indirect effect $(0.146)$ through female head and its second most indirect effect $(0.108)$ through poverty level. Race and ethnicity has the greatest total indirect effect (0.248), the greatest direct effect $(0.549)$, and the greatest total effect $(0.797)$ on the subfamily. It has a relatively small noncausal effect of -.062 . These attributes combine to make it the most important variable in the model in explaining the subfamily. As conceptualized, this demographic variable affects the subfamily directly and indirectly through sociocultural variables (ELOH, $\mathrm{PH}$ and PUNAG) and economic variables (MFI and PHIBP). It does not, however, like the rest of the variables in the model, affect the subfamily through the housing variables (HCAPI and VR). These variables were dropped from the model due to a lack of statistical significance. The second variable is the proportion of foreign born which has its greatest indirect effect $(-.112)$ through female head and its second greatest indirect effect $(-.038)$ through the educational level of 
TABLE IV

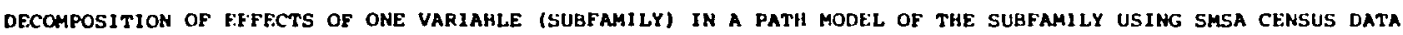

\begin{tabular}{|c|c|c|c|c|c|c|c|c|c|c|c|c|c|}
\hline \multirow{3}{*}{$\begin{array}{l}\text { Dependent } \\
\text { Variable }\end{array}$} & \multirow{3}{*}{$\begin{array}{l}\text { Predeter- } \\
\text { ained } \\
\text { Variable }\end{array}$} & \multicolumn{11}{|c|}{$C A \cup S A L$} & \multirow{3}{*}{ Nonceural } \\
\hline & & \multicolumn{5}{|c|}{ I M D I RECT } & \multicolumn{4}{|c|}{ EPPCTVIA } & \multirow[b]{2}{*}{$\begin{array}{l}\text { Direct } \\
\text { Ef fect }\end{array}$} & \multirow[b]{2}{*}{$\begin{array}{l}\text { Total } \\
\text { Ef fect }\end{array}$} & \\
\hline & & ELOH & $\mathbf{P H}$ & PUNung & GNOMP & MPI & PHIBP & HCAPI & $\mathbf{V R}$ & \begin{tabular}{|c|} 
Total \\
Indirect \\
Bffect
\end{tabular} & & & \\
\hline \multirow[t]{11}{*}{ sF } & RARE & 0.025 & 0.146 & 0.009 & - & -.040 & 0.108 & - & - & 0.248 & 0.549 & 0.797 & -.062 \\
\hline & PFB & -.038 & -.112 & -.022 & - & -.033 & -.028 & - & - & -.167 & - & -.167 & 0.440 \\
\hline & POO & -.021 & - & -.014 & - & 0.017 & -.031 & - & - & -.049 & - & -.049 & 0.027 \\
\hline & ExoH & - & - & -.001 & 0.016 & 0.047 & 0.098 & - & - & 0.160 & -.303 & -.143 & -.059 \\
\hline & $\mathbf{F H}$ & - & - & -.037 & 0.015 & 0.027 & 0.050 & - & - & 0.055 & 0.151 & 0.206 & 0.318 \\
\hline & PUnuag & - & - & - & -.016 & -.031 & - & - & - & -.047 & - & -.047 & 0.473 \\
\hline & LAERP & - & - & - & - & - & 0.051 & - & - & 0.051 & -.086 & -.035 & 0.034 \\
\hline & MPI & - & - & - & - & - & -.212 & - & - & -.212 & 0.309 & 0.097 & -.340 \\
\hline & PHIBP & - & - & - & - & - & - & - & - & - & 0.281 & 0.281 & $0.10 E$ \\
\hline & HCAPI & - & - & - & - & - & - & - & - & - & - & - & - \\
\hline & VR & - & - & - & - & - & - & - & - & - & - & - & - \\
\hline
\end{tabular}


head of household. This demographic variable has no direct effect on the subfamily, as was conceptualized. However, it affects it indirectly through sociocultural and economic variables. In addition, it has the second highest noncausal effect $(0.440)$ in the table. The high noncausal effects of foreign born and other variables in the model seem to warrant additional research to identify the causal links implied by them. Specifying these links will help strengthen the model. This is one possibility for further investigation.

The proportion of the population divorced and not remarried is third and its greatest indirect effect $(-.031)$ is through the proportion of household income below poverty level, and its second greatest indirect effect $(-.021)$ is through the educational level of head of household. It does not have a direct effect on the subfamily. However, it affects it indirectly through sociocultural variables (ELOH and PUNAG) and economic variables (MFI and PHIBP). It's total indirect effect equals its total effect $(-0.049)$ and it has a very small noncausal effect of 0.027 .

The fourth variable is the educational level of head of household and its highest indirect effect $(0.098)$ is through the proportion of household income below poverty level followed by the median family income $(0.047)$. This sociocultural variable affects the subfamily directly and indirectly through economic variables as conceptualized. It has a negligible indirect effect $(-.001)$ through the propor- 
tion of the household population under the age of 18 and living with only one parent. Its total indirect effect is 0.0160 , while the direct effect is -.303 . The total effect $(-.143)$ is relatively small compared to its direct impact because the direct and the indirect effects have opposite signs which cancels each other out. This variable has a small noncausal effect of -.059 .

Female head is the fifth variable and its greatest indirect effect $(0.050)$ is through the proportion of household income below poverty level, followed by the proportion of the household population under the age of 18 and living with only one parent. It has the third highest total effect (0.206) on the subfamily. This total effect is composed of a total indirect effect of 0.055 , a direct effect of 0.151 and a noncausal effect of 0.318 . This sociocultural variable affects the subfamily indirectly through economic variables as conceptualized.

The sixth variable is the proportion of the household population under the age of 18 and living with only one parent. Its highest indirect effect $(-.031)$ is through the median family income. As conceptualized it affects the subfamily indirectly through economic variables (UNEMP and MFI). However, it does not directly impact on the subfami1y. Thus, its indirect effect $(-.047)$ equals its total effect $(-.047)$. In addition, it has the highest noncausal effect $(0.473)$ of all the variables in the model. 
The unemployment rate is the seventh variable. As noted in Table IV, it affects the subfamily directly and indirectly through the proportion of household income below poverty level. Its total indirect effect is 0.051 while the direct effect is -.086 , combining to produce a total effect of -0.035 . It has a noncausal effect of 0.034 .

The eighth variable is median family income and it affects the subfamily directly and indirectly through the proportion of household income below poverty. It has a total indirect effect of -.212 and a direct effect of 0.309 both ranking the second highest in their respective effects. It also has the third highest noncausal effect $(-.340)$. The total effect is reduced and this is due to the fact that the total indirect effect and the direct effect have opposite signs.

The proportion of household income below poverty level is the ninth and final variable that has any effect on the subfamily. It has no indirect effect on the subfamily but has the third highest direct effect $(0.281)$ and the second highest total effect $(0.281)$. Its noncausal effect is 0.108 .

From the analysis demographic, sociocultural and economic characteristics are independent of the housing conditions in affecting the subfamily. It suggests that subfamily will exist regardless of the housing variables. The model holds very well as conceptualized except for the housing variables. 
AN OVERVIEW OF THE RESULTS OF THE LOS ANGELES CENSUS TRACT DATA

Table $\mathrm{V}$ contains the general hypothesis and results using Los Angeles census tract data. The observations made earlier in Table II are applicable here as well. Table VI shows the correlation matrix using LA data. The saturated model using the LA census data is shown in Figure 12 while the trimmed model is shown in Figure 13. The decomposition of effects in the overall path analysis using Los Angeles County census tract data is reported in Appendix $C$, and the regression output is shown in Appendix D.

\section{COMPARISON OF THE PREDICTED MODEL WITH THE FINAL TRIMMED ONE CONTAINING LOS ANGELES COUNTY CENSUS TRACT DATA}

The discussion here will follow the causal ordering of the variables as posited by the model. The trimmed model (Figure 13), using Los Angeles County results, is also based on the significance level of $P<.05$. The analysis here is divided into two parts. The first part, which is this section, will discuss the direct effects of the individual variables on each other and on the subfamily. The second part follows, and it will focus on the indirect and total effects of the variables on the subfamily. Discussion will proceed in the order in which the variables appear in the trimmed model.

The educational level of head of household, the first variable, was predicted in Figure 7 to be negatively influenced by race and ethnicity and the proportion of 
TABLE V

COMPARISON OF PREDICTED RELATIONSHIPS BETWEEN ENDOGENOUS VARIABLES AND EXPLANATORY

VARIABiES WITH THE RESULTS

USING LA COUNTY CENSUS

TRACT DATA

\begin{tabular}{|c|c|c|}
\hline $\begin{array}{l}\text { ENDOGENOUS } \\
\text { VARIABLES }\end{array}$ & EXPLANATORY VARIABLESS (PRLOICTED) & ETPLAMATORY VARLABLES (RESULIS) * \\
\hline EIOH & $\operatorname{RAE}(-)$, PFB (-) & $\operatorname{RAE}(-), \operatorname{PFB}(+)$ \\
\hline FH & RAE $(+)$, POD $(+)$, ELOH $(-)$ & $\operatorname{RAE}(+), \operatorname{PFB}(-)$, POD $(t)$, ELOH $(t)$ \\
\hline PUNAG & FH $(t)$, POD (t) & $\begin{array}{l}\text { RAE }(+), \text { PFB }(+), \text { POD }(+), \text { ELOH }(-) \\
F H(+)\end{array}$ \\
\hline UNEMP & RAE $(+)$, ELOH (-) & $\begin{array}{l}\text { RAE }(+), \text { PFB }(+), \text { ELOH }(-), \text { FH }(+) \text {, } \\
\text { PUNAG }(+)\end{array}$ \\
\hline MFI & $\begin{array}{l}\text { UNEMP }(-), \text { FH }(-), \text { RAE }(-) \\
\text { ELOH }(+), \text { POD }(-)\end{array}$ & $\begin{array}{l}\text { RAE }(-), \text { PFB }(-), \text { POD }(-), \text { ELOH }(+), \\
\text { PUNAG }(-) \text {, UNEMP }(+)\end{array}$ \\
\hline PHIBP & UNEMP $(+)$, MFI $(-)$, PUNAG $(+)$ & $\begin{array}{l}\text { RAE }(t), \text { PFB }(t), \text { POD }(t), \text { FH }(t), \\
\text { PUNAG }(t) \text {, UNEMP }(t), \text { MFI }(-)\end{array}$ \\
\hline HCAPI & UNEMP $(+)$, MFI $(-)$, PHIBP $(+)$ & $\begin{array}{l}\text { RAE }(-), \text { PFB }(+), \text { POD }(+), \text { ELOH }(-), \\
\text { FH }(+), \text { PUNAG }(+), \text { MFI }(+), \text { PHIBP }(+)\end{array}$ \\
\hline VR & HCAPI $(+)$, UNEMP $(+)$, PHIBP $(+)$ & $\begin{array}{l}\operatorname{RAE}(-), \text { PFB }(-), \text { POD }(+), \text { ELOH }(+), \\
\text { FH }(-), \operatorname{MFI}(-), \text { PHIBP }(+), \operatorname{HCAPI}(-)\end{array}$ \\
\hline SF & $\begin{array}{l}\operatorname{RAE}(+), \text { PFB }(t), \text { POD }(+), \\
\text { ELOH }(-), \text { FH }(+), \text { PUNAG }(+) \\
\text { UNEMP }(+), \text { MFI }(-), \text { PHIBP }(+), \\
\text { HCAPI }(+), \text { VR }(-)\end{array}$ & $\begin{array}{l}\text { RAE }(t), \text { POD }(-), \text { ELOH }(-), \text { FH }(+) \\
\operatorname{UNEMP}(t), \operatorname{MFI}(+),\end{array}$ \\
\hline
\end{tabular}

- Significant at $P<.05$ 
TARLS VI

THE CORRELATION MATRIX OR THE VARIABLES IN THE SUBFAMILY MODEL USING LA COUNTY CENSUS TRACT DATA

\begin{tabular}{|c|c|c|c|c|c|c|c|c|c|c|c|c|}
\hline & sP & RAE & PPB & POO & ELOH & $\mathbf{F H}$ & PUNAG & UNEMP & MFI & PHIBP & HCAPI & VR \\
\hline sF & 1.00000 & 0.48892 & 0.17647 & -0.43790 & -0.43790 & 0.32316 & 0.22284 & 0.41060 & -0.30521 & 0.38808 & 0.09603 & -0.05037 \\
\hline PUE & 0.48892 & 1.00000 & 0.52973 & -0.14517 & -0.64889 & 0.40926 & 0.33714 & 0.58813 & -0.63724 & 0.69171 & 0.13051 & -0.01965 \\
\hline PPB & 0.17647 & 0.52973 & 1.00000 & -0.09686 & -0.23159 & -0.19742 & 0.03564 & 0.28361 & -0.36079 & 0.46234 & 0.27356 & 0.01629 \\
\hline POD & -0.12969 & -0.14517 & -0.09686 & 1.00000 & 0.11329 & 0.22705 & 0.48356 & 0.12867 & -0.17876 & 0.11603 & 0.31213 & 0.18963 \\
\hline ELOH & -0.43790 & -0.64889 & -0.23159 & 0.11329 & 1.00000 & -0.22838 & -0.23767 & -0.49330 & 0.75306 & -0.51227 & -0.13820 & 0.04230 \\
\hline $\mathbf{F H}$ & 0.32316 & 0.040926 & -0.19742 & 0.21705 & -0.22838 & 1.00000 & 0.56813 & 0.43168 & -0.27342 & 0.41482 & 0.16846 & 0.01961 \\
\hline PUNAG & 0.22284 & 0.33714 & 0.03564 & 0.48356 & -0.23767 & 0.56823 & 1.00000 & 0.57494 & -0.42709 & 0.63649 & 0.47329 & 0.14467 \\
\hline UNEMP & 0.41060 & 0.58813 & 0.28361 & 0.11867 & -0.49330 & 0.43168 & 0.57494 & 1.00000 & -0.50138 & 0.78074 & 0.33436 & 0.10750 \\
\hline MPI & -0.30521 & -0.63724 & -0.36079 & -0.17876 & 0.75306 & -0.27342 & -0.42709 & -0.50138 & 2.00000 & -0.62701 & -0.26240 & -0.16837 \\
\hline PHIBP & 0.38808 & 0.69171 & 0.46234 & 0.11603 & -0.51227 & 0.41482 & 0.63649 & 0.78074 & -0.62701 & 1.00000 & 0.46392 & 0.16837 \\
\hline HCAPI & 0.09603 & 0.13051 & 0.27356 & 0.31223 & -0.13820 & 0.16846 & 0.47329 & 0.35436 & -0.26240 & 0.46392 & 1.00000 & 0.10147 \\
\hline vis & -0.05037 & -0.01965 & 0.01629 & 0.18963 & 0.04230 & 0.01961 & 0.14467 & 0.10750 & -0.08115 & 0.16837 & 0.10147 & 1.00000 \\
\hline
\end{tabular}




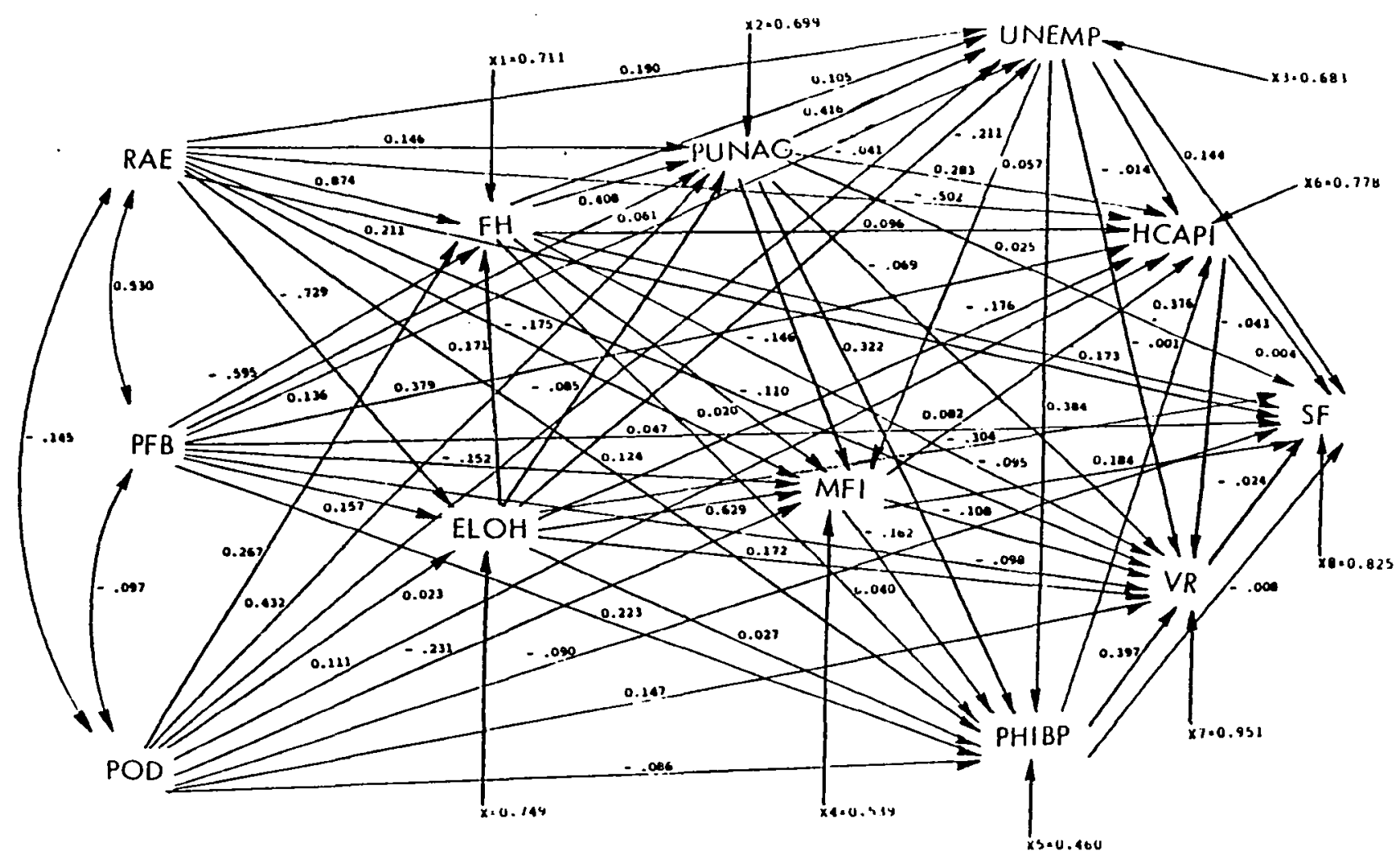

P1gure 12. Path diagras of the effecte on the Subfamily of Race and Ethniclty (RAE), Proportion of Forelgn Born (PFB), Proportion of the Population Divorced and Not Remarried (POD), Educational Lovel of Head of HouseOne Parent (PUNAG), Unemployment Rate (UNEMP), Median Yamily Income (MPI), Proportion of Household Income Below 1979 poverty Level (PHIBP), Housing Cost as percent of Income (HCAPI), and vacancy Rate (VR), ueing LA county census data (the Saturated Model). 


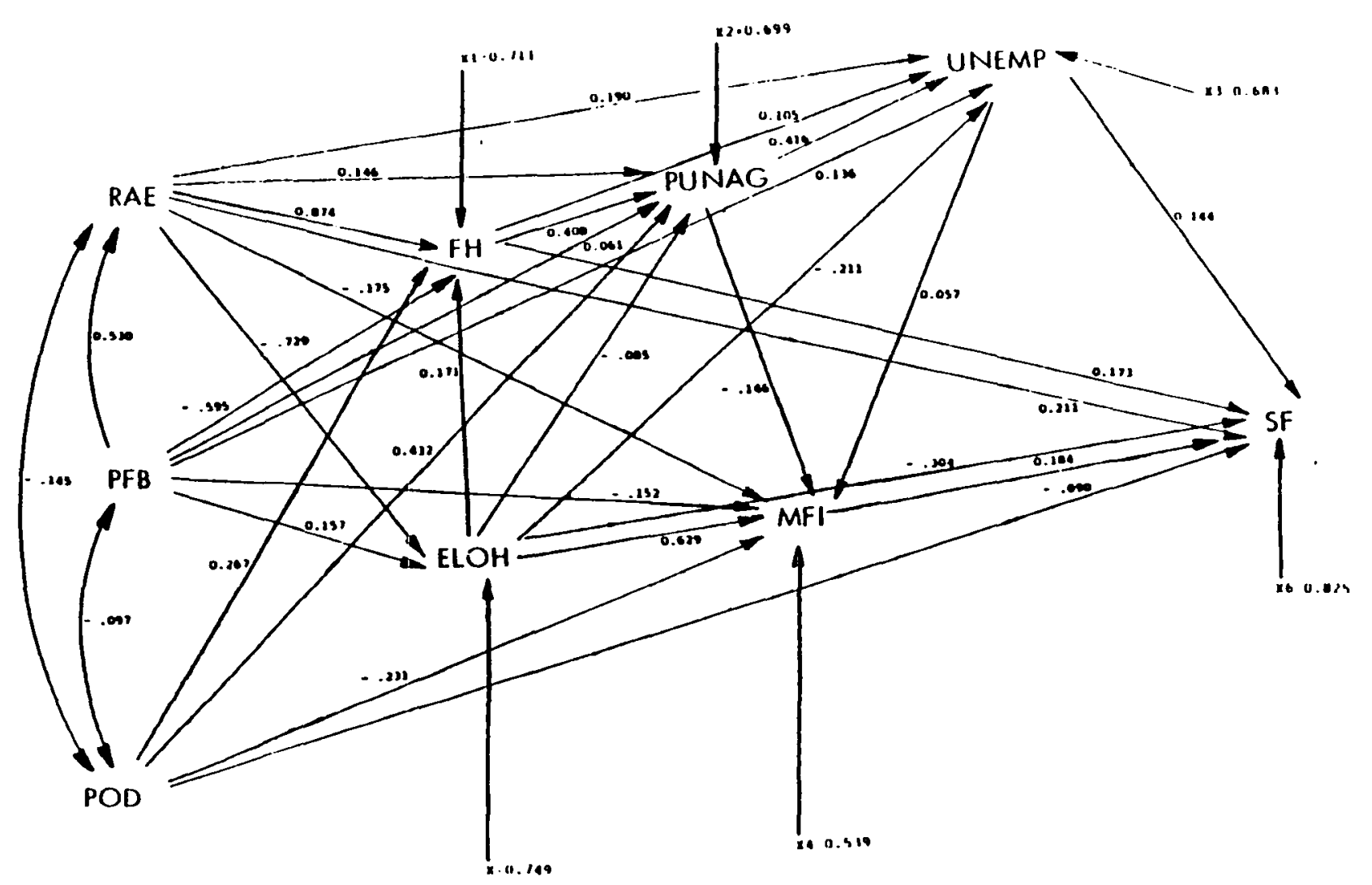

Pigure 13. Path diagram of the effects on the Subfamily of Race and Ethnicity (RAE). Proportion of Forelgn Born (PF). Proportion of the Population Divorced and Not Remarxled (POD), Educat tonal Level of Head of Household ELOH). Pemale Head (FW). Propartion of the Household Population Under the Age of 18 and Living with Only One Parent TPUNAG), Unemployisent Rate (UNEMP), Median Pamily Income (MPI). Proportion of Household Incomo 
foreign born. Race and ethnicity, as can be seen in Figure 13 supports the predicted model. It shows a negative path of -.729. The proportion of foreign born, showing a positive path of 0.157 , does not support the model.

Female head is the second variable in the model. As can be seen in Figure 13 only two (race and ethnicity and the proportion of the population divorced and not remarried) of the three variables predicted to influence female head were validated. The educational level of head of household, the third variable, was not validated. Race and ethnicity shows a large positive path of 0.874 , and the proportion of the population divorced and not remarried shows a positive path of 0.267 . The educational level of head of household, showing a positive path of 0.171 , does not support the predicted model. This variable, as was the case with the SMSA data, was not validated and the theoretical reason for holding it may be faulty. The proportion of foreign born, not assumed to influence female head, shows a negative path of -.595 .

The proportion of the household population under the age of 18 and living with only one parent, the third variable, was predicted to be positively influenced by female head and the proportion of the population divorced and not remarried. These two paths were validated. Female head shows a positive path of 0.408 , and the proportion of the population divorced and not remarried a positive path of 0.432. Race and ethnicity and the proportion of foreign born were not predicted to affect the proportion of the 
household population under the age of 18 and living with only one parent, but they are seen to do so in Figure 13.

The fourth variable, the unemployment rate, was predicted to be positively affected by race and ethnicity and negatively influenced by the educational level of head of household. The two variables support the model. Race and ethnicity has a positive path of 0.190 , and educational level of head of household shows a negative path of -211 . Three other variables--the proportion of foreign born $(0.136)$, female head $(0.105)$, and the proportion of the household population under the age of 18 and living with only one parent $(0.416)$--were not predicted to influence the unemployment rate; however, they are seen to do so in Figure 13.

Median family income, the fifth variable, was posited to be negatively influenced by the unemployment rate, female head, race and ethnicity, and the proportion of the population divorced and not remarried, and positively influenced by the educational level of head of household. Three of the variables, race and ethnicity (-.175), the educational level of head of household (0.629), and the proportion of the population divorced and not remarried (-.231), were validated. The path from female head was dropped at the significance level of $\mathrm{P}<.05$. The unemployment rate did not support the predicted model, showing a negligible positive path of 0.058 . This path was also not validated using SMSA 
data. The proportion of the household population under the age of 18 and living with only one parent was not predicted to have an effect on median family income and it comes with a small negative path of -.146 .

The proportion of household income below poverty, the sixth variable, was predicted to be positively influenced by the unemployment rate and the proportion of the household population under the age of 18 and living with only one parent and negatively by median family income (Figure 7). Figure 13 shows the three variables to be validated. The unemployment rate has a positive path of 0.384 , the proportion of the household population under the age of 18 and living with only one parent a positive path of 0.322 , and median family income a negative path of -.162 . Four other variables not thought to influence the proportion of household income below poverty are seen in Figure 14 to do so. Female head has a negligible positive path of 0.040 , race and ethnicity a small positive path of 0.124 ; proportion of foreign born has a positive path of 0.223 , and the proportion of the population divorced and not remarried a negative path of -.086 .

Subfamily, the seventh variable, was predicted to be positively influenced by all of the variables except the educational level of head of household, median family income and vacancy rate, which was posited to have a negative influence. Figure 13 shows four variables, the unemployment rate $(0.144)$, race and ethnicity (0.211) female head 
$(0.173)$, and the educational level of head of household $(-.304)$ to be validated. The proportion of the population divorced and not remarried $(-.090)$ and median family income (0.184) do not support the model as is the case when using SMSA data. The two housing variables, housing cost as percent of income and vacancy rate, were also dropped here on the basis of the significance level of $P<0.5$. While this result will indicate that housing variables are not important in explaining the subfamily las was the case with SMSA), its dropping out of the model at the LA level is surprising, since there is such a high proportion of ethnic minorities in the city who would be expected to experience difficulty with rent and mortgage. Los Angeles is also generally known to have expensive housing which could have exacerbated affordability and thus lead to extension. The paths from the proportion of foreign born, the proportion of the household population under the age of 18 and living with only one parent and the proportion of household income below poverty were dropped at the significant level of $\mathrm{P}<0.5$.

The proportion of foreign born and the proportion of the household population under the age of 18 and living with only one parent do not support the predicted model. Foreign born generally experience economic problems which incline them to extend. This finding, however, agrees with Angel and Tienda's study (1982) which showed that foreign birth of the head of household had a negative impact on extension. 
The proportion of the household population under the age of 18 and living with one parent does not support the predicted model. Since this variable is directly related to female head of household which was validated, its impact may have been reduced. The correlation coefficient between the two variables, as is seen in Table VI, is high (0.568). Median family income did not support the predicted model here also for similar reasons cited when discussing the SMSA data.

The proportion of household income below the poverty level did not affect the subfamily with LA data. This can be attributed to multicolonearity problems. As can be seen in Table VI the proportion of household income below poverty level is highly correlated with other income related variables--the unemployment rate $(0.780)$ and median family income $(-.627)$ which were validated.

From the preceding discussion the subfamily using LA data can be said to be a function of the unemployment rate, race and ethnicity, female head and the educational level of the head of household. This can be represented as:

$$
S F=f \text { (UNEMP, RAE, FH, ELOH) . }
$$

While some paths were not supported it does not render the overall model invalid. Most paths came out as predicted except for the housing variables. These findings reinforce those of the SMSA analysis. 
COMPARISON OF THE CONCEPTUALIZED MODEL

WITH THE RESULTS USING LOS ANGELES CENSUS TRACT DATA

This is the second part of the analysis using LA data and it will focus on Table VII which shows the decomposition of effects for only one variable--the subfamily. The discussion here will also proceed in the order in which the variables appear in Table VII. The first variable is race and ethnicity and its greatest indirect effect 10.1791 is through female head followed by the educational level of head of household $(0.160)$. It has the largest total indirect effect $(0.390)$, the greatest total effect $(0.601)$ and the second highest direct effect $(0.211)$. Its noncausal effect is -.112. These attributes make it the most important variable in explaining the subfamily, as was the case when using SMSA data. As conceptualized, it affects the subfamily directly and indirectly through sociocultural and economic variables. It does not, however, affect the subfamily through the housing variables which were dropped due to a lack of statistical significance.

The second variable is the proportion of foreign born which has its greatest indirect effect $(-.121)$ through female head followed by the educational level of head of household $(-.034)$. This demographic variable does not have direct effect on the subfamily as conceptualized. However it affects it indirectly through sociocultural and economic variables. It has the second highest total indirect effect 
TABLE VII

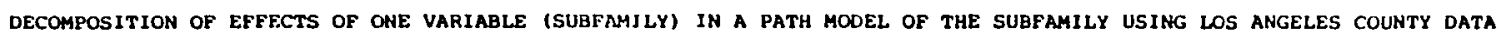

\begin{tabular}{|c|c|c|c|c|c|c|c|c|c|c|c|c|c|}
\hline \multirow{3}{*}{$\begin{array}{l}\text { Dependent } \\
\text { Variable }\end{array}$} & \multirow{3}{*}{$\begin{array}{l}\text { Predeter- } \\
\text { ained } \\
\text { Variable }\end{array}$} & \multicolumn{11}{|c|}{$\operatorname{cous} \wedge$ L } & \multirow{3}{*}{ Honcausal } \\
\hline & & \multicolumn{5}{|c|}{ I NDIREC T } & \multicolumn{4}{|c|}{ EFPET VIA } & \multirow[b]{2}{*}{$\begin{array}{l}\text { Direct } \\
\text { Effect }\end{array}$} & \multirow[b]{2}{*}{$\begin{array}{l}\text { Total } \\
\text { Effect }\end{array}$} & \\
\hline & & BroH & $\mathbf{m}$ & punug & INERP & MPI & PHIBP & HCAPY & VR & $\begin{array}{c}\text { Total } \\
\text { Indirect } \\
\text { Ef fect } \\
\end{array}$ & & & \\
\hline \multirow[t]{11}{*}{ SF } & RAE & 0.160 & 0.179 & 0.054 & 0.029 & -.032 & - & - & - & 0.390 & 0.211 & 0.601 & -.112 \\
\hline & PPB & -.034 & -.121 & -.002 & 0.029 & -.028 & - & - & - & -.152 & - & -.152 & 0.328 \\
\hline & $\mathbf{P O O}$ & - & 0.054 & 0.016 & - & - & - & - & - & 0.070 & -.090 & -.020 & -.110 \\
\hline & ELOH & - & 0.035 & -.003 & -.033 & 0.116 & - & - & - & 0.115 & -.304 & -.189 & -.249 \\
\hline & $\mathbf{F u}$ & - & - & 0.015 & 0.016 & - & - & - & - & 0.032 & 0.273 & 0.204 & 0.129 \\
\hline & PUneng & - & - & - & 0.064 & -.027 & - & - & - & 0.037 & - & 0.037 & 0.186 \\
\hline & unseror & - & - & - & - & 0.010 & - & - & - & 0.010 & 0.144 & 0.154 & 0.257 \\
\hline & nPI & - & - & - & - & - & - & - & - & - & 0.184 & 0.184 & -.489 \\
\hline & Patap & - & - & - & - & - & - & - & - & - & - & - & - \\
\hline & HCAPI & - & - & - & - & - & - & - & - & - & - & - & - \\
\hline & vx & - & - & - & - & - & - & - & - & - & - & - & - \\
\hline
\end{tabular}


$(-.152)$ and the second highest noncausal effect $(0.328)$. Its total indirect effect equals its total effect $(-.152)$.

The proportion of the population divorced and not remarried is the third variable and it affects the subfamily indirectly only through two variables--FH $(0.054)$ and PUNAG (0.016). It has a total effect of -.020 . The total effect is reduced because the total indirect effect and the direct effect have opposite signs. This variable has a noncausal effect of -.110 . As conceptualized it affects the subfamily directly and indirectly through sociocultural variables, however it does not affect it indirectly through economic variables.

The fourth variable is the educational level of head of household and its highest indirect effect $(0.116)$ is through median family income and its second most indirect effect $(0.035)$ is through female head. This sociocultural variable affects the subfamily directly and indirectly through economic variables as conceptualized. It has the third highest total indirect effect $(-.115)$ the greatest direct effect $(-.304)$ and the third highest total effect $(-.189)$. The total effect here is also reduced because the total indirect effect and the direct cancels itself out. This variable has a noncausal effect of -.249 .

The fifth variable is female head and its indirect effect is through only two variables--PUNAG $(0.015)$ and UNEMP (0.016) whose coefficients are almost equal. As conceptualized it affects the subfamily directly and indirectly 
through economic variables. It has a total indirect effect of 0.031 , a direct effect of 0.173 and the second highest total effect of 0.204 . It's noncausal effect is 0.119 .

The proportion of the household population under the age of 18 and living with only one parent is the sixth variable and it has its greatest indirect effect $(0.064)$ through the unemployment rate. It does not have direct effect on the subfamily as conceptualized. However, it affects it indirectly through economic variables. It's total indirect effect $(0.037)$ is the same with the total effect $(0.037)$. It has a noncausal effect of 0.186 .

The seventh variable is the unemployment rate and it affects the subfamily directly as conceptualized. Its indirect effect is through only one variable, the median family income. It has a total indirect effect of 0.010 , a direct effect of 0.144 and a total effect of 0.154 . Its noncausal effect is the third highest.

Median family income is the eighth and final variable in the table that has an effect on the subfamily. As conceptualized, it has direct effect on the subfamily. However, it does not affect it indirectly through any variable. It has the third highest direct effect (0.184) and the highest noncausal effect $(-.489)$. Its total effect is 0.184 .

From the analysis, demographic, sociocultural and economic characteristics are independent of the housing 
characteristics in affecting the subfamily. It suggests that the subfamily will exist regardless of the housing variables. The model as conceptualized holds very well here, except for the housing variables, as was the case with the SMSA level data.

\section{COMPARATIVE ANALYSIS OF THE GENERAL SMSA RESULTS WITH THOSE OF LOS ANGELES COUNTY}

The results of the unstandardized beta for direct effects in the SMSA and LA data is shown in Table VIII and the mean and standard deviation of the two levels is presented in Table IX. A general review of the two trimmed models presented in Figure 11 (SMSA) and in Figure 13 (Los Angeles County) and Table VIII shows differences and similarities. First, some of their major differences will be discussed. Then their similarities will be covered.

The two models show that there are more paths among endogenous variables in Figure 13, the Los Angeles application, than in Figure 11. For example, the unemployment rate, as shown in Figure 13, has five paths leading to it, while in Figure 11 it has only three. Predicted relationships between the variables are more frequently validated in Figure 13 than in Figure 11. For example, in Figure 13 all of the variables assumed to influence the proportion of the household population under the age of 18 and living with only one parent and the unemployment rate are validated. For the data in Figure 11 this can be said only for the 
mans VIII

COMPARISON OF THE UNSTANDARDIZED BETA (B) OF SMSA CENSUS DATA WITH THE UNSTANDARDIZED BETA (B) OF IA COUNTY CENSUS DATA

\begin{tabular}{|c|c|c|c|c|c|}
\hline $\begin{array}{l}\text { IRDEPPEDEATY } \\
\text { VNRTABLE }\end{array}$ & $\begin{array}{l}\text { DEPEDWLTT } \\
\text { VARIABLE }\end{array}$ & & & & \\
\hline & si & SUSA DATA B & $\mathbf{r}$ & wa county bata & $\boldsymbol{F}$ \\
\hline RNR & 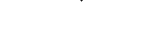 & 0.0278 & $81.877^{*}$ & 0.0145 & $23.284 *$ \\
\hline PFB & & 0.0038 & 0.129 & 0.0094 & 1.950 \\
\hline 100 & & -.0419 & 2.913 & -.0682 & $10.663 *$ \\
\hline ston & & -.0571 & $29.158^{*}$ & -.0738 & $65.310^{\circ}$ \\
\hline$m$ & & 0.0058 & $5.249 \star$ & 0.0066 & $30.207 *$ \\
\hline PUnaG & & 0.0216 & 2.644 & 0.0055 & 0.489 \\
\hline OALAP & & -.0329 & $4.067 *$ & 0.1111 & $17.434^{\circ}$ \\
\hline MrI & & 0.0001 & $16.888^{*}$ & 0.0001 & 22.568 \\
\hline PAIBP & & 0.0612 & $13.730 *$ & -.0026 & 0.031 \\
\hline ECAPI & & -.0369 & 2.418 & 0.0028 & 0.020 \\
\hline \multirow[t]{3}{*}{$\mathbf{V R}$} & . & -.0047 & 0.167 & -.0164 & 1.225 \\
\hline & & \multicolumn{2}{|c|}{$R^{2}=0.667 F=55.657$} & \multicolumn{2}{|c|}{$R^{2}=0.319 \quad F=69.639$} \\
\hline & & & & $\begin{array}{l}\text { Slgnificant (") } \\
\text { Number of cases: }\end{array}$ & $\begin{array}{l}\text { at P }<.05 \\
\text { SMSA }=318 \\
\text { LA }=1644\end{array}$ \\
\hline
\end{tabular}


TRER IX

COMPARISON OF THE MEAN AND STANDARD

DEVIATION OF SMSA CENSUS DATA WITH LA COUNTY CONSUS DATA

\begin{tabular}{|c|c|c|c|c|}
\hline \multirow{2}{*}{ VARIAELE } & \multicolumn{2}{|c|}{ MEAN } & \multicolumn{2}{|c|}{ STANDARD DEVIATION } \\
\hline & SMSA DATA & LA DATA & SMSA DATA & IA DATA \\
\hline SF & 0.0211 & 0.0310 & 0.0084 & 0.0296 \\
\hline RAE & 0.1887 & 0.5786 & 0.1661 & 0.4318 \\
\hline PFB & 0.0457 & 0.2141 & 0.0449 & 0.1493 \\
\hline POD & 0.0626 & 0.0869 & 0.0139 & 0.0390 \\
\hline ELOH & 0.1417 & 0.1558 & 0.0447 & 0.1221 \\
\hline FH & 0.2186 & 0.3590 & 0.2189 & 0.7709 \\
\hline PUNAG & 0.1721 & 0.2315 & 0.0394 & 0.1354 \\
\hline GAETP & 0.0644 & 0.0628 & 0.0219 & 0.0384 \\
\hline MFI & 19944.9119 & 21931.4136 & 2862.9661 & 10397.0408 \\
\hline PHIBP & 0.1226 & 0.1211 & 0.0387 & 0.0937 \\
\hline MCAPI & 0.1410 & 0.1702 & 0.0158 & 0.0397 \\
\hline VR & 0.0679 & 0.0417 & 0.0282 & 0.0430 \\
\hline
\end{tabular}

Cases: SMSA 318

IA 1644 
proportion of the household population under the age of 18 and living with only one parent.

In Table Vili the proportion of household income below poverty, for instance, has $a b$ of $(-.0026)$ with LA data, while it has $a b$ of $(0.0612)$ with the SMSA data. The primary explanation of the differences between SMSA and LoS Angeles County results 1 ies with the fact that each belongs to a different geographical level. The differences in the results above and in such variables like the unemployment rate which was validated with LA data but not with SMSA also indicate that data may be sensitive to aggregation.

At lower aggregation (the LA Census Tract) there is more variability and relationships at a given strength tend to be more statistically significant. In this study the model works also better at the LA level because it is closer to individual level data.

Further differences can be noted in the results of the two geographical levels. For instance the $\mathrm{R}^{2}$ for the SMSA data is 0.667 and its F-ratio is 55.657 while the $R^{2}$ for LA data is 0.319 and it comes with an F-ratio of 69.639. This result, however, is an aberration. Generally the higher the $\mathrm{R}^{2}$, the larger the F-ratio. The differences in the F-ratios can be attributed to different number of cases and different variances in the two data sets. LA data has a total case of 1644 while SMSA has 318 (Table IX). With a larger sample size, lower $R^{2} s$ may be associated with more extreme F-ratios. 
The LA data also has higher variances in all the variables used than the SMSA set (Table IX). For example, the variance for the subfamily using LA data is 0.0296 almost three times as high as that of SMSA $(0.0084)$. What these differences suggest is that the variables are related with subfamilies at the IA census tract in a more conceptually appropriate manner than the SMSA level. At the SMSA's level, the model is operating in general because it is aggregated and has limited variability. It is more removed from the conceptual literature than the less aggregated Los Angeles Census Tract.

Despite these differences there are a great many similarities between the results of the two geographical levels. In Table VIII the betas are relatively equal. For instance, the beta for the proportion of foreign born using SMSA data is 0.0038 and that with LA data is 0.0094 . The beta for the educational level of the head using SMSA is -.0571 and that of IA data is -.0738. The means for the two geographical levels are about the same. With SMSA data the mean for the subfamily is 0.0211 and with LA data it is 0.310 .

The two trimmed models presented in Figure 11 (SMSA) and in Figure 13 (LA) show similar results. Subfamily has the same number of variables affecting it in the two models. The two housing variables were also insignificant in both models. The results suggest that variations of subfamilies is consistent between the two aggregate levels. In both 
analyses the subfamily is systematically predicted by demographic, sociocultural and economic characteristics and not the housing variables. It suggests that subfamily will exist regardless of the housing conditions. 
CHAPTER VII

SUMMARY AND CONCLUSIONS

A major finding of this dissertation is that the subfamily is systematically predicted by demographic, sociocultural and economic characteristics and not by the housing variables. It suggests that the subfamily will exist regardless of the housing conditions. A summary of the findings and their implications for future research are discussed below.

THE DEMOGRAPHIC CHARACTERISTICS

Drawing on the literature, it was conceptualized that demographic characteristics would influence the subfamily in accordance with the views of life-cycle theory, and with Angel and Tienda's study. This concept was then operationalized with race and ethnicity, the proportion of foreign born, and the proportion of the population divorced and not remarried, and was used in a causal model (Figure 7) and tested on two geographical levels--SMSA and Los Angeles census tract. Race and ethnicity was validated and it affects the subfamily directly and indirectly as conceptualized. The result of its direct effect on the subfamily is consistent with those of Angel and Tienda (1982); its effect on sociocultural variables is in accordance with the 
findings of Currie and Skolnick (1984).

The proportion of foreign born did not have direct effect on the subfamily as conceptualized. However, it affects it indirectly through sociocultural and economic variables. The proportion of the population divorced and not remarried was not validated in its direct effect on the subfamily. This finding is at variance with the literature reviewed. However it is still an important variable in explaining the subfamily because it affects it indirectly through sociocultural and economic conditions as assumed.

\section{THE SOCIOCULTURAL CHARACTERISTICS}

On the basis of the literature reviewed, sociocultural characteristics were also conceptualized to influence the subfamily. This follows the views of life cycle theory and Angel and Tienda's study. It was then operationalized with the educational level of head of household, female head of household, and the proportion of the household population under the age of eighteen and living with only one parent. The educational level of head of household and the female head affect the subfamily directly and indirectly through economic variables as assumed. The results of the direct effect of the two variables on the subfamily is in accordance with the findings of Angel and Tienda (1982). The proportion of the household population under the age of eighteen and living with one parent did not affect the subfamily directly as the literature suggests it would. The 
reason for this may be due to multicolonearity. Since this variable is directly related to female head which was validated, its impact may have been reduced. The correlation coefficient between the two variables is high (0.658). The proportion of the household population under the age of eighteen and living with one parent however affects the subfamily through economic variables as conceptualized.

\section{THE ECONOMIC CHARACTERISTICS}

On the basis of a literature review, economic characteristics were conceptualized to affect the subfamily following the life cycle theory, the studies of Angel and Tienda (1982), and that of Agresti (1979). The variables used to operationalize economic characteristics are the unemployment rate, median family income, and the proportion of household income below 1979 poverty level. The unemployment rate was not validated in its direct effect on the subfamily when using SMSA data, but it did with the Los Angeles County data. Results like this are attributable to data sensitivity to aggregation. The SMSA, based on a broader, aggregated referent set, has limited variability, which makes relationship less significant. on the other hand at lower aggregation (the Los Angeles census tract) there is more variability and relationships at a given strength tend to be more statistically significant. The direct association between the unemployment rate and the subfamily when using Los Angeles County data is consistent 
with the findings of Angel and Tienda (1982).

The median family income was not validated in its direct effect on the subfamily when the data from the two geographical levels was used. The reason for this is attributable to the problem of timing in measuring the variable. The data used in this study measures income after extension, not before, so that what is seen is the effect of extension on the median family income and not vice versa as was originally predicted. Extension, then, increases family income. This explanation is consistent with Angel and Tienda's study (1982) which showed that the earnings of nonnuclear members is significantly and positively related to total household income in minority households.

The direct effect of the proportion of household income below poverty level on the subfamily was validated when using SMSA data, but it did not with LA data. This result can be attributed to multicolonearity problems. As was seen in Table VI the proportion of household income below poverty level is highly correlated with other income related variables--the population unemployment rate $(0.780)$ and median family income $(-.627)$ which were validated. Their validation may have reduced its influence on the subfamily.

IMPLICATIONS FOR FUTURE RESEARCH

The research findings indicate that demographic, social and economic circumstances are important determinants for 
variations in the presence of the subfamily. The results also showed that racial and ethnic minorities (groups known to have a long history of preference for extended family living) have the greatest total effect on the subfamily. It may be inferred from this that ethnically related subfamily living represents a preference for extended family life, while the subfamily living associated with social and economic difficulties represents a forced condition. The subfamily, then, may be considered both as a voluntary and an involuntary phenomenon. If subfamily living is voluntarily chosen as a way of life it can be inferred that it is not a problem, but if it is forced and long term, then problems are implied. However, when the subfamily arrangement is involuntary but short term, it may be considered a means of assisting families with temporary social and economic problems.

It cannot be determined from the data used in this study whether subfamily living is a symptom of a major social problem or if it is an acceptable alternative family structure for some families in contemporary society. It might even represent both possibilities simultaneously. Futhermore, it is impossible to tell from the data the duration or consequences of subfamily living arangements. Future research should be directed toward addressing these questions. If subfamily living is determined to be a problem, future research should help planners and policy 
makers formulate and implement programs that will alleviate the negative consequences of subfamily life.

\section{LIMITATIONS OF THE STUDY}

The major limitations of this study stems from the use of aggregate data. This topic would have been better researched with individual level data. However, to do an adequate job on this, a panel design survey with repeated observations over time would be needed. Presently this type of data is not available. The model developed, therefore, is heuristic rather than predictive.

\section{MERITS OF THE STUDY}

A major merit of this dissertation is taking disparate theoretical and empirical literature on the extended family and synthesizing it into a causal model that accounts for the systematic variations in the presence of the extended family living situations (subfamily) in modern American metropolitan areas. In addition, the findings raise a number of questions that must be addressed in determining whether subfamily living is a symptom of a major social problem or if it is an acceptable alternative family structure for some families in contemporary society. At least this type of extended family living was shown here to be a systematic deviation from the nuclear family and the attendant functionalist theory. 


\begin{abstract}
APPLICATION TO OTHER AREAS
The model developed in this study provides one explanation of the determinants in the variations of a particular type of extended family (the subfamily), specifically on the metropolitan and the census tract levels. However, this model or similar ones may also be applied to other geographical units, and to other types of extended families.
\end{abstract}




\section{BIBLIOGRAPHY}

Abrahamse, Allan F., David M. Deferranti, Patricia D. Fleischauer, and Albert Lipson. AFDC Caseload and the Job Market in California: Selected Issues. Rand Corporation, Santa Monica, California, January, 1977.

Agresti, Barbara. "Household Composition and the Family Cycle, and Economic Hardship in a Postbellum Southern County: Walton County, Florida, 1870-1885." International Journal of sociology of the Family, JulyDecember, 1979, 245-258.

American Planning Association. "'Accessory' Apartments: Making Housing Affordable for Homeowners and Home Seekers." News Release, August 17, 1982.

Anderson, Michael. Family Structure in Nineteenth Century Lancashire. Cambridge: Cambridge University Press, 1971 .

Angel, R. and M. Tienda. "Determinants of Extended Household Structure: Cultural Pattern of Economic Need?" American Journal of Sociology, $87(6)$, May 1982, 13601383.

Aries, Phillipe. Centuries of Childhood. New York: Vintage Books, 1962 .

Berkner, Lutz K. "The stem Family and the Developmental Cycle of the Peasant Household: An Eighteenth-Century Austrian Example." American Historical Review, 1972, $77,398-418$.

Berry, Brian. The Human Consequences of Urbanization. New York, 1973.

Bianchi, Suzanne. Household Composition and Racial Inequality. New Brunswick, NJ: Rutgers University Press,

Blake, Judith. "Family size and the Quality of Children." Demography, 18(4), November 1982, 421-442.

Blalock, H.M. (ed.). Causal Models in the Social sciences. Chicago: Aldine, 1970.

Bogue, P. Principles of Demography. New York: John Wiley and Sons, 1969. 
Bradshaw, Benjamin S. and Frank D. Bean. "Some Aspects of Fertility of Mexican Americans." Research Reports, $1972,141-64$.

Burgess, Ernest W. and Harvey J. Locke. The Family: From Institution to Hardship. New York: American Book Company, 1945.

Carliner, Geoffrey. "Determinants of Household Headship." Journal of Marriage and the Family, 37, 1975, 28-38.

Cooper, David. The Death of the Family. New York: Panteon, 1970 .

Corcoran, Mary. "Unemployment Among Family Men: A 10-Year Longitudinal Study." Monthly Labor Review, November, 1979 .

Coser, Rose L. (ed.). The Family, Its Structures and Functions. New York: St. Martin's Press, 1974.

Currie, E. and H. Jerome Skolnick. Social Issues and Public policy. Boston: Little, Brown and Company, 1984.

De Pamphilis, Donald M. "The Dynamics of Household Formation," Business Economics, $12(3)$, May 1977.

Demos, John. A Little Commonwealth: Family Life in Plymouth Colony. New York: Oxford University Press, 1970 .

Douglas, william. The one Parent Family. Graded Press, 1971 .

Duncan, O.D. "Path Analysis: Sociological Examples," The American Journal of Sociology, $72,1966,1-16$.

Duncan, otis. Introduction to structural Equation Models. New York: Academic Press, 1975.

Edington, E. and L. Hays. "Differences in Family Size and Marriage Age Expectation and Aspirations of Anglo Mexican American and Native American Rural Youth," Adolescence, 13, Fall 1978, 393-400.

Ermisch, John F. "An Economic Theory of Household Formation Theory and Evidence from the General Household Survey," Scottish Journal of Political Economy, 28(1), February 1981, 1-19.

Finney, M. John. "Indirect Effects in Path Analysis," Sociological Methods and Research, 1972, 175-186. 
Follain, James, J. Katz, and Raymond Struyk. "Trends in Home Ownership Rates and Cost of Owner Occupancy," occasional Paper in Housing and Community Affairs, Washington, D.C.: Office of Policy Development and Research, HUD, 11, February 1979, 9-41. Washington, D.C.: The Urban Institute UR1101, June
1979,63 .

Freeman, Richard B. The Declining Economic Value of Higher Education and the American Social System. New York: Aspen Institute for Humanistic Studies, $1976 \mathrm{a}$.

Freeman, Richard B. The Overeducated American. New York: Academic, $1976 \mathrm{~b}$.

Glick, P.C. "Family Life and Full Employment," American Journal of Sociology, 54(6), May 1949, 250-259.

Gonder, J. and S. Gordon. "The Housing Needs of 'Nontraditional' Households." Washington, D.C.: U.S. Department of Housing and Urban Development, office of Policy Development and Research, 1980. Goode, William J. World Revolution and Family Patterns.
New York: Free Press, 1963.

Gordon, Michael (ed.). The Nuclear Family in crisis: The Search for an Alternative. New York: Harper \& Row, 1972 .

The American Family in Social-Historical Perspective. New York: St. Martin's Press, 1978.

Greven, Philip. Four Generations: Population, Land and Family in Colonial Andover, Massachusetts. Ithaca, NY: Cornell University Press, 1970.

Guest, M. Avery. "Social structure and U.S. Interstate Fertility Differentials in 1900," Demography, 18(4), November $1981,465-486$.

Hareven, Tamara K. "The Family as Process: The Historical Study of the Family Cycle," Journal of Social History, $7,1974,322-329$.

Harris, Richard J. Housing and Social Policy. New York: Prentice-Hall, 1975.

Heise, R. David. "Problems in Path Analysis and Causal Inference," In E.F. Borgatta (ed.) Sociological Methodology. San Francisco: Jossey-Bass, Inc., 1969. 
Hill, Martha S. "Authority at Work: How Men and Women Differ." In Thousand American Families: Patterns of Economic ?rogress. Ann Arbor: Survey Research Center, University of Michigan, 1980.

Houser, R.M. "Schools and the stratification Process," American Journal of Sociology, 74, May 1969, 587-611.

Katz, Michael. The People of Hamilton, Canada West: Family and Class in a Mid-Nineteenth Century City. Cambridge, MA: Harvard University Press, 1975.

Keefe, Susan E. "Acculturation and the Extended Family Among Urban Mexican Americans." In Amado M. Pasdilla (ed.), Acculturation: Theory, Models, and Some New Findings. Boulder, CO: Westview Press, 1980.

Kerlinger, Fred N. Foundations of Behavioral Research. New York: Holt, Rinehart, \& Winston, 1973.

Klecka, William R., Norman H. Nie, and C.H. Hull, Statistical Package for the social sciences primer. New York: McGraw-Hill, 1975.

Kobrin, F. "The Fall of Household Size and the Rise of the Primary Individual in the United States," Demography, $13(1), 1976,127-138$.

Kowel, Carroll. "Housing Needs of Single Persons," Journal of Housing, June 1976 .

Kuznets, S. "Size and Age Structure of Family Households: Exploratory Comparisons," Population and Development Review, 4, 1978, 187-223.

"Size of Households and Income Disparities," Research in Population Economics, 48(11), Spring 1982, 127 .

Land, K.C. "Principles of Path Analysis," In E.F. Borgatta (ed.), Sociological Methodology. San Francisco: Jossey-Bass, 1969, 3-37.

Lasch, Christopher. "The Family and History," New York Review of Books. November 13, 1975, 33-38.

Laslett, B. "The Family as a Public and Private Institution: An Historical Perspective," Journal of Marriage and Family, 35, 1973, 480-492.

Laslett, Peter. The World We Have Lost. London: Methuen and Company, Ltd., 1965. 
Laslett, Peter and Richard Wall (eds.) Household and Family in Past Time. London: Cambridge University Press,

Lewis-Beck, Michael S. "Applied Regression: An Introduction," Sage University Paper Series on Quantitative Applications in the social science 07-022. Beverly Hills and London: Sage Publications, 1980.

Macklin, Eleanor D. "Nontraditional Family Forms: A Decade of Research," Journal of Marriage and the Family, $42(40)$, November 1980, 905-922.

Medjuck, Sheva. "Wooden Ships and Iron People: The Lives of the People of Moncton, New Brunswick, 1851 to 1871." Unpublished Doctoral Dissertation, York University, 1978 .

"Family and Household Composition in the Nineteenth Century: The Case of Moncton, New Brunswick, 1851 to $1871, "$ Canadian Journal of Sociology, $4(3)$, $1979,275-286$.

Merrick, w. Thomas. "Fertility and Land Availability in Rural Brazil," Demography, 15(3), August 1978.

Metropolitan Life Insurance Company. "Mortality Differentials Favor Women," Statistical Bulletin, 62(2), 1980, 3-7.

Michael, R.V. Fuchs, and S. Scott. "Changes in the Propensity to Live Alone: 1950-1976," Demography, 17(10), $1980,39-56$.

Mirande, Alfredo. "The Chicago Family: A Reanalysis of Conflicting Views," Journal of Marriage and the Family, 39, November 1977, 747-756.

Modell, John and Tamera $K$. Hareven. "Urbanization and the Malleable Household: An Examination of Boarding and Lodging in American Families," Journal of Marriage and the Family, 35, 1973, 467-478.

Monahan, T.P. "The Number of Children in American Families and the Sharing of Households," Marriage and Family Living, 18, August 1956, 201-203.

Montiel, Miguel. "The Social Science Myth of the Mexican American Family," El Grito 3, Summer 1970, 56-63.

Nenno, Mary K. "Single-Person Households: Two Avenues of Hope for Meeting Housing Needs," Journal of Housing, June 1976. 
Newsweek, July 1980 .

Nie, Norman H., C.H. Hull, Jean G. Jenkins, Karin Steinbrenner, and Dale H. Bent. Statistical Package for the Social Sciences. New York: McGraw-Hill, 1975.

Norwood, Janet L. "New Approaches to Statistics on the Family," Monthly Labour Review, 100(7), July 1977 , $31-34$.

Ogburn, William F. "The Changing Functions of the Family." In Robert $F$. Winch and Louie Wolf Goodman (eds.). selected studies in Marriage and the Family. New York: Holt, Rinehart, and Winston, 1968, 58-63.

overall, J. and C. Klett. Applied Multivariate Analysis. New York: McGraw-Hill, 1972 .

Parsons, Talcott and Robert F. Bales. Family, Socialization and Interaction Process. Glencoe, IL: The Free Press, 1965.

Pearce, Diana. "Women in Poverty." In Arthur I. Blanstein (ed.), The American Promise: Equal Justice and Economic Opportunity. New Brunswick, NJ: Transaction, 1982 .

Pitkin, John. "Estimates and Projections of National Housing Needs," Unpublished Working Paper. Office of Policy, Development and Research, HUD, April 1978.

Prince, S.H. "The Canadian Family in Wartime," Marriage and Family Living, 4(2), Spring 1942, 25-28.

Professional Builder Publisher's Letter, March 1980.

Pryor, E.T., Jr. "Rhode Island Family Structure: 1875 and 1960." In P. Laslett and R. Wall (eds.). Household and Family in Past Time. Cambridge, England: Cambridge University Press, 1972, 571-89.

Rabiega and E. Schafer. Unpublished Research Proposal, Portland State University, December 1, 1980.

Reid, Margaret G. Housing and Income. Chicago: University of Chicago press, 1962.

Reiss, Ira L. Family Systems in America. New York: Holt, Rinehart, \& Winston, 1971 .

Rose, A.M. "Living Arrangements of Unattached Persons," American Sociological Review, 12(4), August 1947, $429-435$. 
Rosenfield, Carl. "Job Search of the Unemployed," May 1976," Monthly Labor Review, November 1977.

Ross, Heather and Isabell Sawhill. Time of Transition: The Growth of Families Headed by women. Washington, D.C.: The Urban Institute, 1975, 195.

Russell, Cheryl. "Inside the Shrinking Household," American Demographics, 3(9), October 1981, 28-33.

Schafer, Edward. "An Analysis of Change in the Level of Infant Mortality Using a Causal Model Approach, 19701973," Unpublished Dissertation Proposal, Florida State University, 1985.

Schechter, Henry. "Statement on Prospects for the Housing Industry in the Year 1979," Senate subcommittee on Housing and Urban Affairs, December 22, 1978.

Sennett, Richard. Families Against the City. Cambridge, MA: Harvard University Press, 1970.

Seward, Rudy R. "Family Size in the U.S.: An Exploratory Study of Trends," Kansas Journal of Sociology, 10(2), Fall 1974, 119-136.

Smelser, Neil J. Social Change in the Industrial Revolution. Chicago: University of Chicago Press, 1959.

Staples, Robert and Alfredo Mirande. "Racial and Cultural Variations Among American Families: A Decennial Review of the Literature of Minority Families," Journal of Marriage and the Family, 42, November 1980, 887903 .

Sweet, J.A. Women in the Labor Force. New York: Seminar Press, $19 \overline{973}$

Toward a National Policy for Children and Families. National Academy of Sciences, 1976.

Troll, L.E. "The Family of Later Life: A Decade Review," Journal of Marriage and the Family, 33, 1971, 263-290.

Urban Land Institute. The Affordable Community, 1980.

U.S. Bureau of the Census. "Census of Population and Housing, 1982, Summary Tape File 3," Washington, D.C., 1982 .

U.S. Bureau of the Census, Construction Reports, series C-25, 1981 . 
U.S. Bureau of the Census, "Current Population Reports, Series P-60, No. 129, Money Income of Households, Families, and Persons in the United States: 1979." Washington, D.C.: U.S. Government Printing office, 1981 .

U.S. Bureau of the Census, "Current Population Reports, Series $P-60$, No. 142, Money Income of Households, Families, and Persons in the United States: 1982." Washington, D.C.: U.S. Government Printing office, 1984 .

U.S. Department of Commerce. Census of Population, Detailed Characteristics, 1970.

U.S. Government Printing office. Vital statistics of the United States, 1963.

Weicher, John C. "The Affordability of New Homes," Journal of the American Real Estate and Urban Economics Association, 5, Summer 1977, 209-226.

White, R.B. "Family Size Composition and Differentials Between Central City Suburbs and Metropolitan/Nonmetropolitan Migration streams," Demography, 19(1), February $1982,29-36$.

Wright, S. "Evolution and the Genetics of Population," Vol. 1 , Genetic and Biometric Foundations. Chicago: University of Chicago Press, 1968 .

Wright, S. "Path Coefficients and Path Regression: Alternative or Complementary Concepts?" Biometrics, 16, $1960,189-202$. 
APPENDIX A

DECOMPOSITION OF EFFECTS IN A PATH MODEL OF THE SUBFAMILY USING SMSA CENSUS DATA

\begin{tabular}{|c|c|c|c|c|c|c|c|c|c|c|c|c|c|}
\hline \multirow{3}{*}{$\begin{array}{l}\text { Dependent } \\
\text { Variable }\end{array}$} & \multirow{3}{*}{$\begin{array}{l}\text { Predeter- } \\
\text { nined } \\
\text { Variable }\end{array}$} & \multicolumn{11}{|c|}{ CAUSAL } & \multirow{3}{*}{ Noncausa } \\
\hline & & \multicolumn{5}{|c|}{ INDIREC } & \multicolumn{4}{|c|}{ EFEECT VIA } & \multirow[b]{2}{*}{$\begin{array}{l}\text { Direct } \\
\text { Effect }\end{array}$} & \multirow[b]{2}{*}{$\begin{array}{l}\text { Total } \\
\text { Effect }\end{array}$} & \\
\hline & & ELOH & FH & PUnAG & UNEMP & MFI & PHIBP & HCAPI & VR & \begin{tabular}{|c|} 
Total \\
Indirect \\
Bffect
\end{tabular} & & & \\
\hline \multirow[t]{3}{*}{ ELOH } & RAE & - & - & - & - & - & - & - & - & - & -.175 & -.175 & -.162 \\
\hline & PPB & - & - & - & - & - & - & - & - & - & 0.268 & 0.268 & -.081 \\
\hline & POD & - & - & - & - & - & - & - & - & - & 0.153 & 0.153 & 0.001 \\
\hline \multirow[t]{2}{*}{$\mathbf{F H}$} & RAB & - & - & - & - & - & - & - & - & - & 0.709 & 0.709 & -.295 \\
\hline & PFB & - & - & - & - & - & - & - & - & - & -.544 & -.544 & -.393 \\
\hline
\end{tabular}


APPEAOIX a (continued)

\begin{tabular}{|c|c|c|c|c|c|c|c|c|c|c|c|c|c|}
\hline \multirow{3}{*}{$\begin{array}{l}\text { Dependent } \\
\text { Variable }\end{array}$} & \multirow{3}{*}{$\begin{array}{l}\text { Predeter- } \\
\text { ained } \\
\text { Variable }\end{array}$} & \multicolumn{11}{|c|}{ CAUSAL } & \multirow{3}{*}{ Moncausal } \\
\hline & & \multicolumn{5}{|c|}{ I N D I R E C T } & \multicolumn{4}{|c|}{ E F F E C T V I A } & \multirow[b]{2}{*}{$\begin{array}{l}\text { Direct } \\
\text { Effect }\end{array}$} & \multirow[b]{2}{*}{$\begin{array}{l}\text { Total } \\
\text { Effect }\end{array}$} & \\
\hline & & enoh & Fr & punug & UNEQP & MPI & PHIBP & HCAPT & VR & $\begin{array}{c}\text { Total } \\
\text { Indirect } \\
\text { Bffect }\end{array}$ & & & \\
\hline \multirow[t]{2}{*}{$\mathbf{F H}$} & POD & - & - & - & - & - & - & - & - & - & - & - & - \\
\hline & ELOA & - & - & - & - & - & - & - & - & - & - & - & - \\
\hline \multirow[t]{5}{*}{ Punung } & $\mathbf{R A E}$ & 0.016 & 0.560 & - & - & - & - & - & - & 0.576 & -.184 & 0.392 & 0.037 \\
\hline & PEB & - & - & - & - & - & - & - & - & -.453 & 0.462 & 0.009 & 0.243 \\
\hline & POD & -.014 & - & - & - & - & - & - & - & -.014 & 0.306 & 0.292 & 0.042 \\
\hline & Exot & - & - & - & - & - & - & - & - & - & -.090 & -.090 & 0.112 \\
\hline & FH & - & - & - & - & - & - & - & - & - & 0.790 & 0.790 & -.132 \\
\hline
\end{tabular}


APPEadix A (continued)

\begin{tabular}{|c|c|c|c|c|c|c|c|c|c|c|c|c|c|}
\hline \multirow{3}{*}{$\begin{array}{l}\text { Dependent } \\
\text { variable }\end{array}$} & \multirow{3}{*}{$\begin{array}{l}\text { Predeter- } \\
\text { mined } \\
\text { Variable }\end{array}$} & \multicolumn{11}{|c|}{ C A U S A L } & \multirow{3}{*}{ Moncausa 1} \\
\hline & & \multicolumn{9}{|c|}{ INDIRECTEPEETT VIA } & \multirow[b]{2}{*}{$\begin{array}{l}\text { Direct } \\
\text { effect }\end{array}$} & \multirow[b]{2}{*}{$\begin{array}{l}\text { Total } \\
\text { Effect }\end{array}$} & \\
\hline & & BLOH & FH & PUsug & UNEATP & MPI & PHIBP & HCAPI & VR & $\begin{array}{c}\text { Total } \\
\text { Indirect } \\
\text { Bffect }\end{array}$ & & & \\
\hline \multirow[t]{6}{*}{ UREoup } & RAB & -.073 & -.051 & -.082 & - & - & - & - & - & -.206 & - & -.206 & -.141 \\
\hline & PFB & -.112 & 0.040 & 0.205 & - & - & - & - & - & 0.133 & - & 0.133 & -.172 \\
\hline & PCO & -.064 & - & 0.136 & - & - & - & - & - & 0.072 & - & 0.072 & -.019 \\
\hline & ELOA & - & - & -.039 & - & - & - & - & - & -.039 & -.458 & -.497 & 0.040 \\
\hline & $\mathrm{FH}$ & - & - & 0.349 & - & - & - & - & - & 0.349 & -.423 & -.074 & -.036 \\
\hline & pURAG & - & - & - & - & - & - & - & - & - & 0.443 & 0.443 & -.327 \\
\hline
\end{tabular}


APPEADIX A (continued)

\begin{tabular}{|c|c|c|c|c|c|c|c|c|c|c|c|c|c|}
\hline \multirow{3}{*}{$\begin{array}{l}\text { Dependent } \\
\text { Variable }\end{array}$} & \multirow{3}{*}{$\begin{array}{l}\text { Predeter- } \\
\text { ained } \\
\text { Variable }\end{array}$} & \multicolumn{11}{|c|}{ CA U S A I } & \multirow{3}{*}{ Noncausal } \\
\hline & & \multicolumn{5}{|c|}{ I A E D I R R E C C T } & \multicolumn{4}{|c|}{ EPEECT VIA } & \multirow[b]{2}{*}{$\begin{array}{l}\text { Direct } \\
\text { Effect }\end{array}$} & \multirow[b]{2}{*}{$\begin{array}{l}\text { Total } \\
\text { Effect }\end{array}$} & \\
\hline & & ELOH & FH & Punug & UNEMP & MFI & PHIBP & HCAPI & VR & $\begin{array}{c}\text { Total } \\
\text { Indirect } \\
\text { Effect } \\
\end{array}$ & & & \\
\hline \multirow[t]{7}{*}{ MPI } & RAE & -.080 & 0.020 & 0.059 & - & - & - & - & - & -.001 & -.416 & -.417 & 0.941 \\
\hline & PFB & 0.123 & -.015 & -.148 & - & - & - & - & - & 0.040 & 0.340 & 0.380 & -.284 \\
\hline & $\mathbf{P O O}$ & 0.071 & - & -.098 & - & - & - & - & - & -.027 & 0.176 & 0.149 & -.014 \\
\hline & ELOH & - & - & 0.029 & - & - & - & - & - & 0.029 & 0.487 & 0.516 & 0.009 \\
\hline & FH & - & - & -.253 & - & - & - & - & - & -.253 & 0.281 & 0.028 & -.199 \\
\hline & punag & - & - & - & - & - & - & - & - & - & -.320 & -.320 & 0.173 \\
\hline & UNERTP & - & - & - & - & - & - & - & - & - & - & - & - \\
\hline
\end{tabular}


APPEDTIX A (continued)

\begin{tabular}{|c|c|c|c|c|c|c|c|c|c|c|c|c|c|}
\hline \multirow{3}{*}{$\begin{array}{l}\text { Dependent } \\
\text { Variable }\end{array}$} & \multirow{3}{*}{$\begin{array}{l}\text { Predeter- } \\
\text { mined } \\
\text { Variable }\end{array}$} & \multicolumn{11}{|c|}{ c A v s a } & \multirow{3}{*}{ Honcausal } \\
\hline & & \multicolumn{5}{|c|}{ I N D I R E C T } & \multicolumn{4}{|c|}{ EFEET VI } & \multirow[b]{2}{*}{$\begin{array}{l}\text { Direct } \\
\text { Effect }\end{array}$} & \multirow[b]{2}{*}{$\begin{array}{l}\text { Total } \\
\text { Effect }\end{array}$} & \\
\hline & & ELOH & FH & PURAG & UNEMP & MPI & PHIBP & HCAPI & VR & \begin{tabular}{|c|} 
Total \\
Indirect \\
Effect \\
\end{tabular} & & & \\
\hline \multirow[t]{8}{*}{ PHIBP } & RAR & -.106 & 0.102 & -.059 & - & 0.314 & - & - & - & 0.251 & 0.383 & 0.634 & -.090 \\
\hline & PEB & 0.023 & -.073 & 0.149 & - & -.257 & - & - & - & -.204 & -.099 & -.303 & 0.350 \\
\hline & $\mathbf{P O D}$ & 0.020 & - & 0.099 & - & -.133 & - & - & - & -.054 & -.112 & -.166 & -.284 \\
\hline & EIOA & - & - & -.029 & -.083 & -.368 & - & - & - & -.480 & 0.349 & -.131 & -.046 \\
\hline & $\mathbf{F H}$ & - & - & 0.254 & -.077 & -.212 & - & - & - & -.035 & 0.178 & 0.143 & 0.280 \\
\hline & Penas & - & - & - & 0.080 & 0.242 & - & - & - & 0.322 & - & 0.322 & 0.000 \\
\hline & UNEAP & - & - & - & - & - & - & - & - & - & 0.181 & 0.181 & -.079 \\
\hline & MPI & - & - & - & - & - & - & - & - & - & -.755 & -.755 & 1.502 \\
\hline
\end{tabular}




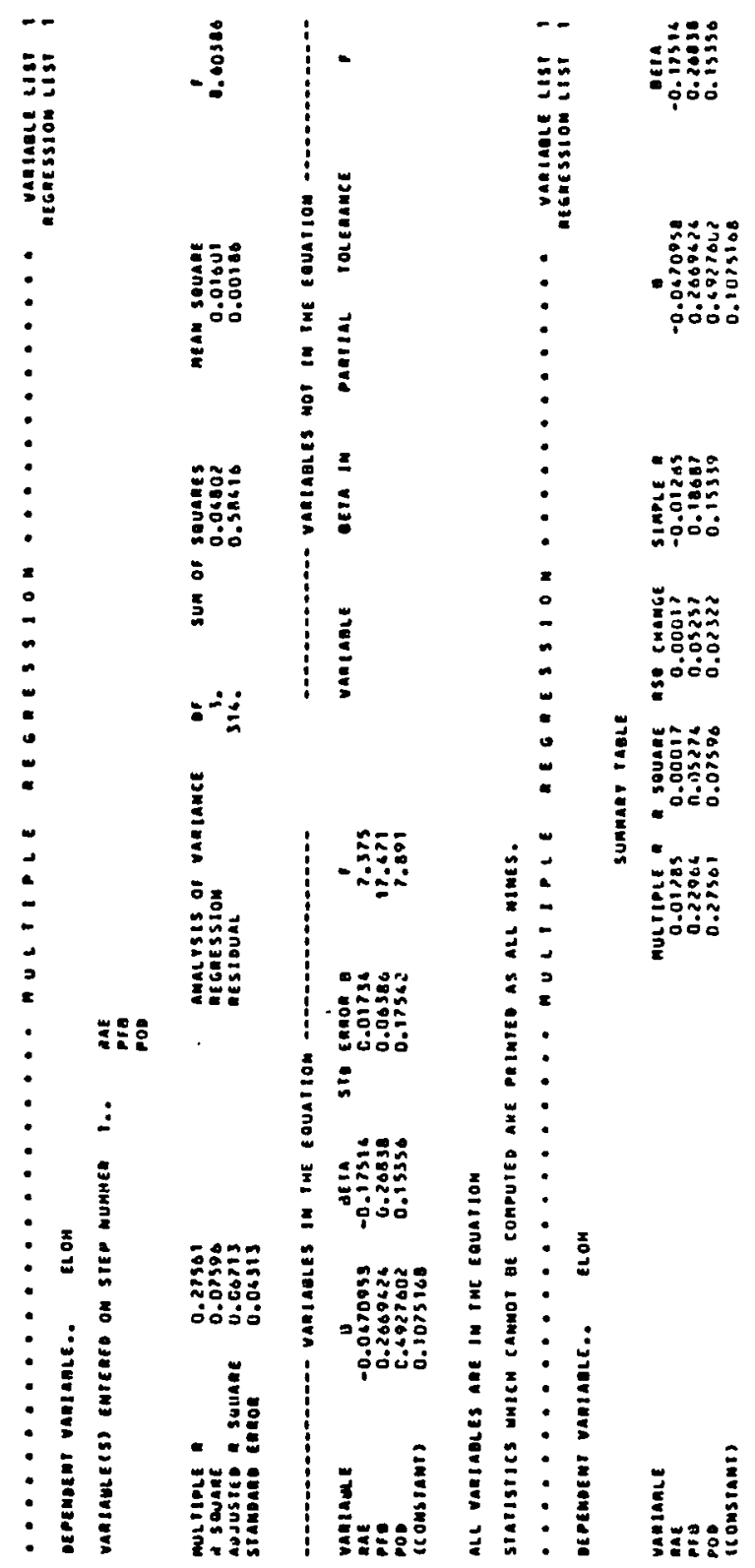


APPENDIX B (continued)

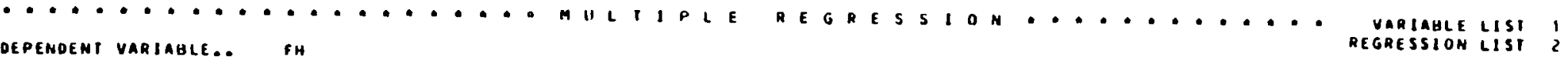

VARIAULE (S) ENTEHTD ON STEP NUAUER 1.. P RAE

VARIAULE (S) ENTEHTD ON STEP NUAUER 1.. P RAE

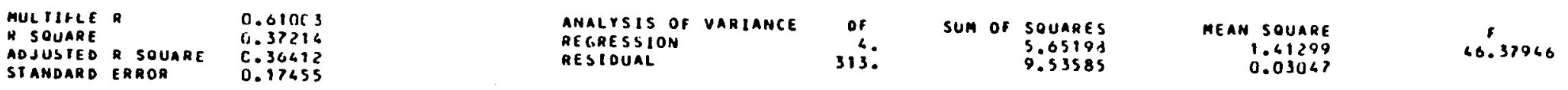

-

\begin{tabular}{|c|c|c|c|c|c|}
\hline $\begin{array}{l}\text { VARIAGLE } \\
\text { RAE } \\
\text { PIO } \\
\text { POD } \\
\text { ELOH } \\
\text { (CONSIANT) }\end{array}$ & $\begin{array}{c}0 \\
0.9360866 \\
-2.0507558 \\
-0.3492021 \\
0.615112 .3 \\
0.1262868\end{array}$ & $\begin{array}{r}\text { UETA } \\
0.70869 \\
-0.54372 \\
-0.02220 \\
0.08490\end{array}$ & STO & $\begin{array}{l}\text { ERROR B } \\
\text { U.DP100 } \\
0.26553 \\
0.71873 \\
0.22837\end{array}$ & $\begin{array}{r}173.102 \\
99.656 \\
0.236 \\
1.320\end{array}$ \\
\hline
\end{tabular}

Wariagle

Beta in partial tolerance

CLT GARIABLES ARE IM THE

all VARIABLES ARE IN THE EQUATIOH

Statistics uhich camiot he computeo are printed as all nines.

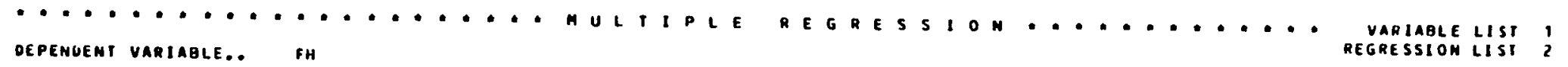

SUMmar T TAOLE

VARIAGLE
RAE
PFB
POD
ELOH
(CONSIANII

$\begin{array}{cccc}\text { MULIIPLE R } & \text { R SOUARE } & \text { RSO CHANGE } & \text { SIMPLER } \\ 0.41613 & 0.17150 & 0.17150 & 0.41613 \\ 0.60668 & 0.36540 & 0.19390 & -0.15062 \\ 0.61655 & 0.36568 & 0.06009 & 0.03640 \\ 0.61003 & 0.37214 & 0.00600 & -0.02928\end{array}$

0.9340864
-2.6507598

$-0.34372$

$\begin{array}{ll}0.4101128 & -0.02220 \\ 0.1202888 & 0.08690\end{array}$ 


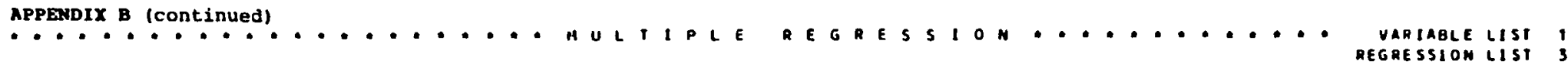
dePEHDENt variagle.. PuHAG

VARIAGLE (S) ENTERED ON SIEP HUHIER 1.. PAE PFG

RAE
PFB
POD
ELOH
FH

$\begin{array}{ll}\text { MULIIPLE R } & 0.81113 \\ \text { R SQUARE } & 0.65194 \\ \text { ADJUSTED R SOUARE } & 0.65260 \\ \text { SIAAMDARD ERROR } & 0.02323\end{array}$

MHALYSIS OF VARIANCE REGRESSION

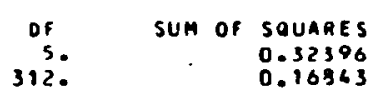

MEAN SUUARE

0.06479
0.00654 $\quad 120.02309$

vahiagles in the euUation

\begin{tabular}{|c|c|c|c|c|c|}
\hline $\begin{array}{l}\text { VARRIAULE } \\
\text { RAE } \\
\text { PRB } \\
\text { POD } \\
\text { ELUH } \\
\text { FH } \\
\text { (CONSTANT) }\end{array}$ & $\begin{array}{c}0 \\
-0.0637277 \\
0.6053933 \\
0.3674062 \\
-0.0798157 \\
0.1624094 \\
0.0876880\end{array}$ & $\begin{array}{r}\text { HETA } \\
-0.18626 \\
10.00183 \\
0.31629 \\
-0.07064 \\
0.79092\end{array}$ & 510 & $\begin{array}{l}\text { ERROR A } \\
0.01178 \\
0.06058 \\
0.09571 \\
0.03056 \\
0.00752\end{array}$ & $\begin{array}{r}F \\
13.785 \\
99.780 \\
82.139 \\
6.321 \\
358.246\end{array}$ \\
\hline
\end{tabular}

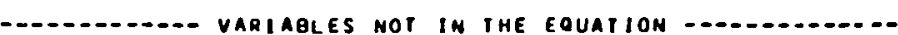

VARIABLE

beta in partial tolerance

;

ALL VAMIABLES ARE IN the EQUATIOH

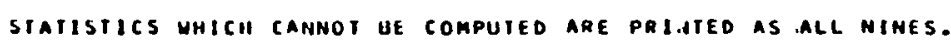

\begin{tabular}{|c|c|c|c|c|c|c|c|}
\hline \multicolumn{8}{|c|}{ SUMmary table } \\
\hline $\begin{array}{l}\text { YARIAULE } \\
\text { RAE } \\
\text { PFU } \\
\text { PUD } \\
\text { ELOH } \\
\text { YH } \\
\text { (CONSIANT) }\end{array}$ & & $\begin{array}{c}\text { MULIIPLE R } \\
0.42885 \\
0.42965 \\
0.51440 \\
0.551495 \\
0.81113\end{array}$ & $\begin{array}{l}\text { R SOUARE } \\
\text { O.18391 } \\
0.18660 \\
0.26407 \\
0.26517 \\
0.65794\end{array}$ & $\begin{array}{c}\text { RSU CHANGE } \\
0.18341 \\
0.00069 \\
0.0806,7 \\
11.00054 \\
0.30276\end{array}$ & $\begin{array}{l}\text { SIMPLE R } \\
0.62845 \\
0.25150 \\
0.33365 \\
0.02210 \\
0.65823\end{array}$ & $\begin{array}{c}A \\
-0.0437277 \\
0.6453983 \\
0.8676062 \\
-0.0798154 \\
0.14241824 \\
0.0476880\end{array}$ & $\begin{array}{r}\text { DEIA } \\
-0.18426 \\
0.66183 \\
0.30329 \\
-0.09066 \\
n .79092\end{array}$ \\
\hline
\end{tabular}


APPENDIX B (continued)

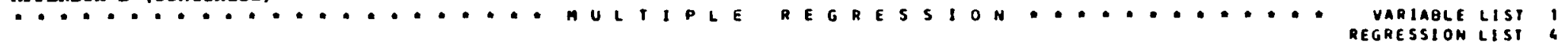
DEPEnUENT VARIAGLE.. INEMP

VARIAHLE(S) CNIERED OII SIEP RUMBER 1.. RAE

RAE
PFL
POD
ELOH
FH

PUNAG

$\begin{array}{ll}\text { MULIIPLE } & \\ \text { R SOUARE } & 0.56025 \\ \text { AOJUSIEO R SRUARE } & 0.31383 \\ \text { SIANOAHO ERROR } & 0.30059 \\ & 0.01832\end{array}$

AHALYSIS OF VARIANCE AOJUSIED R SRUARE O.30059

311.

0.04774
0.10439

mean SQUARE

0.00790

23.70046

.

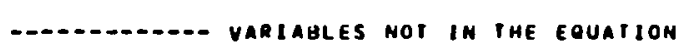

VARIAULE

B
0.0036888

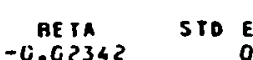

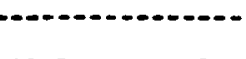

RAE

POD

ELOH

-0.0036888
-0.0567126
0.0030387
-0.0269161

a.100

VARIABLE

BETA IN

parisal tolerance

,

$\begin{array}{llll}-0.0423545 & -0.62320 & 0.02436 & 85.252 \\ 0.00870 & 23.724\end{array}$

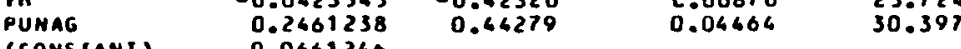

all variables are in the equation

SIATISTICS UHICH CANNUT ige COMPUTEO ARE PRINTED AS ALL Nines.

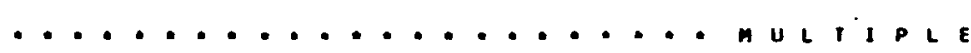

DEPENDENT VARIABLE.. UNEMP

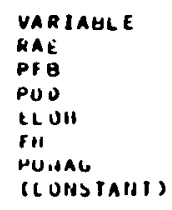

SUMMARY TAGLE

\begin{tabular}{|c|c|c|c|c|c|}
\hline $\begin{array}{c}\text { HULTIPLE R } \\
\text { C.06478 } \\
0.00698 \\
0.08452 \\
0.40337 \\
1.64675 \\
\text { C.5611211 }\end{array}$ & $\begin{array}{l}\text { OSOUARE } \\
\text { O.00619 } \\
0.011422 \\
0.00801 \\
0.26362 \\
0.26676 \\
0.31383\end{array}$ & $\begin{array}{c}\text { ASO CHANGE } \\
0.00619 \\
0.00003 \\
0.00379 \\
0.23561 \\
0.01334 \\
0.06717\end{array}$ & $\begin{array}{l}S I \text { YPLE D } \\
-0.06476 \\
-0.03916 \\
0.05310 \\
-0.65360 \\
-11.110: 5 \\
0.11558\end{array}$ & $\begin{array}{r}13 \\
-0.0030885 \\
-0.0567126 \\
0.0036387 \\
-0.2269141 \\
-0.0423515 \\
0.2461238 \\
0.0661260\end{array}$ & $\begin{array}{r}\text { BE19 } \\
-0.02362 \\
-0.11623 \\
0.00231 \\
-0.65869 \\
-0.62920 \\
0.64279\end{array}$ \\
\hline
\end{tabular}


APPENDIX B (continued)
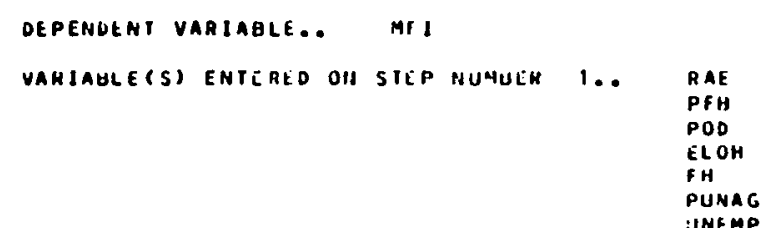

$\begin{array}{ll}\text { MULTIPLE R } & \text { U.630L8 } \\ \text { R SOUARE } & 0.39701\end{array}$

ALJUSTED K SOUARE U. 33339

AIIALYSIS OF VARIANCE

REGRESSIOQ

OF SUM OF SOUARES

310: 1031566603.97064

MEAN SOUARE
167363696.85292
5056090.10827

29.15724

.

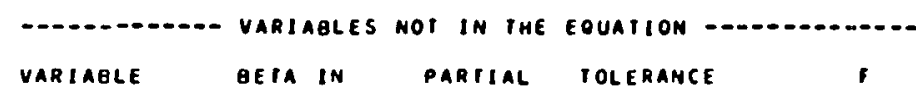

\begin{tabular}{|c|c|c|c|c|}
\hline $\begin{array}{l}\text { YARIAGLE } \\
\text { RAE } \\
\text { PFB } \\
\text { POD } \\
\text { ELOH } \\
\text { FH } \\
\text { PUNAG } \\
\text { UNEMP } \\
\text { (CONSIANT) }\end{array}$ & $\begin{array}{r}\text { B } \\
-7175.1875662 \\
21692.6343675 \\
36238.6090678 \\
31236.2681726 \\
3679.9027075 \\
-23247.5823483 \\
12265.4653677 \\
10019.6141211\end{array}$ & $\begin{array}{r}\text { OE TA } \\
-0.61020 \\
0.36013 \\
0.17615 \\
0.68716 \\
0.28134 \\
-r .32603 \\
11.09385\end{array}$ & $\begin{array}{l}\text { S1D ERROR A } \\
1164.07418 \\
4528.60759 \\
10408.57511 \\
3376.02993 \\
1166.99425 \\
5739.39924 \\
6953.21714\end{array}$ & $\begin{array}{l}5 \\
37.956 \\
22.965 \\
12.122 \\
85.675 \\
11.051 \\
16.407 \\
3.107\end{array}$ \\
\hline
\end{tabular}

VARIABLE

GEIA IN

partial tolerance

all variables are in the equation

SIATISTICS HHICH CAHHOT HE COHPUTEO AHE PRIBITEO AS ALL MINES.

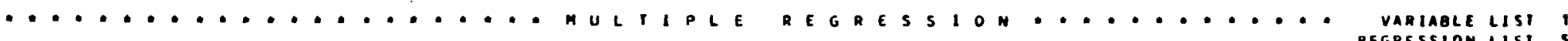
DEPENDENT VARIABLE.. ME I

VARIAULE
MAE
PFB
POO
ELOH
PH
PUINAL
UNEMH
COUNDIANT

Summarer tagle

\begin{tabular}{|c|c|c|c|c|c|}
\hline $\begin{array}{l}\text { MULIIPLE } \\
0.24583 \\
0.36458 \\
0.39483 \\
0.601945 \\
0.061399 \\
0.62527 \\
0.63098\end{array}$ & $\begin{array}{l}\text { ROUARE } \\
0.06043 \\
0.13202 \\
0.159117 \\
0.360613 \\
11.36664 \\
C .39096 \\
0.39701\end{array}$ & 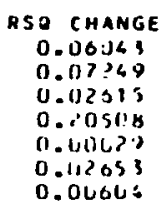 & $\begin{array}{l}\text { SIAPLE AR } \\
-0.26583 \\
0.09605 \\
0.13638 \\
0.5 ? 445 \\
-0.11145 \\
-0.14734 \\
-0.1760 \%\end{array}$ & 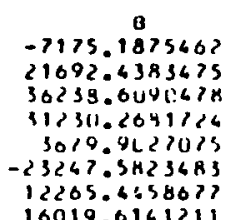 & $\begin{array}{r}0619 \\
-0.61520 \\
0.34018 \\
0.11615 \\
0.48116 \\
0.28136 \\
-0.32016 \\
0.04385\end{array}$ \\
\hline
\end{tabular}




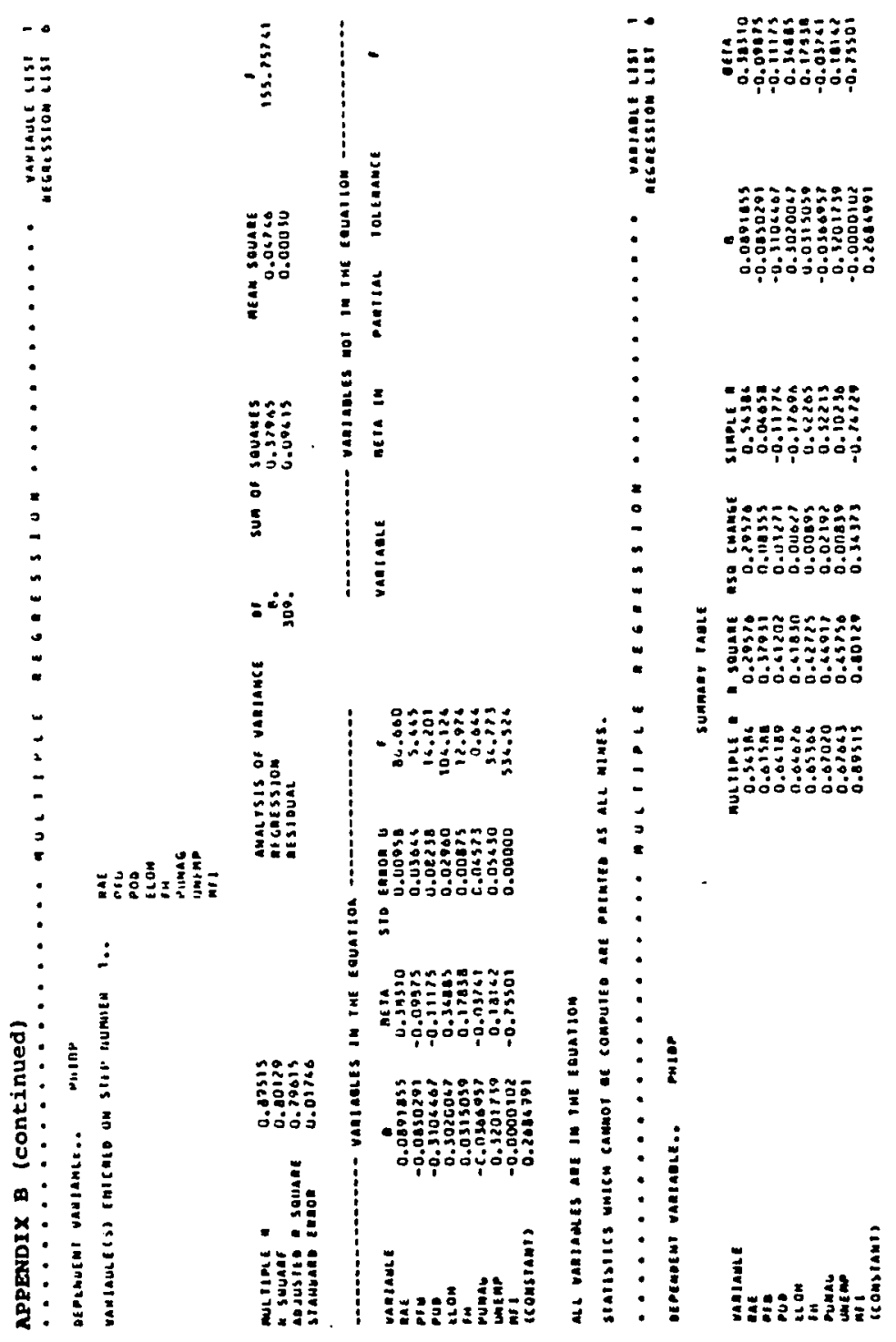




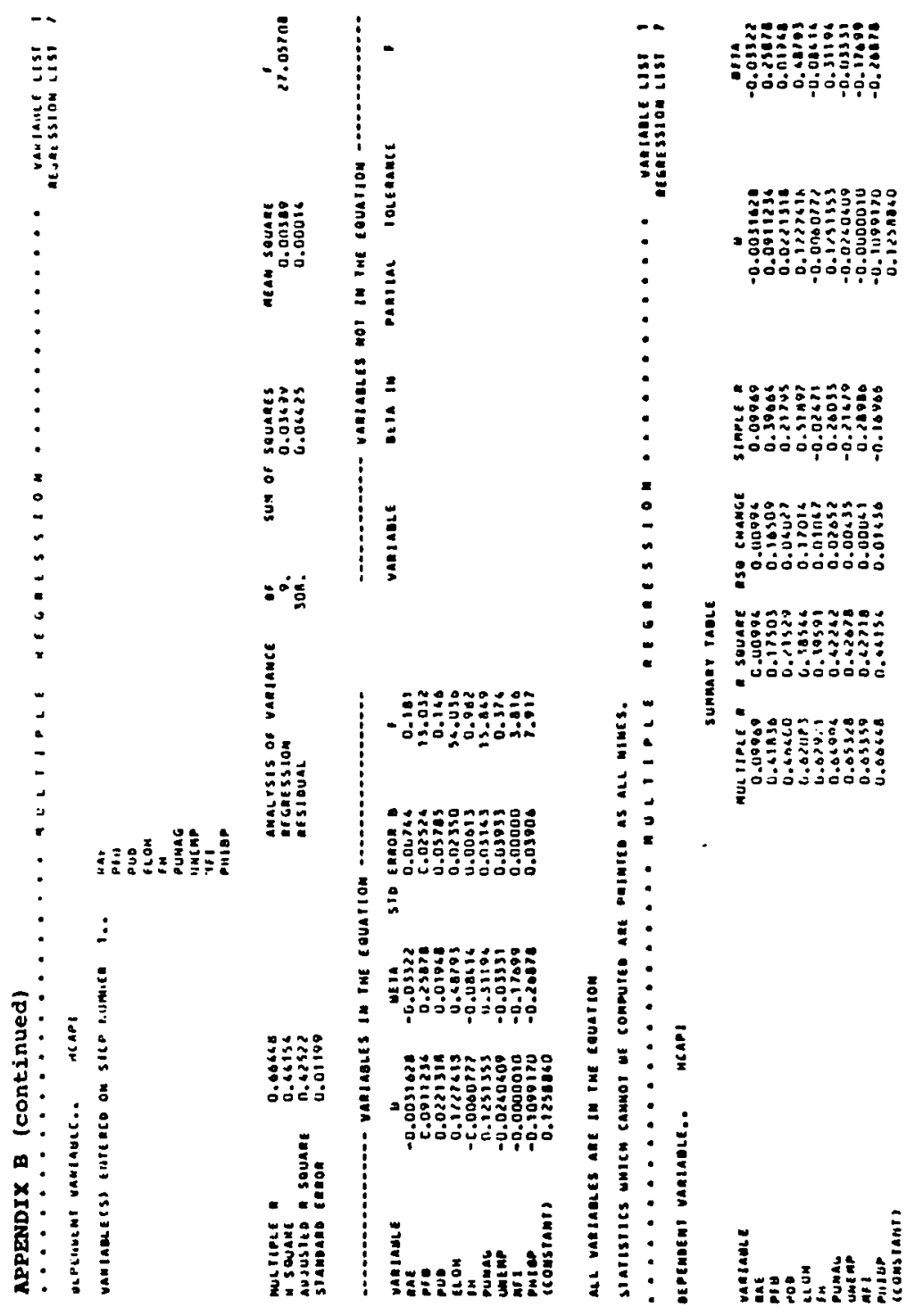




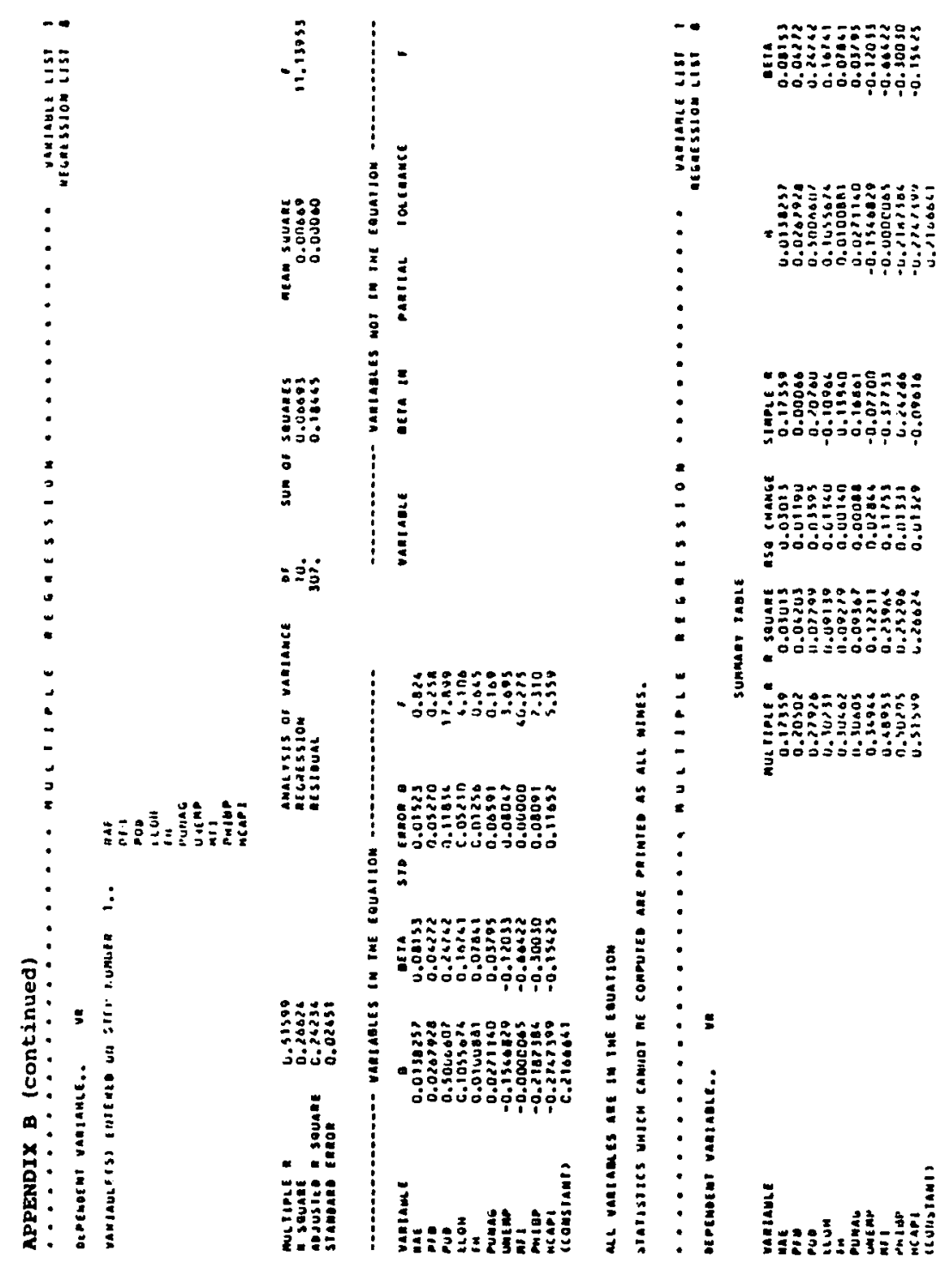




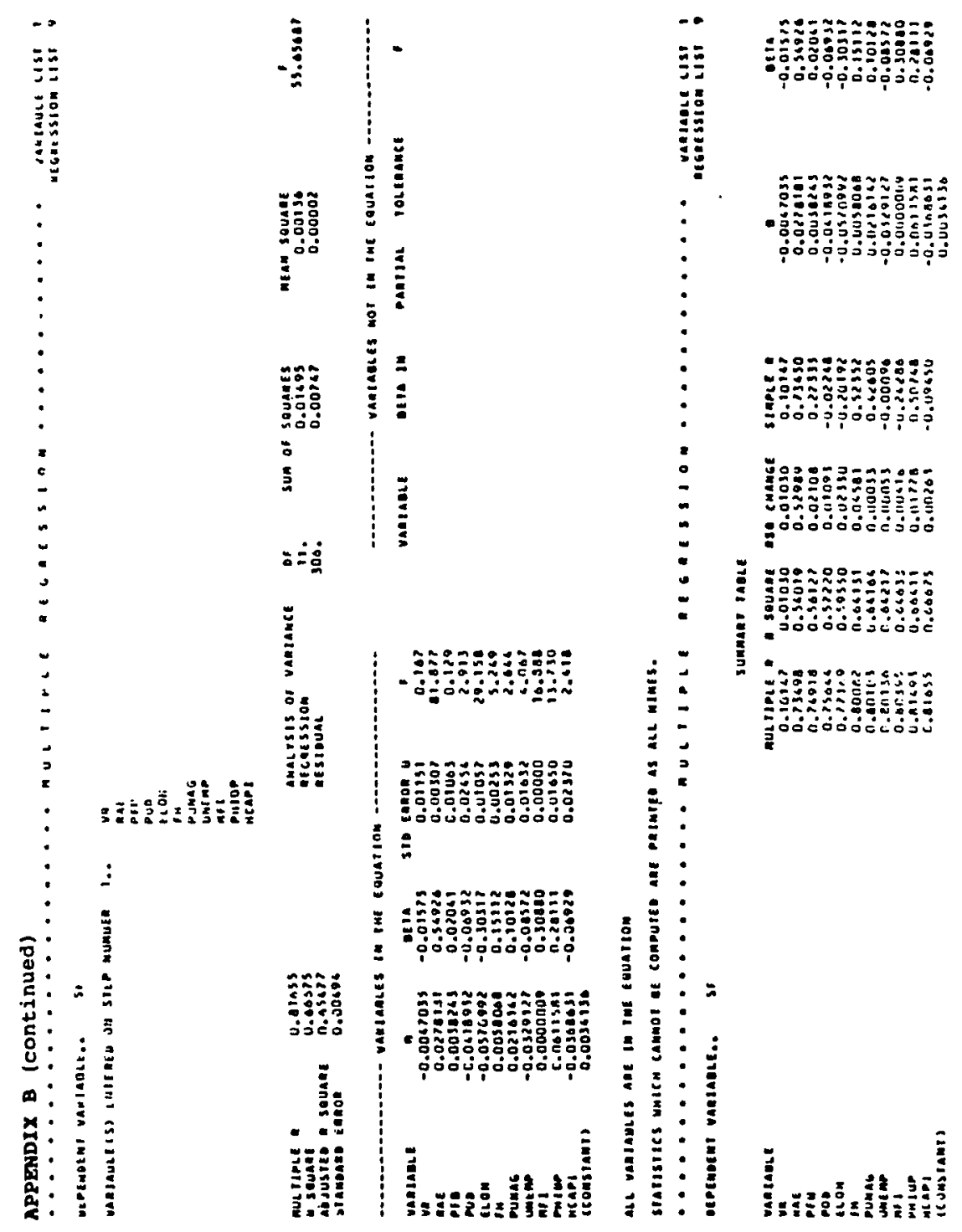


APPENDIX C

DECOMPOSITION OF EFFECTS IN A PATH MODEL OF THE SUBFAMILY USING LOS ANGELES COUNTY TRACT DATA

\begin{tabular}{|c|c|c|c|c|c|c|c|c|c|c|c|c|c|}
\hline \multirow{3}{*}{$\begin{array}{l}\text { Dependent } \\
\text { Variable }\end{array}$} & \multirow{3}{*}{$\begin{array}{l}\text { Predeter- } \\
\text { ained } \\
\text { Variable }\end{array}$} & \multicolumn{11}{|c|}{ CA U S A } & \multirow{3}{*}{ Noncausal } \\
\hline & & \multicolumn{5}{|c|}{ I N D I R E C T } & \multicolumn{4}{|c|}{ EFECT VIA } & \multirow[b]{2}{*}{$\begin{array}{l}\text { Direct } \\
\text { Effect }\end{array}$} & \multirow[b]{2}{*}{$\begin{array}{l}\text { Total } \\
\text { Effect }\end{array}$} & \\
\hline & & ELOH & $\mathbf{F H}$ & PURAG & UNEAMP & MPI & PHIBP & HCAPI & VR & $\begin{array}{c}\text { Total } \\
\text { Indirect } \\
\text { Effect }\end{array}$ & & & \\
\hline \multirow[t]{3}{*}{ ELOH } & RNE & - & - & - & - & - & - & - & - & - & -.729 & -.729 & 1.378 \\
\hline & PFB & - & - & - & - & - & - & - & - & - & 0.157 & 0.157 & -.389 \\
\hline & POD & - & - & - & - & - & - & - & - & - & - & - & - \\
\hline \multirow[t]{2}{*}{$\mathbf{F H}$} & RAE & -.125 & - & - & - & - & - & - & - & -.125 & 0.874 & 0.749 & -.708 \\
\hline & PFB & 0.027 & - & - & - & - & - & - & - & 0.027 & -.595 & -.568 & 0.765 \\
\hline
\end{tabular}


APPEAdIX C (continued)

\begin{tabular}{|c|c|c|c|c|c|c|c|c|c|c|c|c|c|}
\hline \multirow{3}{*}{$\begin{array}{l}\text { Dependent } \\
\text { Variable }\end{array}$} & \multirow{3}{*}{$\begin{array}{l}\text { Predeter- } \\
\text { ained } \\
\text { Variable }\end{array}$} & \multicolumn{11}{|c|}{ CAUSAL } & \multirow{3}{*}{ Moncausal 1} \\
\hline & & \multicolumn{9}{|c|}{ I N D I RE C T E P F E C T U I A } & \multirow[b]{2}{*}{$\begin{array}{l}\text { Direct } \\
\text { Effect }\end{array}$} & \multirow[b]{2}{*}{$\begin{array}{l}\text { Total } \\
\text { Bffect }\end{array}$} & \\
\hline & & ELOH & FH & PUnug & UNEATP & MPI & PHIBP & HCAPI & VR & $\begin{array}{c}\text { Total } \\
\text { Indirect } \\
\text { Effect }\end{array}$ & & & \\
\hline \multirow[t]{2}{*}{$\mathbf{F H}$} & POO & - & - & - & - & - & - & - & - & - & 0.267 & 0.267 & -.050 \\
\hline & ELOH & - & - & - & - & - & - & - & - & - & 0.171 & 0.171 & -.399 \\
\hline \multirow[t]{5}{*}{ PUnag } & RAE & 0.011 & 0.357 & - & - & - & - & - & - & 0.368 & 0.146 & 0.514 & -.177 \\
\hline & PPB & -.002 & -.243 & - & - & - & - & - & - & -.245 & 0.061 & -.184 & 0.220 \\
\hline & POD & - & 0.109 & - & - & - & - & - & - & 0.109 & 0.432 & 0.541 & -.057 \\
\hline & EROH & - & 0.070 & - & - & - & - & - & - & 0.070 & -.085 & -.015 & -.223 \\
\hline & $\mathbf{F H}$ & - & - & - & - & - & - & - & - & - & 0.408 & 0.408 & 0.160 \\
\hline
\end{tabular}


APPEadix C (continued)

\begin{tabular}{|c|c|c|c|c|c|c|c|c|c|c|c|c|c|}
\hline \multirow{3}{*}{$\begin{array}{l}\text { Dependent } \\
\text { Variable }\end{array}$} & \multirow{3}{*}{$\begin{array}{l}\text { Predeter- } \\
\text { ained } \\
\text { Variable }\end{array}$} & \multicolumn{11}{|c|}{$c \wedge \cup \leq \wedge \mathrm{L}$} & \multirow{3}{*}{ Noncausal } \\
\hline & & \multicolumn{5}{|c|}{ I H D I RECT } & \multicolumn{4}{|c|}{ E F P E C T V I A } & \multirow[b]{2}{*}{$\begin{array}{l}\text { Direct } \\
\text { Effect }\end{array}$} & \multirow[b]{2}{*}{$\begin{array}{l}\text { Total } \\
\text { Effect }\end{array}$} & \\
\hline & & ELOH & FH & Puinag & UNEATP & RPI & PHIBP & HCAPI & VR & $\begin{array}{c}\text { Total } \\
\text { Indirect } \\
\text { Effect } \\
\end{array}$ & & & \\
\hline \multirow[t]{6}{*}{ UNEaP } & RARE & 0.146 & 0.240 & 0.061 & - & - & - & - & - & 0.447 & 0.190 & 0.637 & 0.049 \\
\hline & PFB & -.031 & -.163 & 0.025 & - & - & - & - & - & -.169 & 0.136 & 0.033 & 0.317 \\
\hline & poo & - & 0.073 & 0.179 & - & - & - & - & - & 0.252 & - & 0.252 & -.133 \\
\hline & ExOA & - & 0.047 & -.035 & - & - & - & - & - & 0.012 & -.211 & -.199 & -.294 \\
\hline & $\mathbf{H H}$ & - & - & 0.170 & - & - & - & - & - & 0.170 & 0.105 & 0.275 & 0.157 \\
\hline & Penung & - & - & - & - & - & - & - & - & - & 0.416 & 0.416 & 0.159 \\
\hline
\end{tabular}


APPEaDIX C (continued)

\begin{tabular}{|c|c|c|c|c|c|c|c|c|c|c|c|c|c|}
\hline \multirow{3}{*}{$\begin{array}{l}\text { Dependent } \\
\text { Variable }\end{array}$} & \multirow{3}{*}{$\begin{array}{c}\text { Predeter- } \\
\text { mined } \\
\text { Variable }\end{array}$} & \multicolumn{11}{|c|}{ CAUSA L } & \multirow{3}{*}{ Noncausa 1} \\
\hline & & \multicolumn{5}{|c|}{ I N D I R E C T } & \multicolumn{4}{|c|}{ EEEC I VIA } & \multirow[b]{2}{*}{$\begin{array}{l}\text { Direct } \\
\text { Effect }\end{array}$} & \multirow[b]{2}{*}{$\begin{array}{l}\text { Total } \\
\text { Effect }\end{array}$} & \\
\hline & & ETOH & FH & PUing & UNEAP & RPI & PHIBP & HCAPI & VR & $\begin{array}{c}\text { Total } \\
\text { Indirect } \\
\text { Effect } \\
\end{array}$ & & & \\
\hline \multirow[t]{7}{*}{ MPI } & RAE & -.462 & -.052 & -.018 & 0.011 & - & - & - & - & -.521 & -.175 & -.696 & 0.059 \\
\hline & PFB & 0.099 & 0.025 & -.008 & 0.008 & - & - & - & - & 0.124 & -.152 & -.028 & -.333 \\
\hline & $P 00$ & - & -.011 & -.053 & - & - & - & - & - & -.064 & -.231 & -.295 & 0.116 \\
\hline & ELOH & - & -.007 & 0.010 & -.012 & - & - & - & - & -.009 & 0.629 & 0.620 & 0.133 \\
\hline & $\mathbf{F H}$ & - & - & -.050 & 0.006 & - & - & - & - & -.044 & - & -.044 & -.229 \\
\hline & Penng & - & - & - & 0.024 & - & - & - & - & 0.024 & -.146 & -.122 & -.305 \\
\hline & UNEAT & - & - & - & - & - & - & - & - & - & 0.057 & 0.057 & 0.558 \\
\hline
\end{tabular}




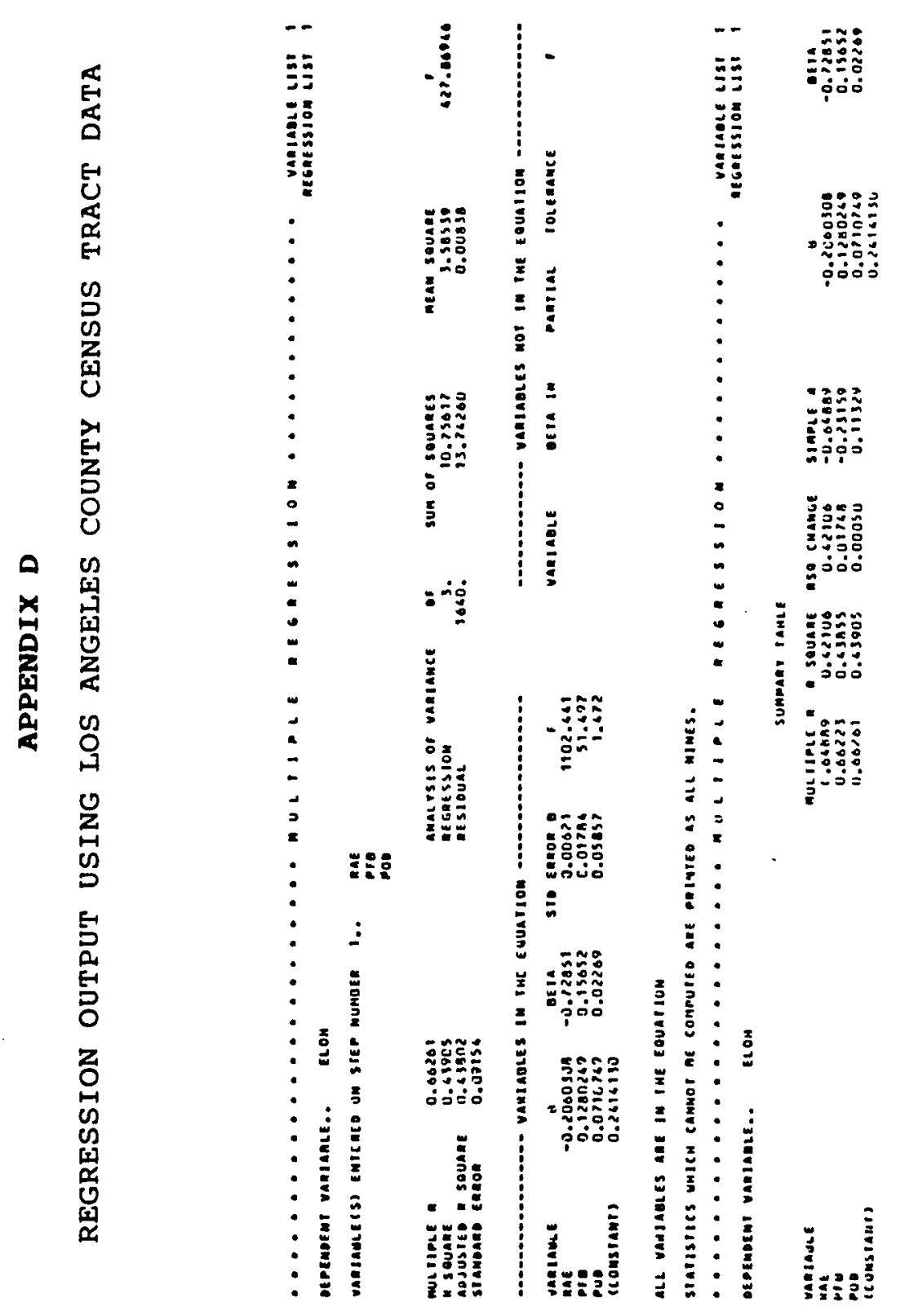


APPENDIX D (continued)

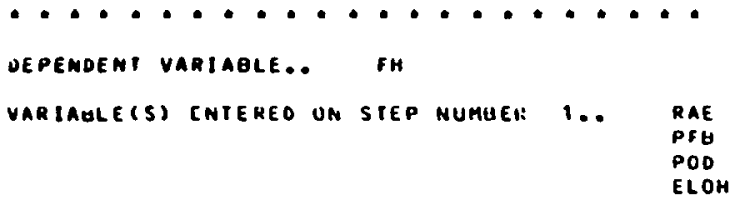

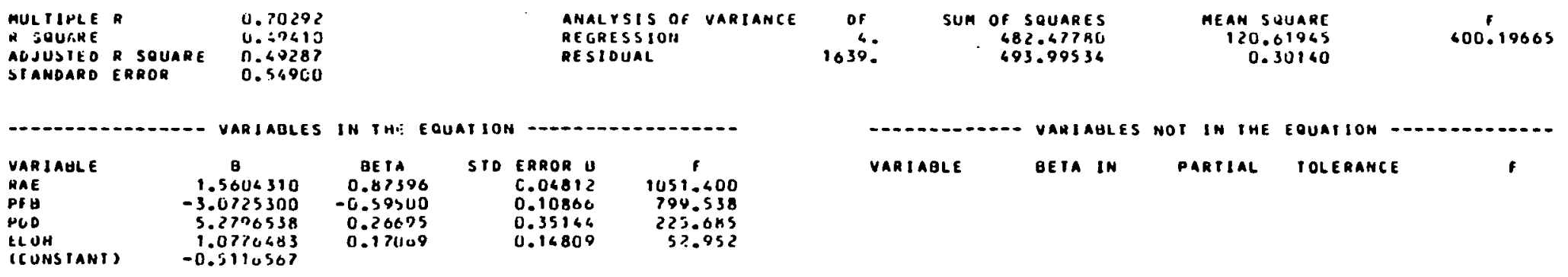

all UaKJAHLES ARE IN THE EQUATION

STATLSTCS HHICH CAHNU BE COMPUTí ARI PRINIEO AS ALL NINES.

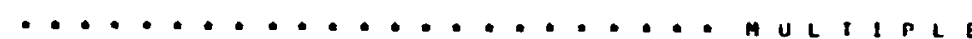
VARIABLE LIST
REGRESSIOM LIST

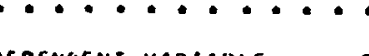

F"

REGQESSION LISI?

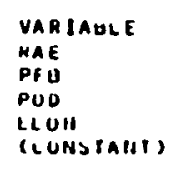

SUMMARY IAGLE

\begin{tabular}{|c|c|c|c|c|c|}
\hline $\begin{array}{c}\text { AULTIPLE R } \\
0.60220 \\
0.03118 \\
0.69120 \\
11.70292\end{array}$ & $\begin{array}{l}\text { PSUUARE } \\
0.16769 \\
0.40600 \\
0.47776 \\
0.69610\end{array}$ & $\begin{array}{c}\text { RSO CHANGE } \\
0.16749 \\
0.23851 \\
0.07176 \\
0.01634\end{array}$ & $\begin{array}{r}\text { SIMPLE N } \\
0.40926 \\
-0.19762 \\
0.21704 \\
-0.22834\end{array}$ & $\begin{array}{c}\theta \\
1.5004310 \\
-3.07253611 \\
5.2790532 \\
1.0770603\end{array}$ & $\begin{array}{c}0 E 1 A \\
0.87390 \\
-0.59500 \\
0.26695 \\
0.17009\end{array}$ \\
\hline
\end{tabular}


APPENDIX D (continued)

oependent variadol... pumac

VARIAULE (S) ENIERED UH SIEP HUMHEH 1 .. PAE PGH

POD
ELOH

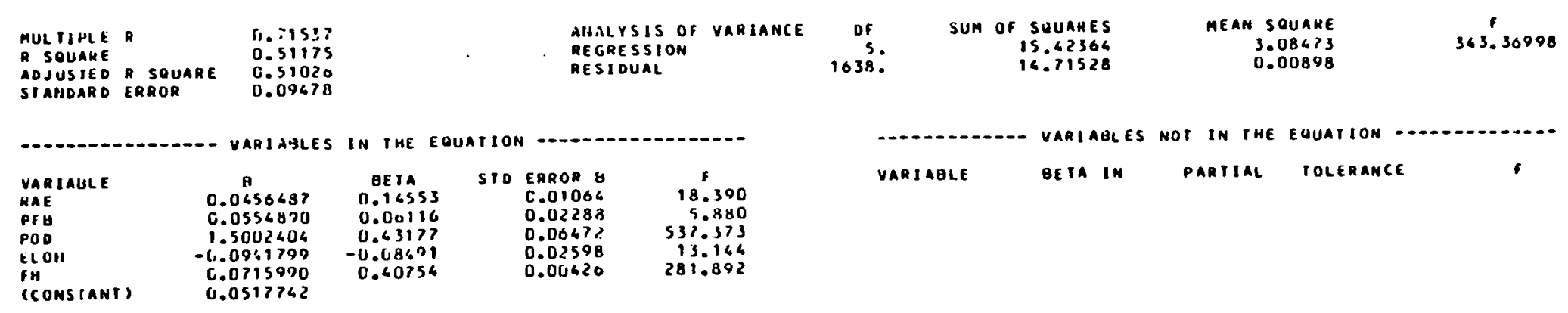

all variaules are in tIIC EOUATIOCH

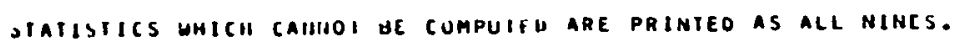

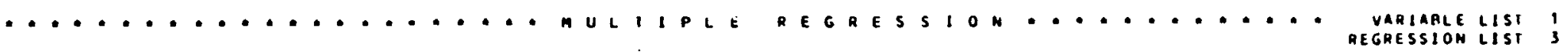

depenuent variagle,. punag

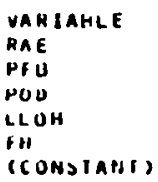

SUMmary TABLE

\begin{tabular}{|c|c|c|c|c|c|}
\hline $\begin{array}{c}\text { MULJIPLE R } \\
0.33714 \\
0.37692 \\
0.65391 \\
0.05601 \\
0.71537\end{array}$ & $\begin{array}{l}\text { R SOUARE } \\
0.11366 \\
0.14201 \\
0.42759 \\
0.42773 \\
0.31173\end{array}$ & $\begin{array}{c}\text { RSO CHANGE } \\
0.11360 \\
0.02861 \\
0.28513 \\
0.101113 \\
0.014613\end{array}$ & $\begin{array}{r}\text { SIMPLE A } \\
0.33716 \\
0.03504 \\
0.48356 \\
-0.23767 \\
0.36813\end{array}$ & $\begin{array}{c}n \\
0.0650687 \\
0.0554490 \\
1.51102864 \\
-0.0941744 \\
0.01159180 \\
0.0517742\end{array}$ & $\begin{array}{r}\text { BE19 } \\
0.16553 \\
0.00116 \\
0.43177 \\
-0.08691 \\
0.60756\end{array}$ \\
\hline
\end{tabular}


APPENDIX D (continued)

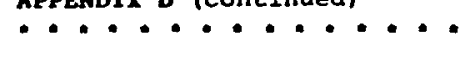

DEPEADENT VARIAGLE.. UNEMP

VARIABLE LIST,
REGESSION LIST

VARIABLE (S) ENIERED ON SIET NUMGCK $1 .$.

RAE
PYB
POD
ELOH
EH
PUNAG

\begin{tabular}{|c|c|c|c|c|c|c|c|c|c|}
\hline $\begin{array}{l}\text { MULIIPLE } \\
\text { R SOUARE } \\
\text { ADJUSIED } \\
\text { SIANDAXO }\end{array}$ & $\begin{array}{l}\text { R } \\
\text { R SUUARE } \\
\text { ERROR }\end{array}$ & $\begin{array}{l}0.733060 \\
0.33607 \\
0.53230 \\
0.02620\end{array}$ & $\begin{array}{l}\text { ANALYSIS OF } \\
\text { REGRESSION } \\
\text { RESIDUAL }\end{array}$ & VARIANCE & $\begin{array}{c}\text { of } \\
1637 \%\end{array}$ & sun of & $\begin{array}{l}\text { SOUARES } \\
1.29384 \\
1.12878\end{array}$ & $\begin{array}{r}\text { MEAH SQUARE } \\
0.21566 \\
0.00069\end{array}$ & 312.72951 \\
\hline
\end{tabular}

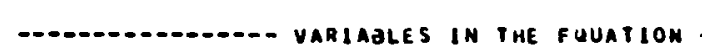

\begin{tabular}{|c|c|c|c|c|c|}
\hline $\begin{array}{l}\text { YARIAGLE } \\
\text { RAE } \\
\text { PFE } \\
\text { POO } \\
\text { ELOH } \\
\text { CH } \\
\text { PUMAG } \\
\text { (CUMSIANT) }\end{array}$ & $\begin{array}{c}B \\
C .0168877 \\
C .03511 .216 \\
-0.03971: 1 \\
-0.0663837 \\
0.0052627 \\
0.1178673 \\
0.0301036\end{array}$ & $\begin{array}{c}\text { BETA } \\
0.18941 \\
0.13618 \\
-6.03059 \\
-0.21112 \\
0.10528 \\
0.61567\end{array}$ & SID & $\begin{array}{l}\text { ERROR O } \\
0.00297 \\
0.06635 \\
0.0206 C \\
0.00723 \\
0.00128 \\
0.00685\end{array}$ & $\begin{array}{c}F \\
32.435 \\
30.408 \\
3.730 \\
84.415 \\
10.800 \\
296.389\end{array}$ \\
\hline
\end{tabular}

VARIABLES MOT IN THE EOHATION

variable beta in partial tolerance

all vaniagles are in the touation

STATISIICS HHICH CAHNOT HF COMPUTEL aHE PRINTED AS ALL NIHES.

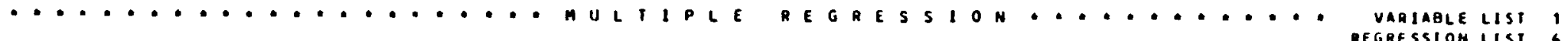
DEPENDEN I VARIAGLE.. UHEHP

\begin{tabular}{|c|}
\hline $\begin{array}{l}\text { UARIAULE } \\
\text { AAE } \\
\text { HFU } \\
\text { PUD } \\
\text { LLUH } \\
\text { BUI } \\
\text { PUHAG } \\
\text { ICUNSIAIII }\end{array}$ \\
\hline
\end{tabular}

SUMMARY TARLE

\begin{tabular}{|c|c|c|c|c|c|}
\hline $\begin{array}{c}\text { MULTIPLE R } \\
0.58813 \\
\text { U.58905 } \\
11.62367 \\
11.06152 \\
11.67160 \\
0.73680\end{array}$ & $\begin{array}{l}\text { SQUARE } \\
0.36589 \\
0.34608 \\
0.38921 \\
0.61154 \\
0.66 .771 \\
0.53607\end{array}$ & $\begin{array}{c}\text { RSQ CHANGE } \\
0.34589 \\
0.00108 \\
0.114223 \\
1.02233 \\
0.113316 \\
0.08636\end{array}$ & $\begin{array}{r}\text { SIMPLE } \\
0.58813 \\
0.28301 \\
0.11867 \\
-0.493311 \\
0.43168 \\
0.57644\end{array}$ & $\begin{array}{r}y \\
0.0103897 \\
0.0350216 \\
-0.0349061 \\
-0.0603884 \\
0.011012627 \\
0.1178693 \\
0.0361036\end{array}$ & $\begin{array}{c}0614 \\
0.18991 \\
0.13616 \\
-0.06051 \\
-0.21112 \\
0.10520 \\
0.61567\end{array}$ \\
\hline
\end{tabular}


APPENDIX D (continued)

oepenuent variagle.. mit

REGRESS I UN............... VARIABLE IIST!

VARIAGLE(S) ENIERED UH STEP NUMUEF 1.. RAE

$\cdots \cdot \cdot$

ALLIIPL

$$
\begin{aligned}
& \text { RAE } \\
& \text { PFH } \\
& \text { POD } \\
& \text { ELOH } \\
& \text { FH } \\
& \text { PUNAG }
\end{aligned}
$$

PUNAG

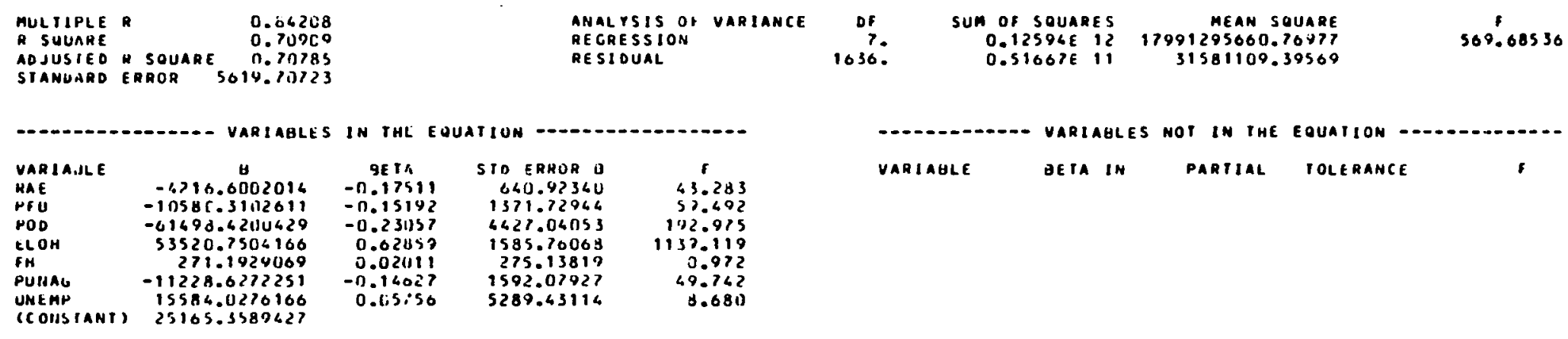

all variahles are in the euUation

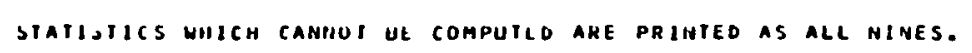

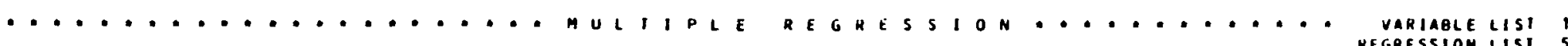
DEPEHDENT VARIABLE.. MFi

\begin{tabular}{|c|c|c|c|c|}
\hline 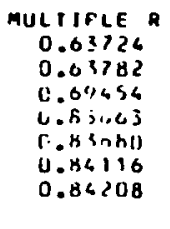 & $\begin{array}{l}\text { R SOUARE } \\
0.60607 \\
0.60682 \\
0.68237 \\
11.07940 \\
0.701,210 \\
0.710753 \\
C .70909\end{array}$ & 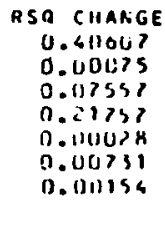 & $\begin{array}{l}\text { SIMPLE H } \\
-0.63724 \\
-0.36019 \\
-0.17418 \\
0.733110 \\
-11.07362 \\
-0.67744 \\
-0.511138\end{array}$ & 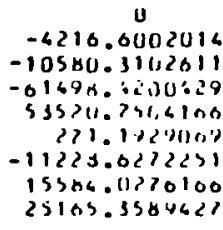 \\
\hline
\end{tabular}

SUMMAR T TAGLE

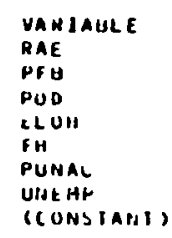

BEIA $-0.15192$ $-0.2305 ?$ 0.02011 $-0.16627$ 0.05750 


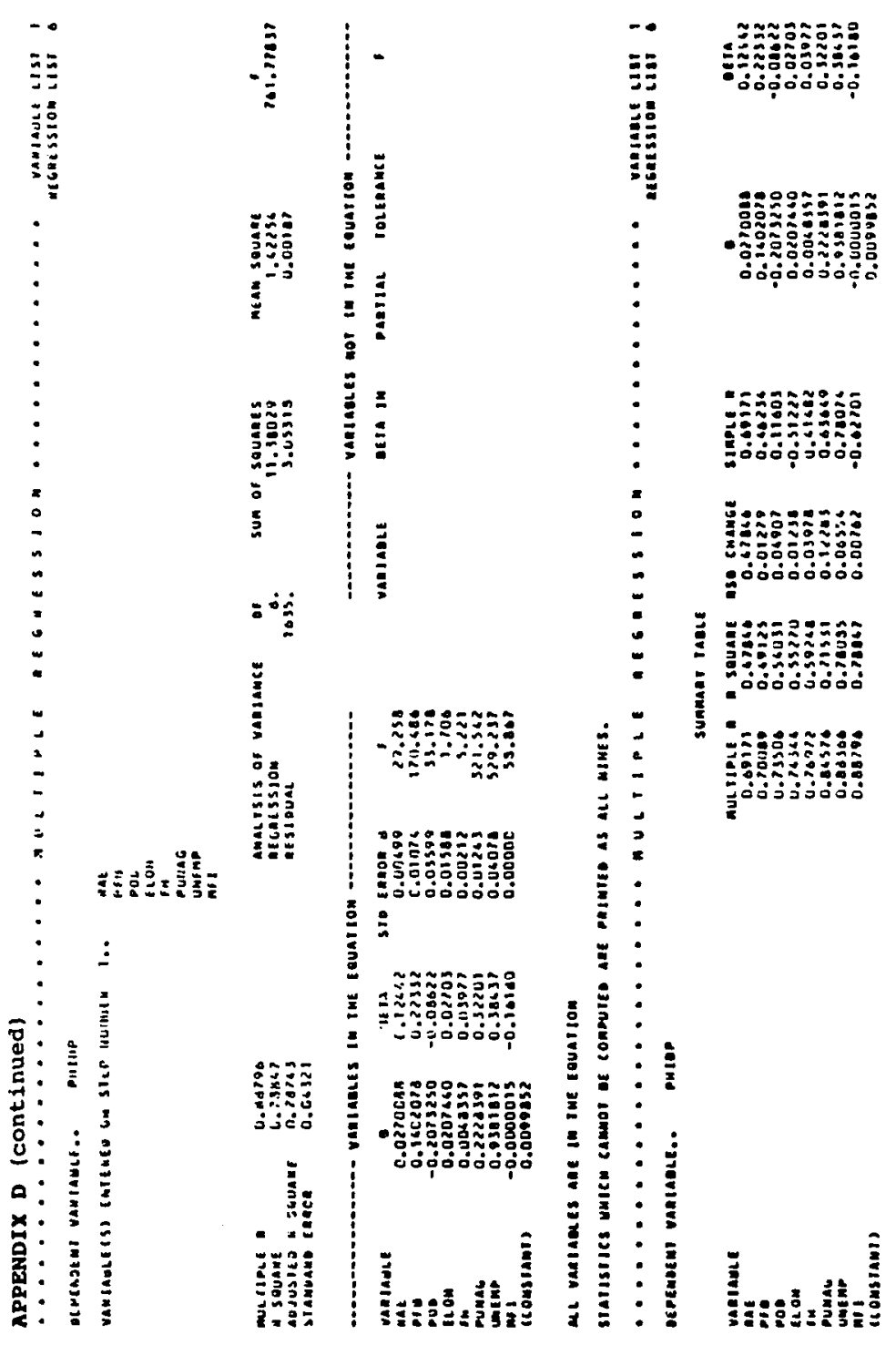




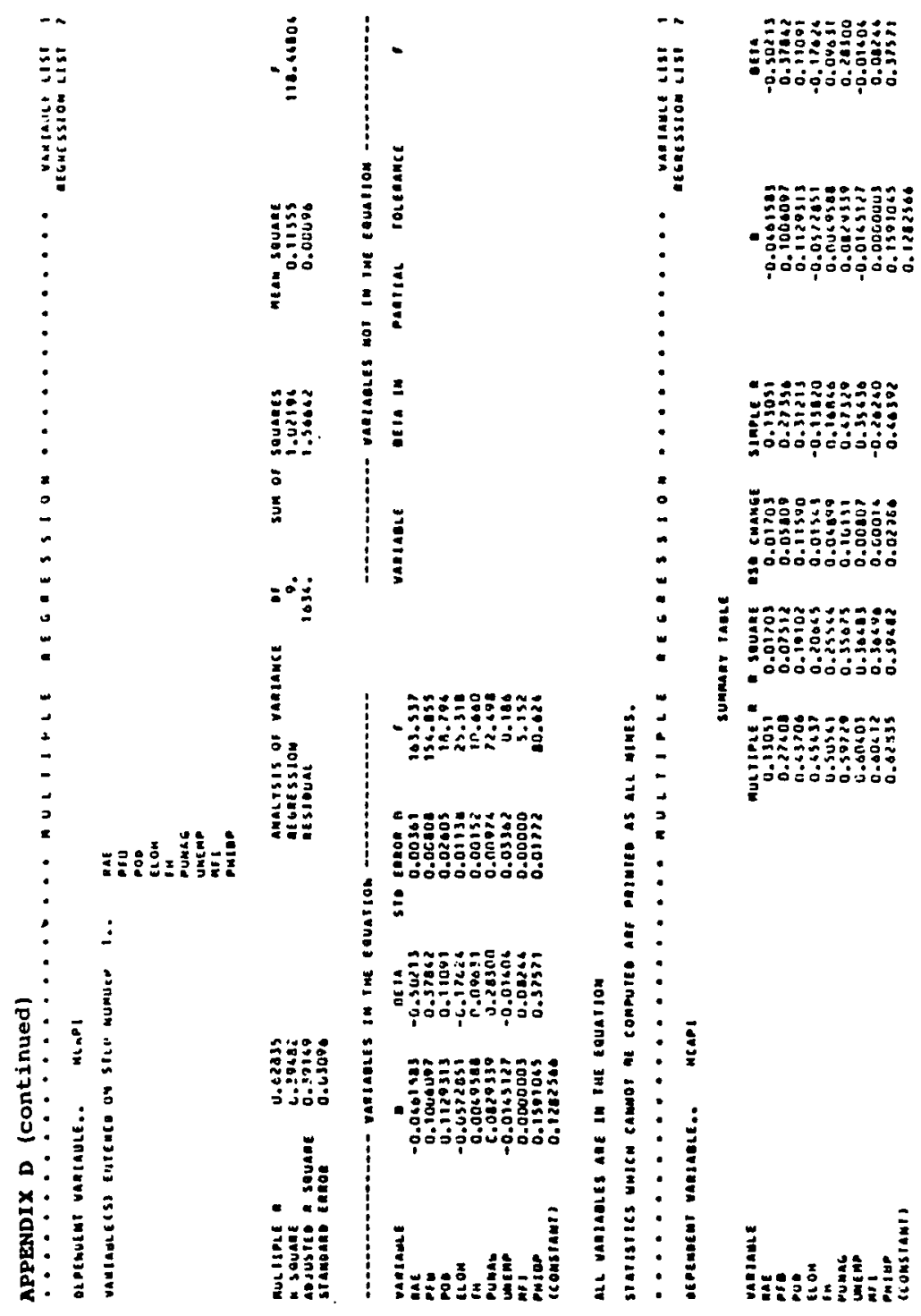




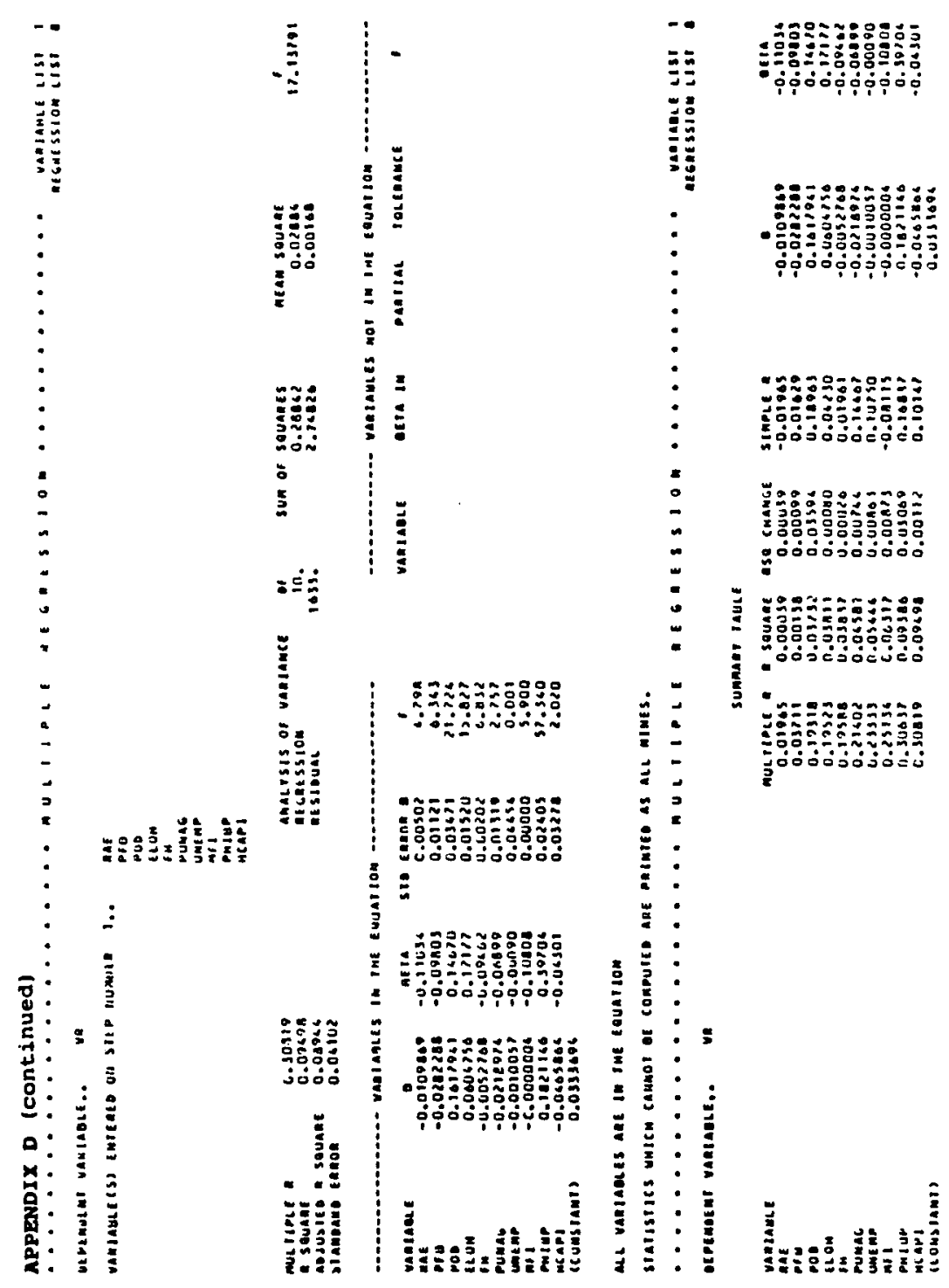




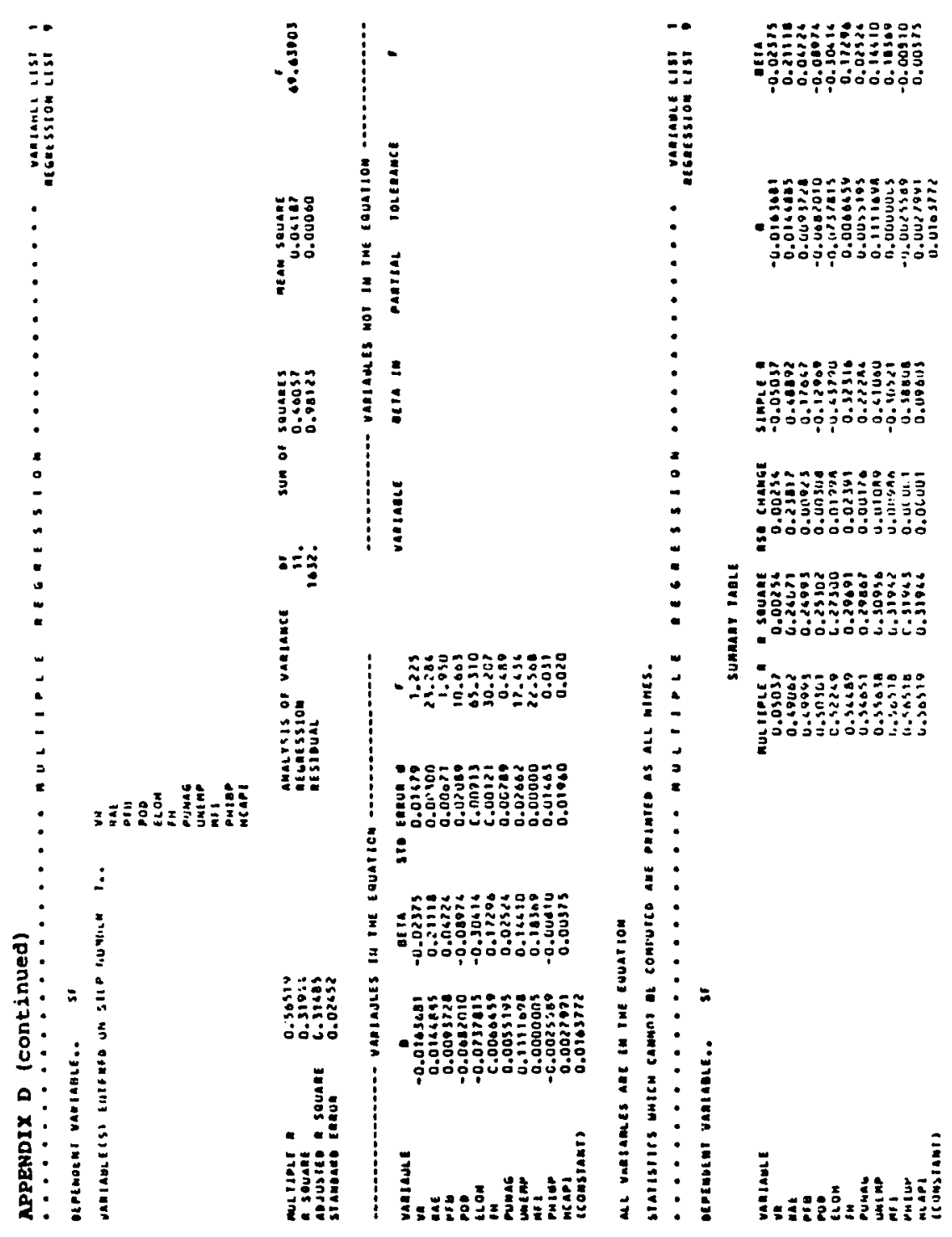

